Florida International University FIU Digital Commons

5-25-2016

\title{
Essays on Volatility Drivers, Transmissions and Equity Market Correlations in a Global Setting
}

Antonio M. Figueiredo

Florida International University, afigu075@fiu.edu

DOI: $10.25148 /$ etd.FIDC000709

Follow this and additional works at: https://digitalcommons.fiu.edu/etd

Part of the Finance and Financial Management Commons

\section{Recommended Citation}

Figueiredo, Antonio M., "Essays on Volatility Drivers, Transmissions and Equity Market Correlations in a Global Setting" (2016). FIU Electronic Theses and Dissertations. 2617.

https://digitalcommons.fiu.edu/etd/2617 


\section{FLORIDA INTERNATIONAL UNIVERSITY \\ Miami, Florida}

\section{ESSAYS ON VOLATILITY DRIVERS, TRANSMISSIONS AND EQUITY MARKET CORRELATIONS IN A GLOBAL SETTING}

A dissertation submitted in partial fulfillment of the

$$
\begin{gathered}
\text { requirements for the degree of } \\
\text { DOCTOR OF PHILOSOPHY } \\
\text { in } \\
\text { BUSINESS ADMINISTRATION } \\
\text { by }
\end{gathered}
$$

Antonio M. Figueiredo 
To: Acting Dean Jose M. Aldrich

College of Business

This dissertation, written by Antonio M. Figueiredo, and entitled Essays on Volatility Drivers, Transmissions and Equity Market Correlations in a Global Setting, having been approved in respect to style and intellectual content, is referred to you for judgment.

We have read this dissertation and recommend that it be approved.

Krishnan Dandapani

Brice V. Dupoyet

Clark M. Wheatley

Ali M. Parhizgari, Major Professor

Date of Defense: May 25, 2016

The dissertation of Antonio M. Figueiredo is approved.

Acting Dean Jose M. Aldrich

College of Business

Andrés G. Gil

Vice President for Research and Economic Development and Dean of the University Graduate School

Florida International University, 2016 
(c) Copyright 2016 by Antonio M. Figueiredo

All rights reserved. 


\section{ACKNOWLEDGMENTS}

First of all, I would like to express my sincere gratitude for all the help, support, understanding, patience and guidance extended to me by my dissertation chair, Dr. Ali M. Parhizgari, while I worked on my dissertation. His assistance was instrumental in the completion of this work. I also want to convey my heartfelt appreciation to all the members of my dissertation committee. I appreciate Dr. Dandapani's willingness to join the committee midway through the dissertation, and I found extremely helpful the inputs and insights from Dr. Dupoyet and Dr. Wheatley. The insights by Dr. Daigler during the dissertation proposal phase were also helpful and greatly appreciated.

I would also like to thank the finance department professors that taught the seminars I attended, as information gained from these seminars enriched my understanding and appreciation for doing research in the field of finance. 


\author{
ABSTRACT OF THE DISSERTATION \\ ESSAYS ON VOLATILITY DRIVERS, TRANSMISSIONS AND EQUITY \\ MARKET CORRELATIONS IN A GLOBAL SETTING \\ by \\ Antonio M. Figueiredo \\ Florida International University, 2016 \\ Miami, Florida \\ Professor Ali M. Parhizgari, Major Professor
}

Volatility is a major topic in financial markets in general, and probably the single most intriguing factor in financial risk management. Although volatility itself is not synonymous with risk, it is closely associated with it in the realm of risk management. In this study, I focus on the volatility in the foreign exchange markets and investigate the spillover of volatility from this market to equity correlations and its impact on global equity markets' bid-ask spreads as a proxy for market quality. I also explore the role that accounting earnings quality play in subsequent volatility in the U.S. equity markets.

I provide a theoretical base and its associated empirics for the link between exchange rate volatilities and global equity correlations. I test this theory using multiple techniques that end with the application of autoregressive error correction analysis, wherein, I demonstrate the predictive power of options implied exchange rate volatilities against ex-ante global equity correlations. My findings indicate that exchange rate implied volatilities, coupled with one-period ex-post correlations, are more predictive of subsequent equity market correlations than other models. I then examine the impact of currency volatilities on the average monthly spreads in ADRs and their underlying local shares. I employ dynamic panel data estimation to show 
that currency volatility explains a significant portion (16.6\%) of the variation in spreads across markets, heretofore largely unexplored by extant finance literature.

Finally, I employ well established accrual measures to calculate aggregate accruals for the S\&P 500 on a quarterly basis and examine the ability of this aggregate measure to forecast future trends in the volatility of the index. I find a statistically significant relation between subsequent twelve-month volatility in the S\&P 500 index and aggregate accruals. This relation holds whether total or abnormal accruals measures are employed. My findings document a rare long-term indicator of volatility in the widely followed index. I also show that my aggregate accrual measure yields additional information about S\&P 500 volatility when compared with simple historical volatility measures or option implied volatility. 


\section{TABLE OF CONTENTS}

CHAPTER

1. FROM CURRENCY VOLATILITIES TO GLOBAL EQUITY CORRELA-

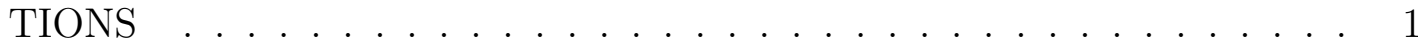

1.1 Introduction . . . . . . . . . . . . . . . . . . . . . . 1

1.2 Prior literature . . . . . . . . . . . . . . . . . . . . 3

1.3 Theoretical model . . . . . . . . . . . . . . . . . . . . . . . 7

1.4 Data and sources . . . . . . . . . . . . . . . . . . . . . . 15

1.5 Empirical applications and results . . . . . . . . . . . . . 16

1.5.1 Identification of employed volatility measures . . . . . . . . . . . . 17

1.5.2 Linking implied volatility with a forecast of one period ahead realized volatility . . . . . . . . . . . . . . . . . . 18

1.5.3 Measuring equity correlations . . . . . . . . . . . . . . . . . 20

1.5.4 Linking currency volatilities with equity correlations . . . . . . . . . . 24

1.5.5 Evaluation of forecast accuracy of FX implied volatility models . . . . 31

1.6 Summary and Conclusions _. . . . . . . . . . . . . . . . . . 38

2. CURRENCY VOLATILITY AND BID-ASK SPREADS OF ADRS AND LOCAL SHARES . . . . . . . . . . . . . . . . . . 42

2.1 Introduction . . . . . . . . . . . . . . . . . . . . . 42

2.2 Prior literature . . . . . . . . . . . . . . . . . . . . . . . 46

2.3 Data and methodology . . . . . . . . . . . . . . . . . 47

2.4 Empirical results . . . . . . . . . . . . . . . . . . . . 52

2.4.1 Correlation among independent variables . . . . . . . . . . . . 53

2.4 .2 ADRs versus Local shares . . . . . . . . . . . . . . . . . . 57

2.4 .3 Fixed-effects analysis . . . . . . . . . . . . . . . . . . . 57

2.4.4 Relation of bid-ask spread to liquidity factors by currency . . . . . . . 60

2.4.5 Dynamic panel data estimation of relation between spreads and liquidity determinants . . . . . . . . . . . . . . 64 64

2.4.6 Principal components analysis of determinants of liquidity . . . . . . . 67

2.5 Summary and conclusions . . . . . . . . . . . . . . . 70

3. DO AGGREGATE ACCRUALS YIELD INCREMENTAL INSIGHTS INTO

S\&P 500 VOLATILITY? . . . . . . . . . . . . . . . 73

3.1 Introduction . . . . . . . . . . . . . . . . . . . . 73

3.2 Prior literature . . . . . . . . . . . . . . . . . . . . . . 74

3.3 Data and methodology . . . . . . . . . . . . . . . 76

3.3.1 Sample construction and accrual calculation . . . . . . . . . . . 77

3.3.2 Analysis of accruals vs returns and volatility . . . . . . . . . . . . 80

3.3.3 Explanatory information about S\&P 500 volatility from aggregate ac-

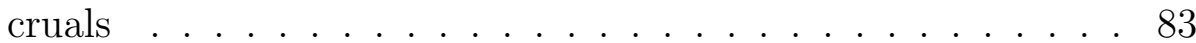

3.4 Empirical results . . . . . . . . . . . . . . . . . . . 85 
3.4.1 Firm level accruals and subsequent twelve-month volatility . . . . . . . 85

3.4.2 S\&P 500 aggregate accruals and subsequent twelve-month S\&P 500 returns ........................ . . 91

3.4.3 S\&P 500 aggregate accruals and subsequent twelve-month S\&P 500 volatility . . . . . . . . . . . . . . . . . . 93

3.4.4 Do option implied volatilities entirely capture insights from the S\&P 500 volatility and aggregate accruals relation? . . . . . . . . 100

3.5 Summary and conclusions . . . . . . . . . . . . . . . 103

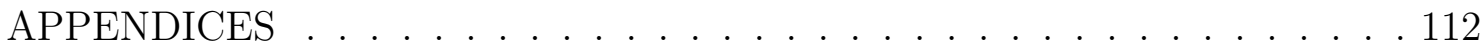

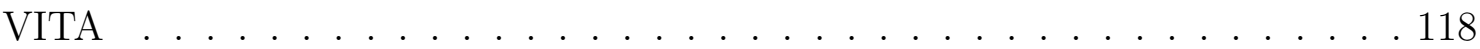




\section{LIST OF TABLES}

TABLE

PAGE

1.1 Summary statistics of the data . . . . . . . . . . . . . . . 19

1.2 FX Implied Volatility as Forecast of Realized Volatilities - MAPE . . . 21

1.3 International equity markets correlations . . . . . . . . . . . . . . . 22

1.4 Average three-month FX implied volatilities for European currencies during periods of low, medium, and high implied FX volatility levels 24

1.5 Tests of relations between international equity market correlations and FX option implied volatilities . . . . . . . . . . . . 26

1.6 Absolute percent error of full model forecasts up to six periods ahead under dynamic and static processes versus naïve model . . . . . . . 34

1.7 Results of simulation of out-of-sample equity correlation forecasts from estimated models . . . . . . . . . . . . . . . . . 37

2.1 Descriptive statistics of sample data by currency . . . . . . . . . . . 54

2.2 Correlation among determinants of liquidity . . . . . . . . . . 56

2.3 Relation of bid-ask spreads to FX volatility: ADRs vs. Local shares . . 58

2.4 Panel regression estimation of full model - entire universe and by currency 61

2.5 Dynamic panel data estimation of full model using GMM - entire universe and by currency . . . . . . . . . . . . . . . 65

2.6 Principal components analysis of liquidity drivers — ADR subgroup . . 68

2.7 Relation of spreads to principal components - ADR subgroup . . . . . 69

3.1 Average 12-mo returns and volatility across yearly accrual deciles . . . . 86

3.2 Robust regressions of subsequent 12-mo volatility on current period accrual measures - annual data . . . . . . . . . . . . . . . . . . . . . 88

3.3 Robust regressions of subsequent 12-mo volatility on current period accrual measures - quarterly data . . . . . . . . . . . . . . . . . . . 89

3.4 Robust regressions of subsequent S\&P 500 12-mo return on aggregate accrual measures - quarterly frequency . . . . . . . . . . . . . 94

3.5 Robust regressions of subsequent S\&P 500 12-mo volatility on recent volatility and aggregate accrual measures — quarterly data . . . . . 98 
3.6 Robust regressions of S\&P 500 12-mo volatility on implied volatility and aggregate accrual - quarterly data . . . . . . . . . . . 102 


\section{CHAPTER 1 \\ FROM CURRENCY VOLATILITIES TO GLOBAL EQUITY CORRELATIONS}

\subsection{Introduction}

Volatility forecasts are vital components of asset pricing and risk management in finance. Prior literature on the measurement, modeling, and forecasting volatility abounds. Poon and Granger (2003) provide a comprehensive review of such studies. Their review, however, does not link volatility with correlations. It is well established that volatility of portfolio assets as well as correlations among these assets play a joint central role. In this paper I propose and test a parsimonious theoretical model to forecast ex-ante correlation among global equity markets. The benefits of forecasting such future correlations with any reasonable accuracy would be worthwhile for several reasons. Notably, correlations dictate the benefits of diversification, are used in the calculation of realized volatility of diversified portfolios, and are key ingredients in portfolio optimization. Further, volatility and correlations among equity markets are shown to be time-varying (see Longin and Solnik, 1995, 2001). Nonetheless, the main determinants of these time variations remain an active area of academic research. Thus, uncovering new insights into the dynamics of the drivers of correlation among global equity markets should be invaluable to academicians and practitioners. This paper explores and identifies such drivers both theoretically and empirically. Testing the derived theory on twelve global equity indices (eleven country indices plus the pan-European STOXX index), the results support the existence of a relation between option implied exchange rate volatility and subsequent correlations among the equity markets represented by these indices. 
In practice, equity correlations among global markets are generally assumed to be stable and as a result the most recent period observed correlations are often used as the forecast for the next period correlations. These correlations are important in the calculation of portfolio weights in the optimization process. Reducing correlation forecast errors should result in more accurate portfolio weights calculation and thus more efficient portfolios with higher Sharpe ratios. For instance, employing the theoretically derived model, I demonstrate how option implied exchange rate volatility can be used to yield lower forecast errors for global equity correlations.

My coverage in this paper is both theoretical and empirical. On the theoretical side I aim to establish a unified framework to link economic fundamentals with correlations among international equity markets. On the empirical side I focus on foreign exchange rates and correlations among the equity markets of eleven countries and the pan-European STOXX index. On both fronts, I contribute to the current literature by examining the relation between currencies, or more specifically between option implied volatility in the foreign exchange markets, and international equity market correlations. In addition, as an extension of my empirics, I compare the relation between FX volatility and equity correlation with that of equity volatility and equity correlation. This comparison provides further insights about the factors that drive international equity correlations and contributes to the establishment of weights that are often arbitrarily set in global minimum-variance portfolio analyses.

Heretofore, several studies, such as Roll (1988) and Longin and Solnik (1995), have demonstrated that international markets tend to move together when equity volatility is high. Longin and Solnik (2001) find that correlations are more specifically related to bearish market trends and not necessarily volatility. In any case, high volatility and declining markets tend to go hand in hand as evidenced by a widely observed negative relation between the CBOE's VIX (an established indi- 
cator of market volatility) and the S\&P 500 index. The empirical evidence linking equity volatility, and the VIX as its proxy, to equity correlation is compelling, but it lacks solid theoretical support. While volatility in the world's largest equity market and economy is likely to affect most equity markets and economies around the globe, the strength of the impact is likely to depend on the extent of bilateral trade and economic interdependence. The VIX measure does not capture any of these dynamics. Since international finance theory says foreign exchange rate is a major factor in bilateral trade, I hypothesize that option implied foreign exchange volatility can better reflect such dynamics between any given two countries, and is thus a more effective predictor of equity correlations than the VIX.

To establish a theoretical link, I resort to prior theoretical findings. My search suggests and I hereby would like to acknowledge that there is no consensus in the finance and economic literature regarding the link between economic fundamentals and correlations among international equity markets. This is somewhat surprising given that there are several, though segmented, proposed theoretical economic models and empirical studies that demonstrate a relation between equity correlations and economic indicators such as business cycles, inflation, and economic output. There are also studies that argue such relation, if it exists, is either not significant enough, or not stable over short and long horizons.

\subsection{Prior literature}

Evidence supporting a link between economic cycles and equity correlations is provided by several researchers. For instance, Erb et al. (1994) find that international equity market correlations tend to be higher during economic downturns. Moskowitz (2003) documents this pattern for the U.S. market. Longin and Solnik (1995) show that dividend yields and short-term interest rates, both of which are 
linked to economic cycles, are related to international equity correlations. Dumas et al. (2003), proposing a framework for a link between country outputs and correlations between their equity markets, show that under the hypothesis of market segmentation the correlation predicted by their model is significantly below what is observed, but match the observed values under a market integration assumption. Forbes and Chinn (2004) provide evidence that bilateral trade is the main factor determining how shocks are transmitted from large economies to other stock markets. Graham et al. (2012) study the integration of twenty-two emerging markets with the U.S. market, and find a high degree of co-movement at lower frequencies. They conclude that diversification benefits of investing in emerging markets from a U.S. investor's perspective is dependent on the investment horizon. Della Corte et al. (2012) find that volatility and correlation timing is possible and clearly beneficial in international asset allocation.

On a related though different front, several studies link equity volatility with equity correlations. For example, Longin and Solnik (2001) find that during bear markets when equity volatility is above normal, equity correlations tend to also be higher. Connolly et al. (2007) show that option implied volatility on the U.S. and German market indices are positively related to subsequent equity market correlations. Cai et al. (2009) consider both economic factors and equity volatility as explanatory variables for international equity correlations. They employ CBOE's VIX measure of implied volatility for the S\&P 500 as a proxy for overall equity volatility and the inflation rate in each country as an economic cycle indicator. They find that equity correlation between two given countries is higher when equity volatility is above normal and both countries' inflation rates are below their respective historical averages, which they interpret to mean that both countries are in an economic contraction phase. 
In contrast to the above strands of research, refuting the relation between economic factors and equity correlations, King et al. (1994) show that economic variables fail to explain the time variation in the covariance of national equity markets. Ammer and Mei (1996) support these findings. Using industrial production data and equity returns from seven major countries, Kizys and Pierdzioch (2006) lend further support to this notion by showing that the relation between business cycles and international equity correlations is not statistically significant. Forbes and Rigobon (2002) refute the notion of contagion during major crises such as the 1997 Asian crisis and the U.S. stock market crash in 1987 by showing no increase in unconditional correlation coefficients during those periods. Instead, they argue that correlations are conditional on market volatility and that this 'interdependence' is present at all times, not only during crises.

As an extension to the Veronesi (1999) model, Ribeiro and Veronesi (2002) propose an intertemporal rational expectations model by which uncertainty about the state of the global economy drives higher international equity correlations during economic downturns. They present a theoretical argument supporting their model and demonstrate that historical patterns on international equity correlations are well explained by their proposed model. Their findings lend some theoretical support to empirical studies linking option implied equity volatility and subsequent equity correlations. See Connolly et al. (2007), and Cai et al. (2009). After all, as an implied volatility measure of the S\&P 500, a benchmark for the equity market in the world's largest economy, the VIX is a good indicator of the market's perceived uncertainty about equity values and the overall economy. Under the assumption that uncertainty about the U.S. markets and the U.S. economy also imply uncertainty about the global economy, and that equity investors would require to be compensated for this increased risk, theory would predict that international equity markets in cycli- 
cal countries would decline somewhat in unison during periods of high uncertainty, thus increasing correlation among these markets. There is ample empirical evidence supporting this phenomenon.

Among other prior works that may be cited at this juncture, Forbes and Chinn (2004), Aslanidis and Casas (2013) and Bodart and Reding (1999) are more related to my study. Forbes and Chinn (2004) provide empirical support for the impact of bilateral trade on financial markets. Aslanidis and Casas (2013) use portfolios of equity and currency to evaluate parametric and semi-parametric models for estimating the conditional cross-correlation matrix for portfolio allocation. They find that a semi-parametric model performs better when using out-of-sample data. Contrary to my findings that equity correlations are positively related to implied exchange rate volatility, Bodart and Reding (1999) find that "an increase in exchange rate volatility is accompanied by a decline in international correlations between bond and, to a lesser extent, stock markets." Obviously, there are important and clear distinctions between my study and Bodart and Reding (1999)'s. First, their study is on bond rather than equity markets. Further, rather than employing measures of foreign exchange rate volatility, Bodart and Reding's results are based primarily on the comparison between countries within and outside the Exchange Rate Mechanism of the European Monetary System. My study, on the other hand, examines how the equity correlation between a given pair of international equity markets is related to the volatility of the pertinent exchange rate for these two markets. Specifically, my analysis utilizes a daily market-driven measure of implied volatility for exchange rates.

Given the above brief review, it is clear that the breadth and scope of the prior contributions are highly diverse, that a clear consensus is lacking, and that a wellgrounded and empirically tested approach to establish the link between currency 
volatilities and global equity correlations is warranted. This is, as stated earlier, the aim of this study.

\subsection{Theoretical model}

Based on the notion that there is no widely accepted theory that links exchange rate volatility with international equity market correlations, I first consider a few preliminary intuition-based relations that draw upon asset pricing models and international finance parity fundamentals. These provide preliminary theoretical underpinning for my analysis. I then derive a generalized theoretical framework that could assist me with my empirical pursuits.

I start with the widely accepted stochastic model for spot exchange rates that can be used as the basis for pricing exchange rate options such that implied exchange rate volatility can be imputed by observed market prices for such options. For simplicity, I start with a two-market (country) two-currency situation. I will use EUR and US for the two countries with the dollar/euro spot rate as the exchange rate in what follows. My reference to EUR may be interpreted as any country in the Euro zone.

$$
S_{t}=S_{0} \exp \left\{\left(r_{E U R}-r_{U S}\right) t-\sigma^{2} t / 2+\sigma W_{t}\right\}
$$

where $S_{t}$, expressed in euros per dollar, is the spot exchange rate at time $t, S_{0}$ is the

spot exchange rate at time $0, r_{U S}$ and $r_{E U R}$ are the respective dollar-denominated and euro-denominated risk free rates for the pertinent period from time 0 to time $t, \sigma$ is the expected volatility, at time $t$, for the exchange rate over the life of the option, and $W_{t}$ is a Wiener process.

The above expression is consistent with stochastic asset pricing that forms the basis for option pricing under Black-Scholes. The risk-free rates represent the ob- 
served risk-free rates at time $\mathrm{t}$ for the U.S. and Euro zone markets, and $\sigma$ is the expected volatility, at time $t$, for the exchange rate over the life of the option.

On the surface, relation 1.1 is seemingly unrelated to the real side of the economy, e.g., equity markets ${ }^{1}$. Upon further scrutiny, I will demonstrate that $S_{t}$ or its volatility is indeed related to the real side of the global economy and thereby to the correlations among its components. To facilitate the derivations that follow, I have provided a schematic flow chart that shows the steps in my approach from one end, e.g., currency volatility, to the other end, e.g., global equity correlations.

The differential interest rate term $\left(r_{E U R}-r_{U S}\right)$ in relation 1.1 is highly crucial in moving us forward in my derivations. For spot exchange rate quotes at time $t$, I assume an equilibrium price based on a micro-based macro model for the dollareuro spot rate that is a simplified version of the model proposed by Evans and Lyons (2009). The original model, along with several other exchange rate models, are described in detail in Evans (2011). My simplified version of the model has the form:

$$
S_{t}=\mathbb{E}_{t} S_{t+1}+\left[r_{E U R, t}-r_{U S, t}\right]
$$

where $\mathbb{E}_{t}$ denotes market expectations based upon available information at time $t$, $r_{U S}$ and $r_{E U R}$ are as defined earlier and are now analogous to risk-free short-term dollar and euro rate for a given period. Moving forward one period, equation 1.2 becomes:

$$
\mathbb{E}_{t} S_{t+1}=\mathbb{E}_{t} S_{t+2}+\mathbb{E}_{t}\left[r_{E U R, t+1}-r_{U S, t+1}\right]
$$

1Zellner's (1962) "Seemingly Unrelated Regressions (SUR)" is a good reference point for this topic. 
In equation 1.2, the risk-free rates at time $t$ are observed, while in equation 1.3 they are based on equilibrium market expectations of central banks' actions (for instance, the FED and the ECB) in response to changes in the macro economy.

To expand relation 1.3, I resort to the Taylor rule. Taylor rule based models for interest rates assume that central banks set nominal rates according to divergences of inflation from inflation targets and divergences of GDP from potential GDP. Specifically, employing a modified version of real exchange rate definition based on Evans (2011), interest rate expectations are set according to:

$$
\begin{aligned}
\mathbb{E}_{t}\left[r_{E U R, t+1}-r_{U S, t+1}\right] & =\left(1+\lambda_{\pi}\right) \mathbb{E}_{t}\left[\pi_{E U R, t+1+i}-\pi_{U S, t+1+i}\right] \\
& +\lambda_{y} \mathbb{E}_{t}\left[y_{E U R, t+1}-y_{U S, t+1}\right]-\lambda_{\xi} \xi_{t+1}
\end{aligned}
$$

where $i>0, \pi_{E U R, t+1+i}-\pi_{U S, t+1+i}$ represents the future difference between inflation in the Euro zone and the U.S., $y_{E U R, t+1}-y_{U S, t+1}$ represents the future difference in log output gap between the Euro zone and the U.S., $\xi_{t}=S_{t}+p_{E U R, t}-p_{U S, t}$ is the real exchange rate, and $\lambda_{\pi}, \lambda_{y}, \lambda_{\xi}$ are positive. See Appendix A for a derivation of relation 1.4 .

Relation 1.4 implies that market participants expect the euro-dollar rate differential to be higher when the corresponding future inflation differential is higher, the output gap is wider, or when the real exchange rate declines. The first two implications suggest central banks should raise short-term interest rates when inflation and output gap rises, a widely held view. The last implication suggests that deviations from purchasing power parity levels have some impact on central banks' rate setting decisions. My model, as is the case in the original Evans and Lyons (2009) model, does not require that central banks follow a known recipe for setting rates such as the Taylor rule, but simply that market expectations for future rates are driven by market expectations for the inflation and output macro variables. The output gap 
in essence is a substitute for the differential in productivity measures, which in turn could easily be linked to the equity market returns. ${ }^{2}$ Irrespective of these details, my intent to link $S_{t}$ with the real side of the economy is well in place in light of relations 1.1 through 1.4 .

Substituting the value for rate expectations from relation 1.4 into relation 1.3 and iterating forward yields:

$$
\mathbb{E}_{t} S_{t+1}=\mathbb{E}_{t} \sum_{i=1}^{\infty} \gamma^{i} f_{t+1}
$$

where it is assumed that $\mathbb{E}_{t} \lim _{i \rightarrow \infty} \gamma^{i} S_{t+i}=0, \quad \gamma=1 /\left(1+\lambda_{\xi}\right)<1$, and

$$
f_{t}=\left(1+\lambda_{\pi}\right)\left[\pi_{E U R, t+1}-\pi_{U S, t+1}\right]+\lambda_{y}\left[y_{E U R, t}-y_{U S, t}\right]+\left(\frac{1-\gamma}{\gamma}\right)\left[p_{U S, t}-p_{E U R, t}\right]
$$

See Appendix B for a detailed derivation. Equation 1.5 expresses the market expectations for exchange rates for the next period in terms of the market expectations for macroeconomic fundamentals denoted by $f_{t}$. Substituting the results of equation 1.5 into equation 1.2 we have:

$$
S_{t}=\left(r_{E U R, t}-r_{U S, t}\right)+\mathbb{E}_{t} \sum_{i=1}^{\infty} \gamma^{i} f_{t+1}
$$

Defining variation in exchange rate as $\Delta S_{t+1}=\mathbb{E}_{t} \Delta S_{t+1}+S_{t+1}-\mathbb{E}_{t} S_{t+1}$, and embedding it into equation 1.2 yields:

$$
\Delta S_{t+1}=\left(r_{E U R, t}-r_{U S, t}\right)+S_{t+1}-\mathbb{E}_{t} S_{t+1}
$$

Equations 1.2 through 1.8 draw heavily upon Evans (2011), save some minor modifications. Considering relations 1.7 and 1.8 together, variations in exchange rates over short periods are primarily driven by revisions of future expectations of the macroeconomic variables, or the asset side of the economy. This can also

\footnotetext{
${ }^{2}$ See, for instance, Parhizgari and Aburachis (2003).
} 
be inferred by taking the variance on both sides of equation 1.5. Consequently, volatility in exchange rate is driven by the volatility in future expectations of the macroeconomic variables. Based on the definition of the macro fundamentals $f_{t}$ in relation 1.6, this volatility is a function of the variance in the difference of macroeconomic variables in two countries and the correlation among them, implying that high volatility in exchange rates are associated with high correlation among the difference in macroeconomic variables. This arises because of the identity:

$$
\operatorname{Var}(a X+b Y)=a^{2} \sigma_{x}^{2}+b^{2} \sigma_{y}^{2}+2 a b \rho_{x, y} \sigma_{x} \sigma_{y}
$$

From the above identity, it is clear that given a certain value of $\sigma_{x}, \operatorname{Var}(a X+b Y)$ will be maximized when $\rho_{x, y}=1$ since $\sigma_{x}>0, \sigma_{y}>0$, and $-1 \leq \rho_{x, y} \leq 1$. Therefore, taking into account just the first two terms from equation 1.6, I can conclude that volatility of dollar/euro exchange rate will be maximized when the correlation between the inflation differential $\left[\pi_{E U R, t+1}-\pi_{U S, t+1}\right]$ and the log output gaps $\left[y_{E U R, t}-y_{U S, t}\right]$ is 1 . In this maximization state, the inflation differential is a linear combination of the log output gaps and thus could be expressed as:

$$
\pi_{E U R, t+1}-\pi_{U S, t+1}=K_{1, t}\left[y_{E U R, t+1}-y_{U S, t+1}\right]+K_{2, t}
$$

where $K_{1, t}$ and $K_{2, t}$ are constants, $y_{U S, t}$ and $y_{E U R, t}$ represent the log of the real output for the U.S. and the Euro zone, respectively. Relation 1.10 also implies that

$$
r_{E U R, t}-r_{U S, t}=K_{1, t}\left[y_{E U R, t}-y_{U S, t}\right]+K_{2, t}
$$

since the Fisher Effect holds that an increase (decrease) in the expected inflation rate in a country will cause a proportional increase (decrease) in the interest rate in the country. After some simple exponential algebra (See Appendix C), relation 1.11 can be expressed as:

$$
K_{0, t} \frac{Y_{E U R, t}}{\exp \left(r_{E U R, t} / K_{1, t}\right)}=\frac{Y_{U S, t}}{\exp \left(r_{U S, t} / K_{1, t}\right)}
$$


where $Y_{U S, t}$ represents the real output for the U.S., $K_{0, t}=\exp \left(\frac{K_{2, t}}{K_{1, t}}\right)$, and analogously $Y_{E U R, t}$ represents the real output for the Euro zone. Therefore, in the spot rate volatility maximization state, equation 1.10 states that the correlation between the inflation differential in the U.S. and the Euro zone and the output gap between the countries is maximized at 1 . This also implies that the correlation between the discounted real output of the two countries is also maximized at 1 as shown in equation 1.12 .

Further assuming that investors are risk-neutral, the broad equity market value for the U.S., denoted as $M_{U S}$, is given by:

$$
\mathbb{E}_{t} M_{U S, t}=\int_{t}^{\infty} e^{r} U S^{(\tau-t)} D_{\tau} d \tau
$$

where $D_{\tau}$ represents an aggregate cash payout to investors that is linked to the country's output. The broad equity market value for the Euro zone is defined analogously.

If the cash payout to investors in each country is a proportion of the real output for each country, then I can conclude that when the volatility of the spot rate between the two countries approaches a maximum, the correlation between the discounted market values for the two countries should also approach its maximum of 1. This theoretical link is illustrated in Figure 1.1. Assuming that all (currency, equity, and option) market participants have the same access to information regarding interest rates and the state of the macro economy, the model described in this section provides a theoretical justification for the hypothesis that implied volatility in currency option prices is positively related to equity market correlations over the life of the option.

So far, I have shown that under some plausible assumptions there is a theoretical justification for equity correlations between two countries to be elevated when the 


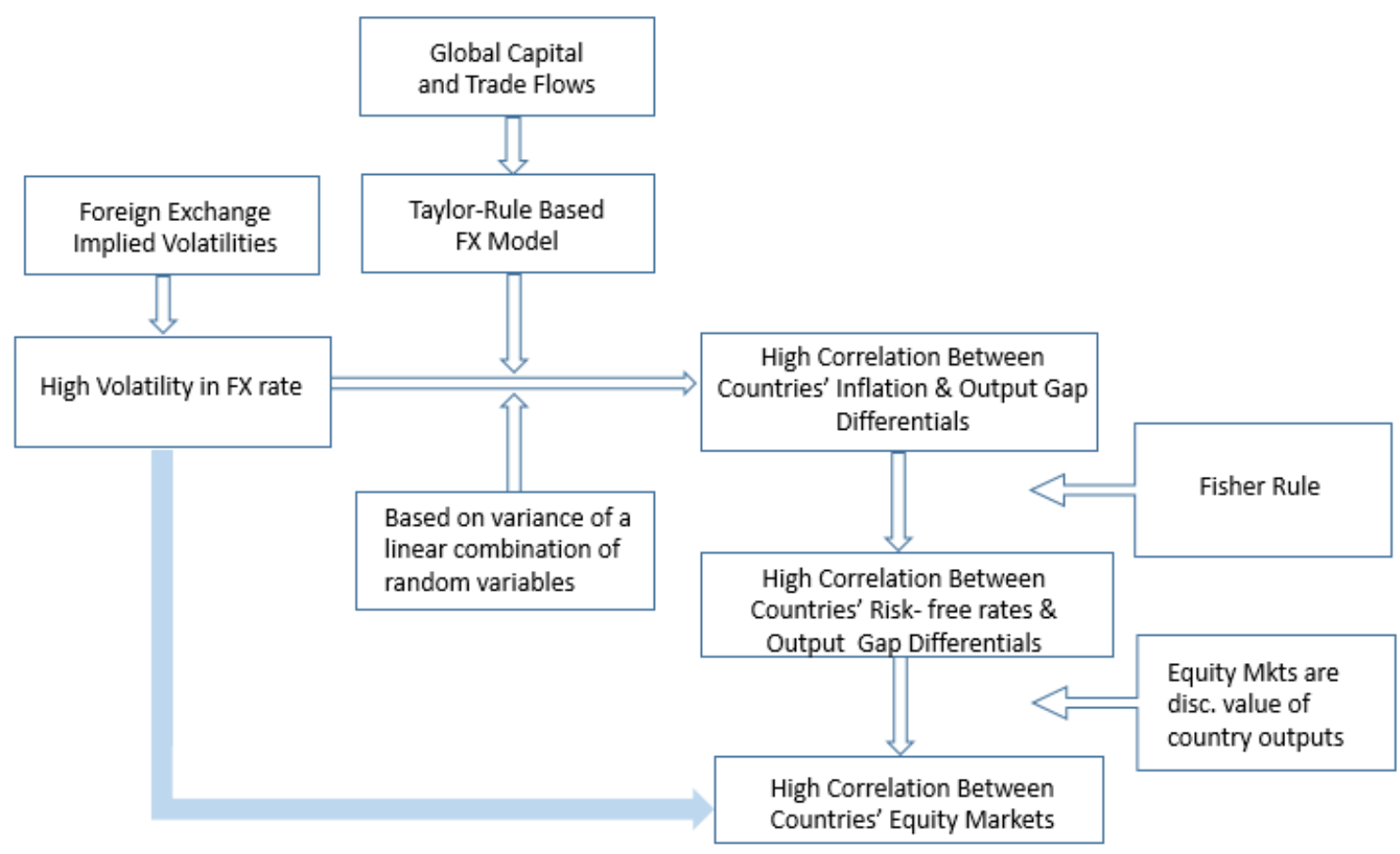

Figure 1.1: Theoretical link between FX volatility and equity correlation.

This flow chart briefly depicts the potential links between foreign exchange rate volatility and equity correlation. It brings together a stochastic model of exchange rates, Taylor rule based market expectations of interest rates, and underlying assumptions related to widely accepted parity conditions (i.e. international Fisher rule). It also assumes that broad equity markets value should reflect the discounted present value of future aggregate cash payouts and that these payouts are linearly related to each country's output (GDP).

volatility of the exchange rate between the two countries' currencies is also elevated. Assuming that option implied foreign exchange rate volatility is a good predictor of subsequent observed foreign exchange rate volatility, it should then follow that option implied exchange rate volatility would be a contributing factor in the forecast of subsequent equity correlations.

At the empirical level, further modification and fine tuning of the above relations become necessary. These will be discussed in Section 1.5.

As was mentioned earlier, the forecast of correlations is a key ingredient in the calculation of component weights for the optimal portfolio. In the case of a global 
portfolio comprised of broad exposure to equity markets in various countries, I contend that the forecast of future correlations between any country pair would be more accurate if the pertinent option implied exchange rate volatility is a factor in such forecast. Nonetheless, the theoretical justification I have put forth suggests that this is especially true when the exchange rate volatility is elevated. Therefore, my empirical work centers on evaluating the following relation:

$$
\operatorname{Corr} X Y_{t, t+3}=\operatorname{Corr} X Y_{t-3, t}+F X I V_{t}+F X d u m m y_{t}+\varepsilon_{t}
$$

where $\operatorname{Corr} X Y_{t, t+3}$ corresponds to the pairwise correlation over the three-month ahead period starting at time $t, \operatorname{Corr} X Y_{t-3, t}$ represents the pairwise correlation over the thee-month period preceding time $t, F X I V_{t}$ is the pertinent FX option implied volatility at time $t$, and $F X d u m m y_{t}$ is the interaction between this implied volatility and a dummy variable set to 1 (zero) to indicate a period of high (low) volatility. The threshold value used to set this dummy variable was based on historical patterns of volatility levels.

Taking into consideration the findings of previous studies that demonstrate the relation between equity volatility and equity correlations (see Longin and Solnik, 2001; Connolly et al., 2007; Cai et al., 2009), I also consider the following relation:

$$
\operatorname{Corr} X Y_{t, t+3}=\operatorname{Corr} X Y_{t-3, t}+F X I V_{t}+F X d u m m y_{t}+V I X d u m m y_{t}+\varepsilon_{t}
$$

where VIXdummyt is the interaction between the value of the VIX at time $t$ and a dummy variable set to 1 (zero) to indicate a period of high (low) volatility when the VIX index is above (below) 25 at time t. All other variables are as defined in equation 1.14. Once again, the threshold value used to set the VIXdummyt variable was based on historical patterns of VIX levels. Empirically evaluating relation 1.15 is necessary to determine whether the inclusion of exchange rate volatility in the forecast yields any incremental benefits when equity volatility is also used as a factor. 


\subsection{Data and sources}

My primary data includes daily values for eight FX exchange rates, S\&P 500 30day implied volatility VIX measure, one-month, three-months, and one-year at-themoney implied FX rate volatility, and returns of eleven international single country equity indices and the pan-European STOXX index. The coverage is from January 1, 1999, to June 30, 2015. The starting date for the sample period coincides with the introduction of the Euro currency.

The implied volatility for the eight U.S. dollar cross exchange rates are provided by Bloomberg. The eight foreign currencies used are: Euro, British Pound, Japanese Yen, Swiss Franc, Canadian Dollar, Australian Dollar, Mexican Peso, and the Brazilian Real. The implied FX volatilities reflect the market expected future volatility for a given FX exchange rate from now (time t) until maturity. I consider one-month, three-months and one-year maturity horizons, but use three-month option implied FX volatility in the estimation of my regressions. Bloomberg implied volatility measures can be used to obtain the correct Black-Scholes price for a delta neutral straddle struck at maturity.

In order to compute correlations among international equity markets in a common currency, I employ the Datastream U.S. dollar denominated daily values for the equity indices in my study. In total, I examine the return and pairwise correlations for twelve equity indices. Four of these markets (plus the pan-European STOXX index) are markets where the Euro is the official currency. The other seven of these markets correspond to markets wherein each of the other foreign currencies in my sample is the official currency. The U.S. is the benchmark market in my sample used for the correlations calculations. Specifically, I use the main equity index in the United States (S\&P 500), Canada (S\&P/TSX composite), United Kingdom 
(FTSE 100), Australia (S\&P/ASX 300), Germany (DAX 30), France (CAC-40), Switzerland (SMI), Spain (IBEX 35), Italy (FTSE MIB), Japan (NIKKEI 225), Mexico (IPC), and Brazil (BOVESPA) as proxies for the broad equity markets in these countries.

\subsection{Empirical applications and results}

At the empirical level, applications of relations 1.8 through 1.13 in conjunction with relation 1.1 require computation of a few underlying concepts and some substitutions. Very briefly, these are:

1. Identification of employed volatility measures

2. Linking implied volatility with a forecast of one period ahead realized volatility

3. Measuring equity correlations, and finally

4. Linking currency volatilities of steps 1 and 2 with equity correlations of step 3 via an autoregressive error correction model ${ }^{3}$ (See Appendix D).

Obviously, steps 1 through 4 above do not automatically correspond with any of the relations expressed in 1.8 through 1.13 . This 'seemingly unrelated' reference will be clarified as I move on in each step and as I identify and assign components to their underlying variables in relations 1.8 through 1.13. Further, to expand the breadth of my empirics, additional relations and simplifying assumptions are also introduced.

\footnotetext{
${ }^{3}$ This model corrects for autocorrelation in the error term by modeling the random error term with an autoregressive model. It is not the same as the error correction model in Engle and Granger (1987).
} 


\subsubsection{Identification of employed volatility measures}

As implied volatility measures, I employ Bloomberg's exchange rate implied volatility for one month, three months, and one year. Realized exchange rate volatility is calculated via two approaches: variance of exchange rates over a given period (Classical method), and by employing Garman and Klass (1980) methodology. The former is given by

$$
\sigma_{S_{t}}^{2}=\frac{1}{N} \sum_{t=1}^{N}\left(F X_{-} R E T_{t}-\overline{F X_{-} R E T}\right)^{2}
$$

where $F X_{-} R E T_{t}$ represents the daily change in the $\mathrm{FX}$ exchange rate at day $t$ calculated using first differences, and $\overline{F X_{-} R E T}$ is the mean FX exchange daily return over the measured period. The standard deviation is simply the square root of the calculated variance. I then annualize the daily standard deviation by multiplying it by the square root of 365. I perform this calculation for each of the eight foreign exchange rates used in my study and over each day in my data sample, measuring realized volatility over rolling periods of one-, three-, and twelve-months ahead.

In the second method, following Garman and Klass, I utilize open, close, high, and low daily values to measure volatility of $\Delta S_{t}$. It is shown that this measure is about eight times more efficient than a simpler measure that uses close-to-close daily values. ${ }^{4}$ Specifically, I employ the reduced-form estimator which yields virtually the same efficiency as the full-form estimator. The difference is that the reducedform estimator specification has marginally different coefficients and excludes crossproduct terms. Under this methodology, I calculate realized volatility as the average

\footnotetext{
${ }^{4}$ Garman and Klass, 1980, pg. 74
} 
of the daily volatilities during the period, where the volatility for a given day $t$ is:

$$
\sigma_{S_{t}}^{2}=\frac{1}{2}[\ln (\text { High })-\ln (\text { Low })]^{2}-[2 \ln 2-1][\ln (\text { Open })-\ln (\text { Close })]^{2}
$$

where ln denotes the natural logarithm function, and High, Low, Open, and Close represent the daily high, low, open, and close exchange rate. Once again, I perform this calculation for each of the eight foreign exchange rates used in my study and for each day in my data sample, measuring realized volatility over rolling periods of one-, three-, and twelve-months ahead. Table 1.1 contains summary statistics for the volatilities of the currencies and the VIX used in my study.

\subsubsection{Linking implied volatility with a forecast of one period ahead re- alized volatility}

Utilizing the above two computed measures of realized volatility, I am in a position to employ and examine the efficacy of Bloomberg's option implied FX rate volatility measures ${ }^{5}$ as forecasts of actual currency volatilities. The aim is to simply test and establish a set of currency forecast measures of volatility that are currently readily available. Within the framework I have adopted, I evaluate the forecasts for one-, three-, and twelve-month horizons using both of the afore-calculated volatility measures. To evaluate the results, I compute the mean absolute percent error (MAPE) for each forecast. I report the results of this evaluation in Table 1.2. An analysis of the results lead to the following general conclusions: 1) Bloomberg's option implied currency volatilities are good predictors of actual subsequent currency volatility with mean absolute percent errors lower than $0.5 \%$ in all cases using the Garman-Klass method except for the Brazilian real, 2) shorter horizon forecasts

\footnotetext{
${ }^{5}$ These measures are readily available from Bloomberg. See Section 1.4 on data and sources.
} 
are more accurate, and 3) forecast errors are lower for the major currencies versus the emerging market currencies. The observed trends are consistent with greater liquidity for options of major currencies and with shorter maturities.

Table 1.1: Summary statistics of the data

This table contains summary statistics for the daily percentage returns in FX exchange rates, daily values of annualized implied one-month ahead volatilities, rolling daily values of one month ahead volatilities calculated under the "classic" method as in equation 1.16, and rolling daily values of one month ahead volatilities calculated under Garman-Klass measurement described in equation 1.17.

\begin{tabular}{|c|c|c|c|c|c|c|c|}
\hline & Obs & Mean & Max & Min & $\sigma^{2}$ & Skew & Kurtosis \\
\hline \multicolumn{8}{|c|}{ Panel A: Daily returns in FX rates. Mean and Std dev. are annualized. } \\
\hline Canadian Dollar & 4,301 & -0.017 & 0.033 & -0.04 & 0.108 & 0.143 & 3.185 \\
\hline Australian Dollar & 4,301 & 0.018 & 0.083 & -0.073 & 0.157 & -0.346 & 9.499 \\
\hline British Pound & 4,301 & -0.005 & 0.029 & -0.035 & 0.106 & -0.264 & 2.328 \\
\hline Euro & 4,301 & -0.005 & 0.035 & -0.025 & 0.122 & 0.038 & 1.295 \\
\hline Swiss Franc & 4,301 & -0.032 & 0.091 & -0.194 & 0.144 & -3.63 & 107.189 \\
\hline Japanese Yen & 4,301 & 0.008 & 0.055 & -0.035 & 0.124 & 0.032 & 3.598 \\
\hline Mexican Peso & 4,299 & 0.039 & 0.07 & -0.067 & 0.128 & 0.662 & 12.34 \\
\hline Brazilian Real & 4,179 & 0.085 & 0.1 & -0.103 & 0.212 & 0.328 & 10.952 \\
\hline \multicolumn{8}{|c|}{ Panel B: Daily values of annualized implied one-month ahead volatilities (in pct). } \\
\hline Canadian Dollar & 3,943 & 8.862 & 26.945 & 4 & 3.384 & 2.137 & 6.376 \\
\hline Australian Dollar & 4,296 & 11.712 & 44.53 & 5.575 & 4.286 & 2.714 & 12.169 \\
\hline British Pound & 4,291 & 8.897 & 29.623 & 4.335 & 3.054 & 2.677 & 10.348 \\
\hline Euro & 4,300 & 10.268 & 28.885 & 4.165 & 3.082 & 1.377 & 4.154 \\
\hline Swiss Franc & 4,268 & 10.579 & 28.375 & 4.485 & 2.66 & 1.206 & 3.9 \\
\hline Japanese Yen & 4,299 & 10.605 & 38.42 & 4.45 & 3.19 & 1.93 & 7.294 \\
\hline Mexican Peso & 3,724 & 10.869 & 71.43 & 4.8 & 5.907 & 3.967 & 23.534 \\
\hline Brazilian Real & 3,029 & 14.387 & 66.345 & 5.347 & 6.458 & 3.179 & 15.173 \\
\hline \multicolumn{8}{|c|}{ Panel C: Daily values of SEPP00's 30-day implied volatility-CBOE's VIX. } \\
\hline VIX & 4,149 & 20.977 & 80.86 & 9.89 & 8.732 & 2.002 & 6.688 \\
\hline
\end{tabular}


Table 1.1: Summary statistics of the data - cont'd

\begin{tabular}{lccccccc}
\hline & Obs & Mean & Max & Min & $\sigma^{2}$ & Skew & Kurtosis \\
\hline Panel D: Rolling & daily one-month & realized & return volatility & classic & method. \\
Canadian Dollar & 4,280 & 9.81 & 41.141 & 3.55 & 4.626 & 2.293 & 8.878 \\
Australian Dollar & 4,280 & 13.958 & 86.038 & 5.47 & 7.287 & 4.414 & 30.933 \\
British Pound & 4,280 & 9.967 & 31.237 & 3.012 & 3.662 & 2.189 & 8.033 \\
Euro & 4,280 & 11.538 & 30.098 & 3.332 & 3.848 & 0.826 & 1.603 \\
Swiss Franc & 4,280 & 12.783 & 85.75 & 3.872 & 6.819 & 6.406 & 59.341 \\
Japanese Yen & 4,280 & 11.639 & 38.14 & 3.793 & 4.299 & 1.549 & 5.467 \\
Mexican Peso & 4,280 & 11.037 & 66.201 & 3.107 & 6.288 & 3.539 & 20.316 \\
Brazilian Real & 4,280 & 17.528 & 89.344 & 2.959 & 10.976 & 2.571 & 9.663 \\
Panel E: Rolling & daily one-month & realized & return volatility- & Garman-Klass. \\
Canadian Dollar & 4,280 & 9.668 & 33.433 & 4.396 & 4.028 & 1.825 & 5.448 \\
Australian Dollar & 4,280 & 13.426 & 63.88 & 5.907 & 5.912 & 3.534 & 19.493 \\
British Pound & 4,280 & 9.827 & 36.853 & 3.852 & 3.927 & 3.019 & 12.407 \\
Euro & 4,280 & 11.184 & 29.312 & 3.621 & 3.449 & 1.187 & 3.211 \\
Swiss Franc & 4,280 & 12.081 & 37.841 & 3.987 & 3.558 & 1.948 & 8.854 \\
Japanese Yen & 4,280 & 11.328 & 33.864 & 3.885 & 3.57 & 1.632 & 5.296 \\
Mexican Peso & 4,280 & 10.439 & 75.616 & 3.76 & 6.153 & 4.449 & 32.502 \\
Brazilian Real & 4,280 & 14.464 & 59.885 & 3.734 & 7.829 & 2.369 & 7.924 \\
\hline
\end{tabular}

\subsubsection{Measuring equity correlations}

Considering relations 1.10 and 1.12 and their ensuing discussions related to the correlation between the real sides of the two economies, this section paves the way for the empirics via simple assumptions and substitutions. First, it is assumed that the real side of the economy may be represented by the assets side or the equity markets in each country. Second, to address the notion that correlations increase in times of higher volatility, I designate September 2008 to August 2009 as the most recent notable period of high volatility and treat it as a separate time period. I then calculate unconditional correlations among the twelve equity markets for each 
Table 1.2: FX Implied Volatility as Forecast of Realized Volatilities - MAPE

This table contains the mean absolute percentage error (MAPE) obtained from using the Bloomberg FX rate implied volatilities as the forecast for the subsequent realized volatilities. Results are tabulated for one-month, three-month, and oneyear option implied foreign exchange volatilities as forecasts of realized volatilities calculated using both the "classical" and the Glass-Karman methods.

\begin{tabular}{lcccccc}
\hline & \multicolumn{3}{c}{ Classical Method } & \multicolumn{3}{c}{ Garman-Klass } \\
Currency & 1-mo & 3-mo & 1-year & 1-mo & 3-mo & 1-year \\
\hline Canadian Dollar & 0.283 & 0.306 & 0.326 & 0.189 & 0.231 & 0.27 \\
Australian Dollar & 0.683 & 0.753 & 0.81 & 0.415 & 0.472 & 0.496 \\
British Pound & 0.206 & 0.202 & 0.269 & 0.167 & 0.178 & 0.231 \\
Euro & 0.273 & 0.265 & 0.291 & 0.18 & 0.193 & 0.235 \\
Swiss Franc & 0.741 & 0.697 & 0.53 & 0.285 & 0.258 & 0.258 \\
Japanese Yen & 0.345 & 0.322 & 0.342 & 0.233 & 0.232 & 0.275 \\
Mexican Peso & 0.546 & 0.561 & 0.643 & 0.441 & 0.454 & 0.486 \\
Brazilian Real & 1.17 & 1.32 & 1.28 & 0.609 & 0.644 & 0.639 \\
\hline
\end{tabular}

of these two time periods. ${ }^{6}$ The results, tabulated in Table 1.3, are compared and saved for further application in step 4.

Other high/low categorizations for equity markets also appear logical. Again, considering the monetary components of relations 1.10 and 1.12, it would be pressing to categorize the equity markets according to the volatility of the currency markets. Based on the historical implied FX volatilities of three major currencies (Euro, British Pound, and Swiss Franc), I divide the equity sample into three sub-periods of low, medium, and high implied FX volatility. Similar to the above categorization, equity market correlations are then calculated separately for each of these three subperiods and are utilized in the next step. Table 1.4 summarizes the results of this analysis for the three major European currencies. Notice that average volatility for

\footnotetext{
${ }^{6}$ Correlations are measured using daily returns of the U.S. dollar denominated value of the equity indices provided by Datastream. In order to address the time zone effect, I lag the Japanese and Australian markets by one day when calculating correlations.
} 


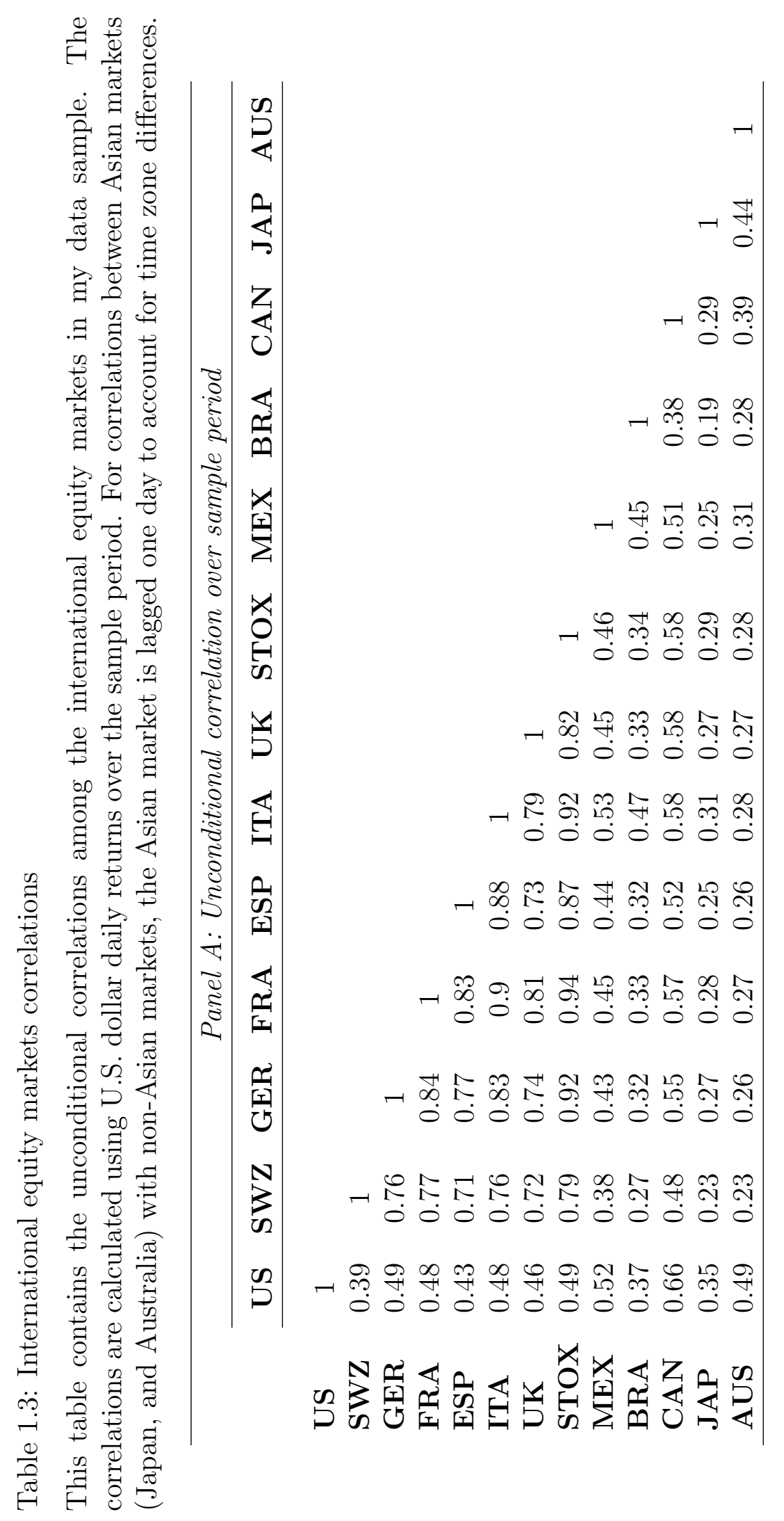




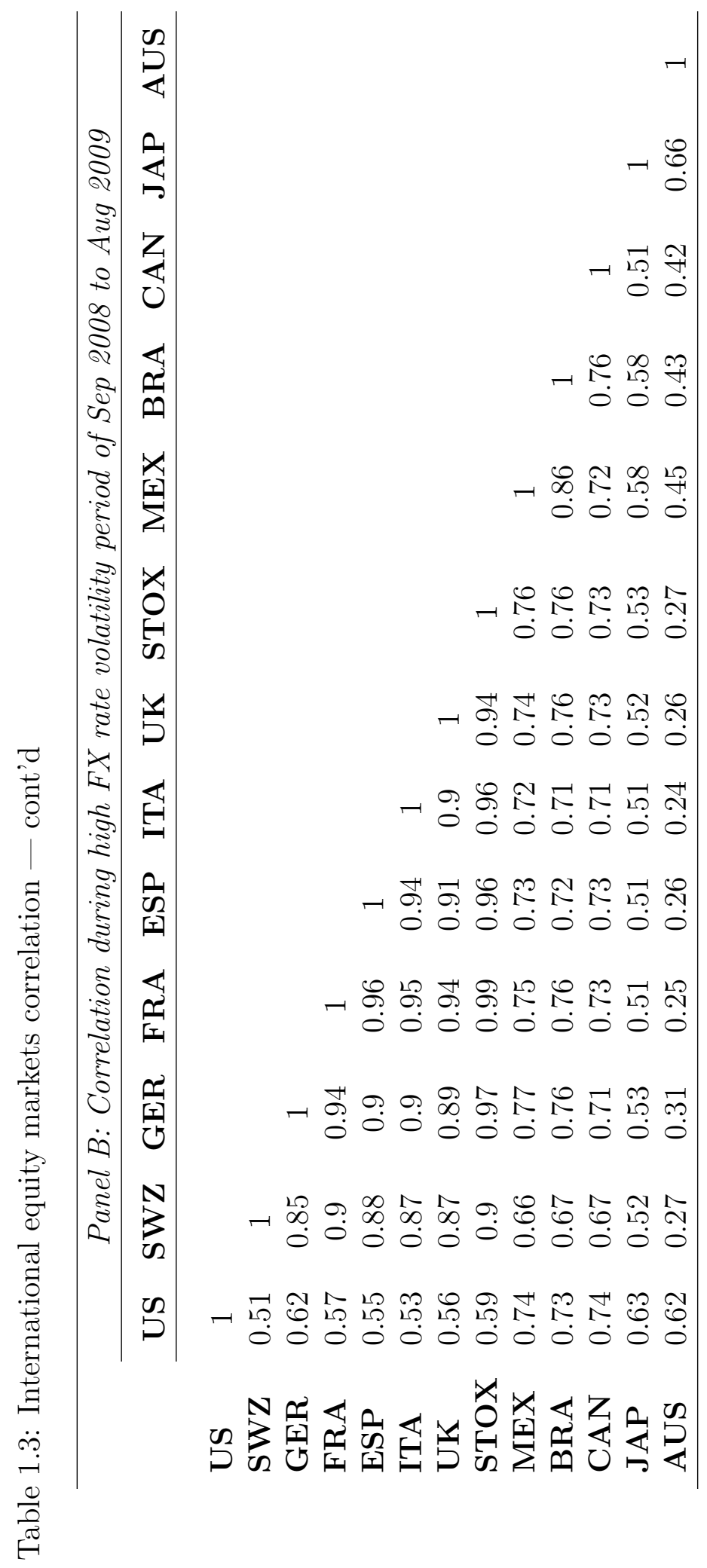


Table 1.4: Average three-month FX implied volatilities for European currencies during periods of low, medium, and high implied FX volatility levels

This table contains the average three-month FX implied volatility for each European currency in my sample calculated as the simple average of daily values of 3-month implied volatility. The sample period for this table is from January 1999 through June 2015. Low implied FX volatility level refers to the following sub-periods: Feb2005-Nov2007 and Sept2012 - Jun2015. High implied FX volatility level refers to the following periods: Aug2000 - Sept2001, Sept2008 - Aug2009, and May2010 Jan2012. All other sub-periods are deemed to have medium levels of implied FX volatility. EUR refers to the Euro, USD refers to the US dollar, GBP refers to the British Pound, and CHF refers to the Swiss Franc.

\begin{tabular}{|c|c|c|c|}
\hline & \multicolumn{3}{|c|}{ Currency } \\
\hline & EUR-USD & GBP-USD & CHF-USD \\
\hline \multicolumn{4}{|l|}{ Implied Volatility Level } \\
\hline $\begin{array}{l}\text { Low } \\
\end{array}$ & 7.88 & 7.36 & 8.61 \\
\hline Medium & 10.53 & 8.94 & 11.01 \\
\hline High & 13.87 & 11.87 & 13.16 \\
\hline
\end{tabular}

the Euro in each category is similar to that of the Swiss Franc and generally higher than the volatility of the British Pound. Figure 1.2 graphically depicts how the volatility of the Euro and the Swiss Franc appear to move together. This trend is not surprising given the economic interdependence between Switzerland and the Euro zone. In fact, the Swiss National Bank pegged the two currencies for a period of about three years. The surprise abolishment of this peg on January 15, 2015 resulted in a temporary spike in the Swiss Franc option implied volatility, clearly visible on the graph in Figure 1.2.

\subsubsection{Linking currency volatilities with equity correlations}

This step brings together and sets side by side the components that are so far separately computed. In brief, this step links currency volatilities of steps 1 and 2 with equity correlations of step 3 via an autoregressive error correction model. 
Expressed differently, the implied measures of, or the substitutes for, the underlying concepts of both sides of relation 1.10 or 1.12 are now ready for further empirical analysis. As discussed at the end of Section 1.3, using monthly data I estimate relation 1.15, repeated here for convenience and relabeled relation 1.18. Each time period $t$ refers to a one-month period, thus the dependent variable in relation 1.18 represents the correlation of variables $X$ and $Y$ over three months starting at time t. The other variables are as described in Section 1.3. Based on historical ranges for FX implied volatility discussed in Section 1.5.3, FXdummyt in the evaluation of relation 1.18 was computed as the interaction of $F X I V_{t}$ and a dummy set to 1 when the FX implied volatility is 11 or greater (12 was used for the Brazilian real and Mexican peso) and set to 0 otherwise. Similarly, the threshold for the VIX dummy variable was set at 25 .

$$
\operatorname{Corr} X Y_{t, t+3}=\operatorname{Corr} X Y_{t-3, t}+F X I V_{t}+F X d u m m y_{t}+V I X d u m m y_{t}+\varepsilon_{t}
$$

The autoregressive error correction methodology I employ is a modified OLS by which the autocorrelation of the errors is accounted for via an autoregressive model for the random error (See appendix D). Specifically, I estimate four stepwise variations of relation (17) and refer to these variations as Models 1, 2, 3, and 4. Model 1 contains $\operatorname{Corr} X Y_{t-3, t}$ (also labeled $\operatorname{Lag} \operatorname{Corr} X Y$ ) as the sole independent variable. Model 2 extends Model 1 by adding $F X I V_{t}$ as the second independent variable, and Model 3 extends Model 2 by including $F X d u m m y_{t}$ as a third independent variable. Model 4 includes all independent variables listed in relation 1.18. These four variations of relation 1.18 are evaluated a total of twelve times for each of the country equity index pairs listed in Section 1.4 plus the pan-European STOXX index. The results of these 48 (12 equity market pairs x 4 models) regression estimations are summarized in Table 1.5. 
Table 1.5: Tests of relations between international equity market correlations and FX option implied volatilities

This table contains the results of regressions of three-month correlations between the U.S. S\&P500 index and eight other country equity indices. Correlations are measured ex-post using daily U.S. dollar returns with the other indices. The variable $\operatorname{Lag} \operatorname{Corr} X Y$ is the most recent three-month correlation up until observation day. Measured on daily observations, VIX dummy is the interaction with the VIX index of a dummy set to 1 (zero) if the VIX is above (below) 25, and FXIV dummy is the interaction with the FX rate of a dummy set to 1 (zero) if the pertinent FX rate 3 -month implied volatility is above (below) 11. Each Panel contains the results for a given currency/country. Numbers below the coefficient estimates are t-values. The asterisks ${ }^{* * *}$, and ${ }^{* * *}$ indicate statistical significance at the $10 \%, 5 \%$, and $1 \%$ level, respectively. Sample period includes monthly observations from Jan 1, 1999 to Jun 30, 2015.

\begin{tabular}{|c|c|c|c|c|c|c|}
\hline & Intercept & $\underset{\text { CorrXY }}{\text { Cag }}$ & FX IV & $\begin{array}{l}\text { FX IV } \\
\text { dummy }\end{array}$ & $\begin{array}{c}\text { VIX } \\
\text { dummy }\end{array}$ & $\underset{R^{2}}{\operatorname{Adj} .}$ \\
\hline \multicolumn{7}{|c|}{ Panel A: US-Germany equity market correlation } \\
\hline Model 1: & $\begin{array}{c}0.2724^{* * *} \\
(7.99)\end{array}$ & $\begin{array}{c}0.5150^{* * *} \\
\quad(8.64)\end{array}$ & & & & 0.282 \\
\hline Model 2: & $\begin{array}{c}0.1955^{* * *} \\
\quad(4.63)\end{array}$ & $\begin{array}{c}0.4730^{* * *} \\
\quad(7.87)\end{array}$ & $\begin{array}{c}0.0095^{\text {*** }} \\
(2.98)\end{array}$ & & & 0.314 \\
\hline Model 3: & $\begin{array}{c}0.2826^{* * *} \\
(4.89)\end{array}$ & $\begin{array}{c}0.4672^{* * *} \\
\quad(7.84)\end{array}$ & $\begin{array}{c}-0.0013 \\
(-0.22)\end{array}$ & $\begin{array}{c}0.0058^{* *} \\
(2.18)\end{array}$ & & 0.331 \\
\hline Model 4: & $\begin{array}{c}0.3532^{* * *} \\
\quad(5.74)\end{array}$ & $\begin{array}{c}0.4431^{* * *} \\
\quad(7.51)\end{array}$ & $\begin{array}{c}-0.0088 \\
(-1.40)\end{array}$ & $\begin{array}{c}0.0064^{* *} \\
(2.45)\end{array}$ & $\begin{array}{c}0.0024^{* * *} \\
(2.96)\end{array}$ & 0.361 \\
\hline \multicolumn{7}{|c|}{ Panel B: US-UK equity market correlation } \\
\hline Model 1: & $\begin{array}{c}0.2125^{* * *} \\
\quad(7.36)\end{array}$ & $\begin{array}{c}0.5869^{* * *} \\
(10.61)\end{array}$ & & & & 0.372 \\
\hline Model 2: & $\begin{array}{c}0.1526^{* * *} \\
\quad(4.18)\end{array}$ & $\begin{array}{c}0.5542^{* * *} \\
\quad(9.92)\end{array}$ & $\begin{array}{c}0.0084^{\text {*** }} \\
\quad(2.61)\end{array}$ & & & 0.394 \\
\hline Model 3: & $\begin{array}{c}0.2259^{* * *} \\
(3.66)\end{array}$ & $\begin{array}{c}0.5319^{* * *} \\
(9.22)\end{array}$ & $\begin{array}{c}0.0002 \\
(.04)\end{array}$ & $\begin{array}{c}0.0052 \\
(1.47)\end{array}$ & & 0.401 \\
\hline Model 4: & $\begin{array}{c}0.2386^{* * *} \\
(3.82)\end{array}$ & $\begin{array}{c}0.5357^{* * *} \\
\quad(9.28)\end{array}$ & $\begin{array}{c}-0.0021 \\
(-0.32)\end{array}$ & $\begin{array}{c}0.0048 \\
(1.36)\end{array}$ & $\begin{array}{l}0.001 \\
(1.26)\end{array}$ & 0.406 \\
\hline
\end{tabular}


Table 1.5: Tests of relations between international equity market correlations and FX option implied volatilities - cont'd (2 of 5)

\begin{tabular}{|c|c|c|c|c|c|c|}
\hline & Intercept & $\underset{\text { CorrXY }}{\operatorname{Lag}}$ & FX IV & $\begin{array}{c}\text { FX IV } \\
\text { dummy }\end{array}$ & $\begin{array}{c}\text { VIX } \\
\text { dummy }\end{array}$ & $\underset{R^{2}}{\operatorname{Adj} .}$ \\
\hline \multicolumn{7}{|c|}{ Panel C: US-Switzerland equity market correlation } \\
\hline Model 1: & $\begin{array}{c}0.2179^{* * *} \\
(7.65)\end{array}$ & $\begin{array}{c}0.4873^{* * *} \\
(7.73)\end{array}$ & & & & 0.24 \\
\hline Model 2: & $\begin{array}{c}0.1567^{* * *} \\
(3.05)\end{array}$ & $\begin{array}{c}0.4727^{* * *} \\
\quad(7.42)\end{array}$ & $\begin{array}{c}0.0063 \\
(1.43)\end{array}$ & & & 0.248 \\
\hline Model 3: & $\begin{array}{c}0.2187^{* * *} \\
\quad(2.98)\end{array}$ & $\begin{array}{c}0.4689^{* * *} \\
\quad(7.36)\end{array}$ & $\begin{array}{c}-0.0012 \\
(-0.16)\end{array}$ & $\begin{array}{c}0.0035 \\
(1.18)\end{array}$ & & 0.253 \\
\hline Model 4: & $\begin{array}{c}0.2993^{* * *} \\
\quad(3.81)\end{array}$ & $\begin{array}{c}0.4332^{* * *} \\
\quad(6.75)\end{array}$ & $\begin{array}{c}-0.0092 \\
(-1.12)\end{array}$ & $\begin{array}{c}0.0037 \\
(1.28)\end{array}$ & $\begin{array}{c}0.0024^{* * *} \\
\quad(2.61)\end{array}$ & 0.279 \\
\hline \multicolumn{7}{|c|}{ Panel D: US-Canada equity market correlation } \\
\hline Model 1: & $\begin{array}{c}0.3035^{* * *} \\
(7.38)\end{array}$ & $\begin{array}{c}0.5306^{* * *} \\
(8.59)\end{array}$ & & & & 0.281 \\
\hline Model 2: & $\begin{array}{c}0.2783^{* * *} \\
\quad(6.26)\end{array}$ & $\begin{array}{c}0.5062^{* * *} \\
(7.94)\end{array}$ & $\begin{array}{c}0.0047 \\
(1.47)\end{array}$ & & & 0.289 \\
\hline Model 3: & $\begin{array}{c}0.4121^{* * *} \\
\quad(5.7)\end{array}$ & $\begin{array}{c}0.4516^{* * *} \\
\quad(6.72)\end{array}$ & $\begin{array}{c}-0.0093 \\
(-1.37)\end{array}$ & $\begin{array}{c}0.0093^{* *} \\
(2.33)\end{array}$ & & 0.309 \\
\hline Model 4: & $\begin{array}{c}0.4301^{* * *} \\
\quad(5.92)\end{array}$ & $\begin{array}{c}0.4207^{* * *} \\
\quad(6.09)\end{array}$ & $\begin{array}{c}-0.0099 \\
(-1.47)\end{array}$ & $\begin{array}{c}0.0077^{*} \\
(1.9)\end{array}$ & $\begin{array}{c}0.0015^{*} \\
(1.78)\end{array}$ & 0.321 \\
\hline \multicolumn{7}{|c|}{ Panel E: US-Australia equity market correlation } \\
\hline Model 1: & $\begin{array}{c}0.3453^{* * *} \\
\quad(9.51)\end{array}$ & $\begin{array}{c}0.2885^{* * *} \\
\quad(4.05)\end{array}$ & & & & 0.079 \\
\hline Model 2: & $\begin{array}{c}0.3325^{* * *} \\
\quad(7.41)\end{array}$ & $\begin{array}{c}0.2829^{* * *} \\
\quad(3.91)\end{array}$ & $\begin{array}{c}0.0013 \\
(.49)\end{array}$ & & & 0.081 \\
\hline Model 3: & $\begin{array}{c}0.2734^{* * *} \\
\quad(4.88)\end{array}$ & $\begin{array}{c}0.2679^{* * *} \\
\quad(3.7)\end{array}$ & $\begin{array}{c}0.0099^{*} \\
(1.77)\end{array}$ & $\begin{array}{c}-0.0048^{*} \\
(-1.75)\end{array}$ & & 0.095 \\
\hline Model 4: & $\begin{array}{c}0.3752^{* * *} \\
(5.68)\end{array}$ & $\begin{array}{c}0.2088^{* * *} \\
(2.81)\end{array}$ & $\begin{array}{l}0.001 \\
(.16)\end{array}$ & $\begin{array}{c}-0.0032 \\
(-1.18)\end{array}$ & $\begin{array}{c}0.0027^{* * *} \\
\quad(2.78)\end{array}$ & 0.131 \\
\hline
\end{tabular}


Table 1.5: Tests of relations between international equity market correlations and FX option implied volatilities - cont'd (3 of 5)

\begin{tabular}{|c|c|c|c|c|c|c|}
\hline & Intercept & $\underset{\text { CorrXY }}{\operatorname{Lag}}$ & FX IV & $\begin{array}{l}\text { FX IV } \\
\text { dummy }\end{array}$ & $\begin{array}{c}\text { VIX } \\
\text { dummy }\end{array}$ & $\underset{R^{2}}{\text { Adj. }}$ \\
\hline \multicolumn{7}{|c|}{ Panel F: US-Japan equity market correlation } \\
\hline Model 1: & $\begin{array}{c}0.3717^{* * *} \\
(10.75)\end{array}$ & $\begin{array}{c}0.2088^{* * *} \\
(2.95)\end{array}$ & & & & 0.044 \\
\hline Model 2: & $\begin{array}{c}0.2656^{* *} \\
(5.62)\end{array}$ & $\begin{array}{c}0.1700^{* *} \\
(2.42)\end{array}$ & $\begin{array}{c}0.0118^{\text {*** }} \\
\quad(3.21)\end{array}$ & & & 0.093 \\
\hline Model 3: & $\begin{array}{c}0.2263^{* * *} \\
\quad(3.28)\end{array}$ & $\begin{array}{c}0.1676^{* *} \\
(2.39)\end{array}$ & $\begin{array}{c}0.0166^{* *} \\
(2.31)\end{array}$ & $\begin{array}{c}-0.0022 \\
(-0.78)\end{array}$ & & 0.096 \\
\hline Model 4: & $\begin{array}{c}0.2788^{* * *} \\
(3.59)\end{array}$ & $\begin{array}{c}0.1465^{* *} \\
(2.05)\end{array}$ & $\begin{array}{c}0.0114 \\
(1.41)\end{array}$ & $\begin{array}{c}-0.0014 \\
(-0.48)\end{array}$ & $\begin{array}{c}0.0012 \\
(1.45)\end{array}$ & 0.106 \\
\hline \multicolumn{7}{|c|}{ Panel G: US-Brazil equity market correlation } \\
\hline Model 1: & $\begin{array}{c}0.2603^{* * *} \\
\quad(5.87)\end{array}$ & $\begin{array}{c}0.5687^{* * *} \\
(8.11)\end{array}$ & & & & 0.331 \\
\hline Model 2: & $\begin{array}{c}0.2046^{* * *} \\
\quad(3.7)\end{array}$ & $\begin{array}{c}0.5328^{* * *} \\
(7.31)\end{array}$ & $\begin{array}{c}0.0054^{*} \\
(1.67)\end{array}$ & & & 0.345 \\
\hline Model 3: & $\begin{array}{c}0.2208^{* * *} \\
\quad(3.27)\end{array}$ & $\begin{array}{c}0.5331^{* * *} \\
(7.29)\end{array}$ & $\begin{array}{c}0.0031 \\
(.49)\end{array}$ & $\begin{array}{c}0.0014 \\
(.42)\end{array}$ & & 0.346 \\
\hline Model 4: & $\begin{array}{c}0.3380^{* * *} \\
(3.83)\end{array}$ & $\begin{array}{c}0.4909^{* * *} \\
(6.53)\end{array}$ & $\begin{array}{c}-0.0058 \\
(-0.76)\end{array}$ & $\begin{array}{c}0.0029 \\
(.83)\end{array}$ & $\begin{array}{c}0.0031^{* *} \\
(2.04)\end{array}$ & 0.366 \\
\hline \multicolumn{7}{|c|}{ Panel H: US-Mexico equity market correlation } \\
\hline Model 1: & $\begin{array}{c}0.3439^{* * *} \\
\quad(8.14)\end{array}$ & $\begin{array}{c}0.4704^{* * *} \\
(7.37)\end{array}$ & & & & 0.229 \\
\hline Model 2: & $\begin{array}{c}0.3148^{* * *} \\
\quad(7.15)\end{array}$ & $\begin{array}{c}0.4388^{* * *} \\
(6.75)\end{array}$ & $\begin{array}{c}0.0044^{* *} \\
(2.11)\end{array}$ & & & 0.247 \\
\hline Model 3: & $\begin{array}{c}0.3957^{* * *} \\
\quad(6.66)\end{array}$ & $\begin{array}{c}0.4086^{* * *} \\
(6.17)\end{array}$ & $\begin{array}{c}-0.0033 \\
(-0.75)\end{array}$ & $\begin{array}{c}0.0051^{* *} \\
(2.01)\end{array}$ & & 0.264 \\
\hline Model 4: & $\begin{array}{c}0.4253^{* * *} \\
\quad(6.82)\end{array}$ & $\begin{array}{c}0.3880^{* * *} \\
(5.76)\end{array}$ & $\begin{array}{c}-0.0056 \\
(-1.21)\end{array}$ & $\begin{array}{c}0.0051^{* *} \\
(2 .)\end{array}$ & $\begin{array}{c}0.0013 \\
1.52)\end{array}$ & 0.273 \\
\hline
\end{tabular}


Table 1.5: Tests of relations between international equity market correlations and FX option implied volatilities — cont'd (4 of 5)

\begin{tabular}{|c|c|c|c|c|c|c|}
\hline & Intercept & $\underset{\text { CorrXY }}{\operatorname{Lag}}$ & FX IV & $\begin{array}{c}\text { FX IV } \\
\text { dummy }\end{array}$ & $\begin{array}{c}\text { VIX } \\
\text { dummy }\end{array}$ & $\underset{\mathrm{R}^{2}}{\operatorname{Adj}}$ \\
\hline \multicolumn{7}{|c|}{ Panel I: US-France equity market correlation } \\
\hline Model 1: & $\begin{array}{c}0.2541^{* * *} \\
(7.85)\end{array}$ & $\begin{array}{c}0.5208^{* * *} \\
(8.74)\end{array}$ & & & & 0.287 \\
\hline Model 2: & $\begin{array}{c}0.1898^{* *} \\
(4.29)\end{array}$ & $\begin{array}{c}0.5068^{* * *} \\
(8.53)\end{array}$ & $\begin{array}{c}0.0068^{* *} \\
(2.11)\end{array}$ & & & 0.303 \\
\hline Model 3: & $\begin{array}{c}0.3058^{* * *} \\
\quad(4.97)\end{array}$ & $\begin{array}{c}0.4865^{* * *} \\
(8.25)\end{array}$ & $\begin{array}{c}-0.0068 \\
(-1.13)\end{array}$ & $\begin{array}{c}0.0073^{* * *} \\
\quad(2.66)\end{array}$ & & 0.329 \\
\hline Model 4: & $\begin{array}{c}0.3562^{* * *} \\
\quad(5.39)\end{array}$ & $\begin{array}{c}0.4708^{* * *} \\
(7.98)\end{array}$ & $\begin{array}{c}-0.0123^{*} \\
(-1.87)\end{array}$ & $\begin{array}{c}0.0077^{* * *} \\
(2.85)\end{array}$ & $\begin{array}{c}0.0017^{* *} \\
(1.99)\end{array}$ & 0.343 \\
\hline \multicolumn{7}{|c|}{ Panel J: US-Italy equity market correlation } \\
\hline Model 1: & $\begin{array}{c}0.2529^{* * *} \\
\quad(7.99)\end{array}$ & $\begin{array}{c}0.4898^{* * *} \\
(7.96)\end{array}$ & & & & 0.25 \\
\hline Model 2: & $\begin{array}{c}0.1758^{* * *} \\
\quad(3.9)\end{array}$ & $\begin{array}{c}0.4733^{* * *} \\
(7.73)\end{array}$ & $\begin{array}{c}0.0081^{* *} \\
(2.38)\end{array}$ & & & 0.272 \\
\hline Model 3: & $\begin{array}{c}0.2904^{* * *} \\
(4.57)\end{array}$ & $\begin{array}{c}0.4551^{* * *} \\
(7.49)\end{array}$ & $\begin{array}{l}-0.0055 \\
(-0.87)\end{array}$ & $\begin{array}{c}0.0073^{* *} \\
(2.52)\end{array}$ & & 0.296 \\
\hline Model 4: & $\begin{array}{c}0.3428^{* * *} \\
\quad(4.96)\end{array}$ & $\begin{array}{c}0.4337^{* * *} \\
(7.05)\end{array}$ & $\begin{array}{l}-0.011 \\
(-1.57)\end{array}$ & $\begin{array}{c}0.0078^{* * *} \\
\quad(2.7)\end{array}$ & $\begin{array}{c}0.0017^{*} \\
(1.85)\end{array}$ & 0.308 \\
\hline \multicolumn{7}{|c|}{ Panel K: US-Spain equity market correlation } \\
\hline Model 1: & $\begin{array}{c}0.2625^{* * *} \\
\quad(8.22)\end{array}$ & $\begin{array}{c}0.4529^{* * *} \\
(7.1)\end{array}$ & & & & 0.21 \\
\hline Model 2: & $\begin{array}{c}0.1912^{* * *} \\
\quad(4.17)\end{array}$ & $\begin{array}{c}0.4368^{* * *} \\
(6.87)\end{array}$ & $\begin{array}{c}0.0075^{* *} \\
(2.15)\end{array}$ & & & 0.229 \\
\hline Model 3: & $\begin{array}{c}0.2733^{* * *} \\
\quad(4.16)\end{array}$ & $\begin{array}{c}0.4223^{* * *} \\
(6.62)\end{array}$ & $\begin{array}{c}-0.0022 \\
(-0.33)\end{array}$ & $\begin{array}{c}0.0052^{*} \\
(1.74)\end{array}$ & & 0.241 \\
\hline Model 4: & $\begin{array}{c}0.3366^{* * *} \\
(4.74)\end{array}$ & $\begin{array}{c}0.3976^{* * *} \\
(6.2)\end{array}$ & $\begin{array}{c}-0.0089 \\
(-1.24)\end{array}$ & $\begin{array}{c}0.0058^{*} \\
(1.96)\end{array}$ & $\begin{array}{c}0.0020^{* *} \\
(2.21)\end{array}$ & 0.26 \\
\hline
\end{tabular}


Table 1.5: Tests of relations between international equity market correlations and FX option implied volatilities — cont'd (5 of 5)

\begin{tabular}{|c|c|c|c|c|c|c|}
\hline & Intercept & $\underset{\text { CorrXY }}{\operatorname{Lag}}$ & FX IV & $\begin{array}{c}\text { FX IV } \\
\text { dummy }\end{array}$ & $\begin{array}{c}\text { VIX } \\
\text { dummy }\end{array}$ & $\underset{\mathrm{R}^{2}}{\operatorname{Adj}}$ \\
\hline \multicolumn{7}{|c|}{ Panel L: US-STOXX equity market correlation } \\
\hline Model 1: & $\begin{array}{c}0.2841^{* * *} \\
\quad(8.26)\end{array}$ & $\begin{array}{c}0.4779^{* * *} \\
(7.73)\end{array}$ & & & & 0.239 \\
\hline Model 2: & $\begin{array}{c}0.2187^{* * *} \\
(4.88)\end{array}$ & $\begin{array}{c}0.4595^{* * *} \\
\quad(7.44)\end{array}$ & $\begin{array}{c}0.0072^{* *} \\
(2.24)\end{array}$ & & & 0.259 \\
\hline Model 3: & $\begin{array}{c}0.3165^{* * *} \\
\quad(5.15)\end{array}$ & $\begin{array}{c}0.4456^{* * *} \\
(7.26)\end{array}$ & $\begin{array}{c}-0.0045 \\
(-0.75)\end{array}$ & $\begin{array}{c}0.0062^{* *} \\
(2.3)\end{array}$ & & 0.279 \\
\hline Model 4: & $\begin{array}{c}0.3808^{* * *} \\
\quad(5.81)\end{array}$ & $\begin{array}{c}0.4239^{* * *} \\
\quad(6.94)\end{array}$ & $\begin{array}{c}-0.0113^{*} \\
(-1.75)\end{array}$ & $\begin{array}{c}0.0068^{* *} \\
(2.54)\end{array}$ & $\begin{array}{c}0.0021^{* *} \\
(2.55)\end{array}$ & 0.303 \\
\hline
\end{tabular}

In all of the above experiments, the foreign exchange option implied volatility is for the three-month horizon. As noted earlier in Section 1.5.2, I consider onemonth, three-month, and twelve-month option implied volatilities in my analysis. Although FX option implied volatility is a more accurate predictor of actual volatility for shorter maturity options, calculation of cross-country one-month correlations using daily data is not always practical due to the lack of sufficient number of observations. ${ }^{7}$ Thus, the next shorter horizon (three months) is used in my regression analysis. I recognize that there is a bit of a horizon mismatch with the VIX volatility measure as it captures the options implied volatility on the S\&P500 for the next thirty days, not three months. Although a three-month VIX volatility measure is available, it is not nearly as widely followed and its underlying options are significantly less liquid. Since the focus of my analysis is on the relation between equity

\footnotetext{
${ }^{7}$ For instance, February usually contains three trading holidays for the Brazilian market due to the Carnival holiday and one U.S. trade holiday in observance of President's Day (2nd Monday in February). This results in too few overlapping trading days to calculate a significant correlation between the S\&P 500 and the Bovespa for such months.
} 
correlations and FX implied volatility (not the VIX), I do not believe this choice impacts the interpretation of my results.

I find that in all country pairs, with the exception of US-Switzerland and USBrazil, the coefficients for FX implied volatility and/or the interaction of implied volatility and the FX dummy are significant in Models 2 and 3. This is consistent with my theoretical premise of a contemporaneous relation between FX volatility and equity correlations. Moreover, the use of FX implied volatility in the analysis is backed by my earlier empirical findings that option implied FX volatility are good proxies for subsequent FX volatility. Since all the independent variables in relation 1.18 are known ex ante at time $t$ and the dependent variable is the equity correlation over time $t$ to $t+3$, my findings suggest that FX implied volatility is useful in forecasting subsequent equity correlation between pertinent broad country equity markets.

Next, I evaluate the performance of the aforementioned four model variations when predicting equity correlations using out-of-sample data. In this exercise I also evaluate how a naïve forecast would compare to these models. A naïve forecast is defined as using the most recent three-month observed equity correlation as the forecast for the next three-month equity correlation.

\subsubsection{Evaluation of forecast accuracy of FX implied volatility models}

To forecast 'ex-ante', I re-estimate the full model as specified in relation 1.15 while excluding the last six periods from the sample data. The goal is to use these six periods/months in out-of-sample forecasts and compare the results with those of the naïve model, i.e., that next period correlations are the same as the current ones. I follow two approaches, dynamic and static forecasts, i.e., I forecast one- or more-periods ahead 'without' re-estimating the model (= dynamic), or I re-estimate 
the model before each period forecast ( = static). The former is a more stringent test of the model. Each periodic forecast, by my structure, is for the subsequent three-month correlations between a pair of equity markets.

Forecast errors are calculated as MAPE (mean absolute percentage error). The results are reported in Table 1.6. Panels A and B contain the MAPEs for the naïve and the full model under the dynamic process, respectively, while panels $\mathrm{C}$ and $\mathrm{D}$ are the same but under the static alternative. Panels A and B, by definition, may not be the same. The reported errors are over 'one period' only. In the vast majority of the cases, the naïve model errors (panels A and C) are greater than the corresponding errors in the full model (panels B and D). This is strong evidence that the full model yields more accurate forecasts than the naïve model. Thus, the full model provides a more accurate tool for the practitioners who use current correlations as the best forecast for the next period. These results are not surprising since the analysis discussed in Section 1.5.4 points out that Model 4, the complete model as described in relation 1.15, yielded the highest $\bar{R}^{2}$. Somewhat surprisingly, the errors in Panel $\mathrm{D}$ are not consistently lower than those in Panel B. In fact, for the last period, the opposite is true. It is expected that in out-of-sample forecasts without model re-estimation the forecast errors further out into the future would build up and be larger. I attribute this anomaly to three factors: 1) I only estimated a limited six periods ahead, 2) equity market correlations are known to cluster and vary gradually over time, and 3) each correlation forecast has a two-month overlap with the adjacent period, thus mitigating the advantage of monthly model re-estimation.

In order to evaluate the out-of-sample forecast accuracy of all the model variations I reported in Section 1.5.4 I employ a simulation analysis to systematically produce 132 forecasts for each of the model variations. All models are re-estimated over a fixed number of observations ( $=60$ months) in a rolling regression process 


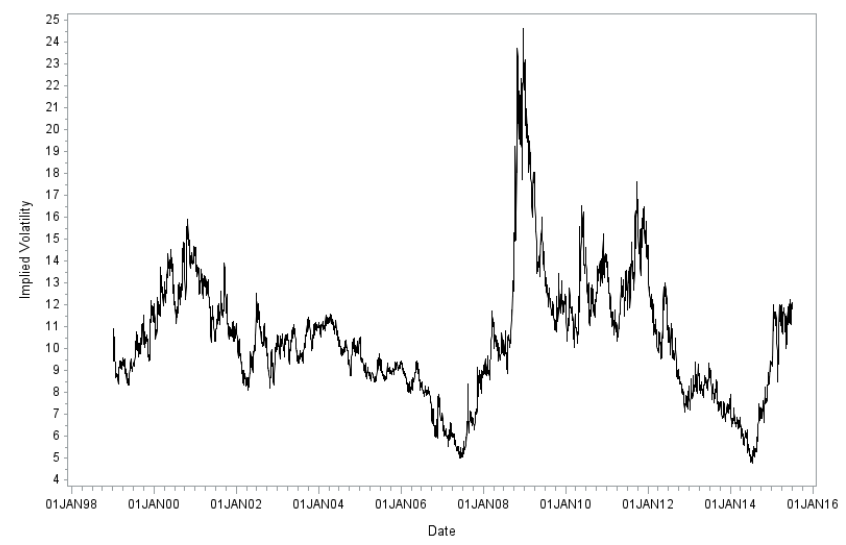

(a) Implied 3-mo volatility: eur-usd

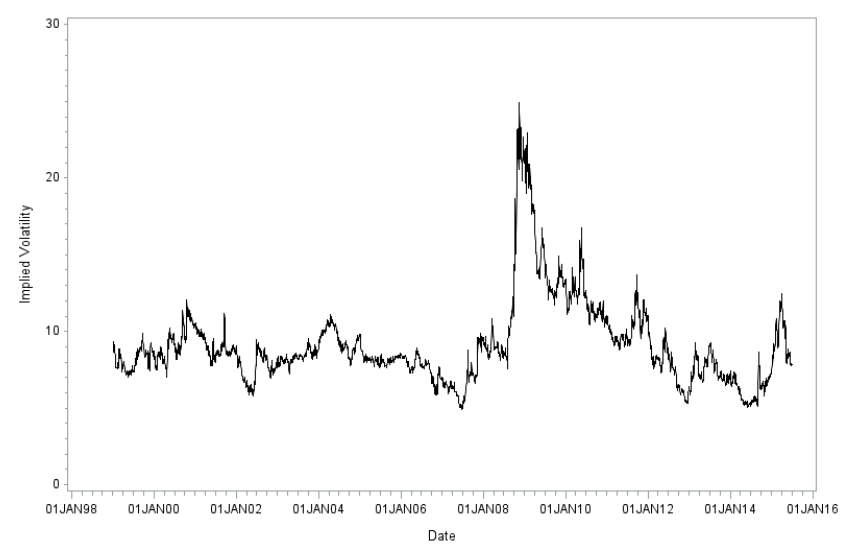

(b) Implied 3-mo volatility: gbp-usd

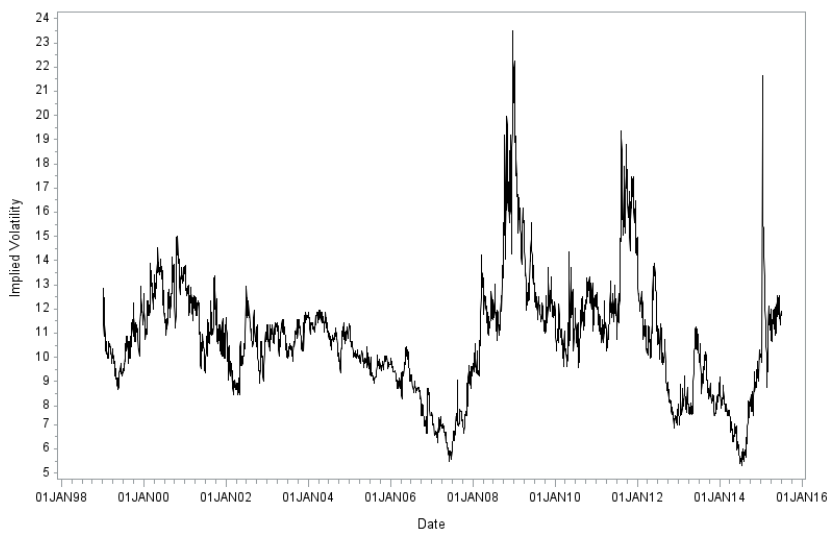

(c) Implied 3-mo volatility: chf-usd

Figure 1.2: Three-month implied volatility of European currencies 


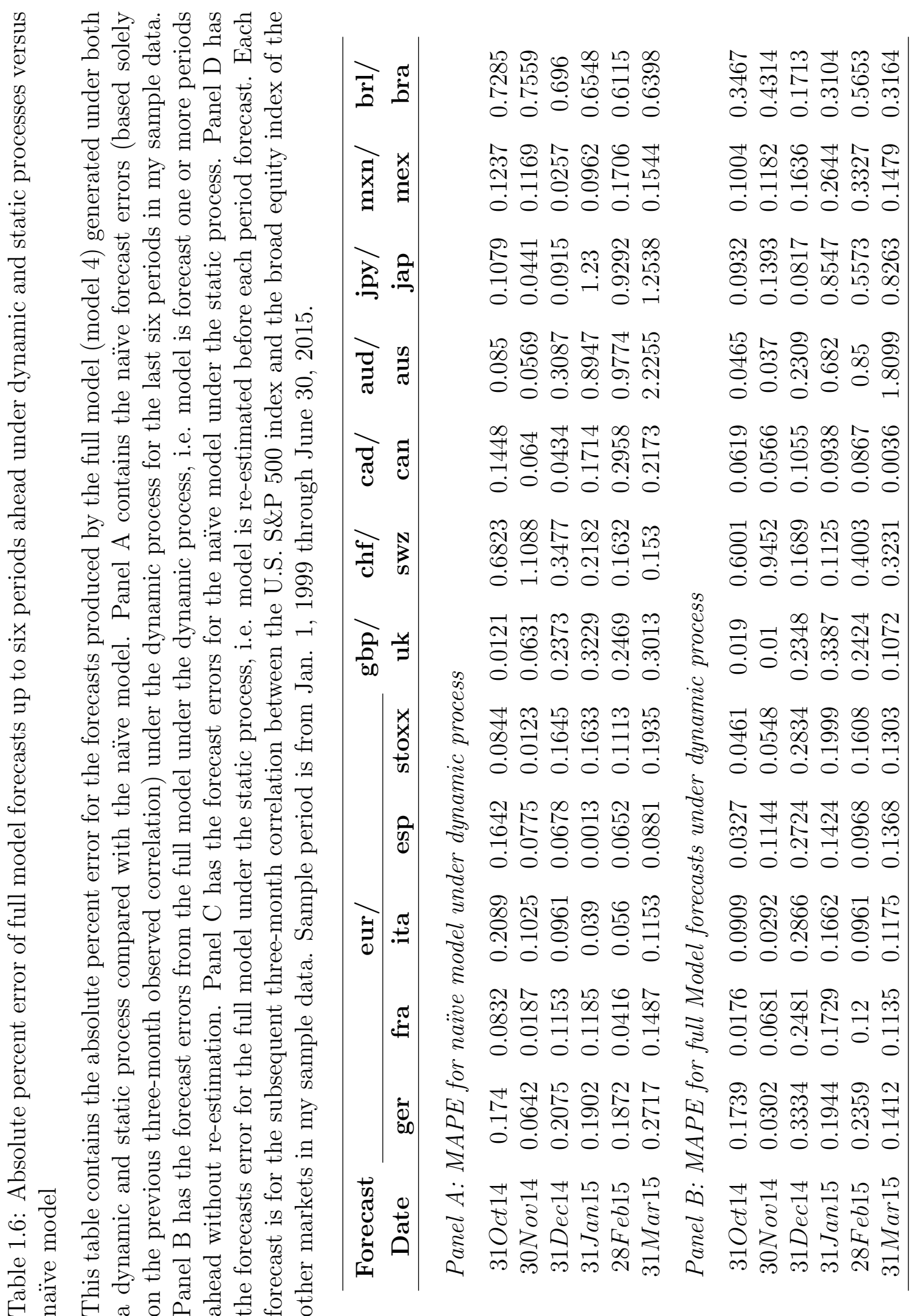




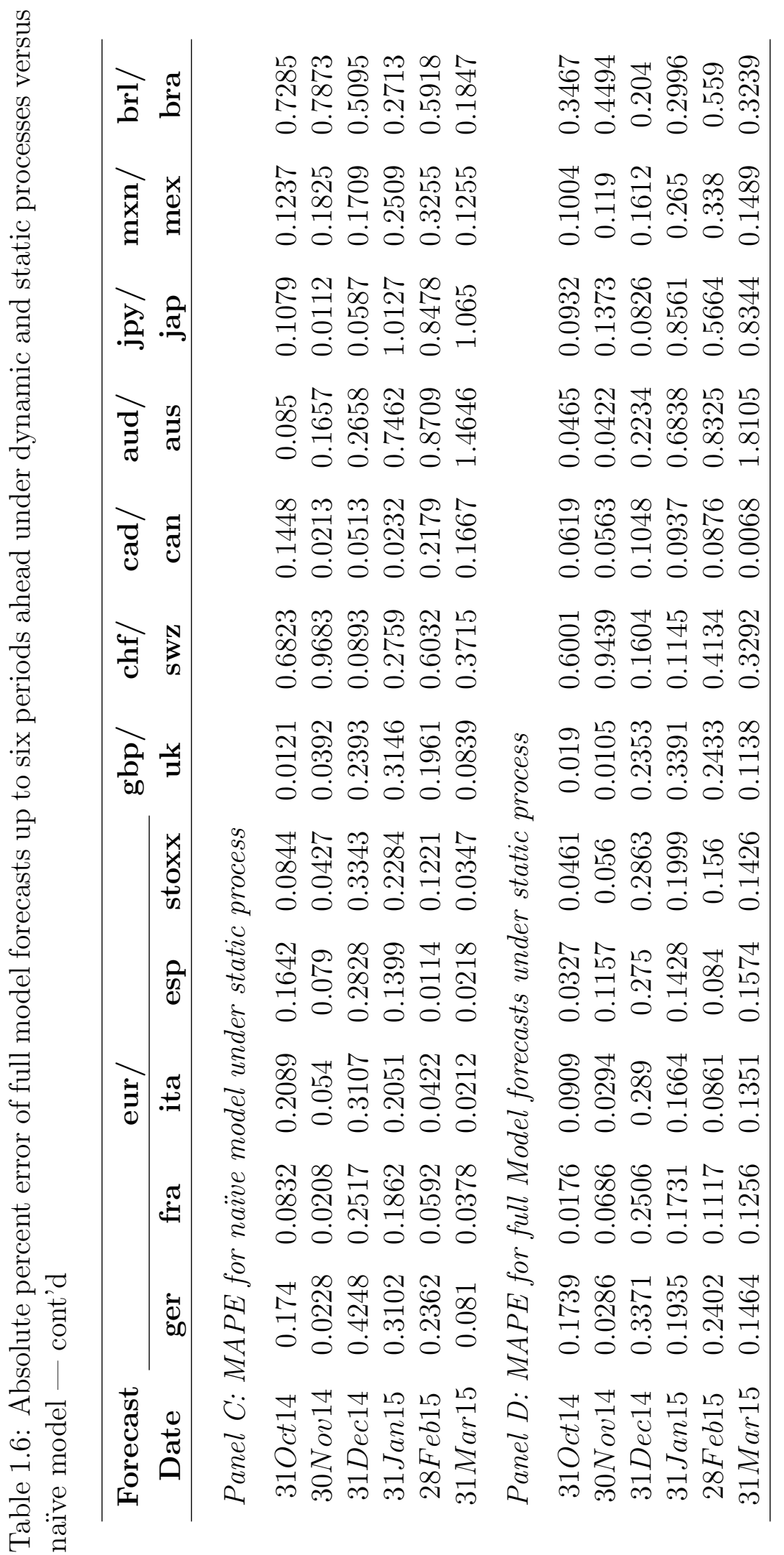


while generating one-period ahead forecasts. The simulation is designed to retain the models that yield statistically significant parameters in each re-estimation. Initially, I estimate each model for the first five years ${ }^{8}$ and then re-estimate it rolling forward one month at a time. The last re-estimated model includes observations on $t-3$ equity correlation, while values for the independent variables are as of time $t .^{9}$

The MAPE results of the simulation forecasts for all the models are reported in Table 1.7. Since the forecast error measures are in percent, they are comparable across the models. The number of occurrences (observations) used in the calculation of MAPE (not observations in the re-estimation of equations) is included in the table. The lowest MAPE for each currency/equity index pair is bolded. In the calculation of MAPE for the naïve model, 132 forecasts (cases) are used. For all other instances, fewer forecasts (cases) are used since some of the re-estimations do not yield statistically significant coefficients (at the $10 \%$ level or below). ${ }^{10}$

${ }^{8}$ Data for the Brazilian Real implied volatility starts in 2003 so the sample period including this currency is shorter. The data for the Mexican Peso implied volatility is sporadic for 1999 so it also results in slightly fewer observations. All other currencies have data for the entire sample period.

${ }^{9}$ For instance, the estimation of the first rolling regression uses monthly data from January 1, 1999 through December 31, 2003 (five years) for the values of the VIX and FX implied volatility, while data for 3-months ahead realized correlation extend into March 2004. The one-period ahead monthly forecast is calculated based on the regression coefficients and the values of the VIX and pertinent FX implied volatility as of the last trading day in March 2004. That forecast is compared with the realized correlation over the ensuing three months starting the first trading day in April 2004 and ending the last trading day of June 2004. Therefore, there is no look-ahead bias and the estimation of the regression coefficients does not employ any data from the forecast period. After calculating each forecast the regression evaluation period is rolled forward one month and the whole process is repeated until the end of the sample period in June 2015. This yields a total of 132 forecasts.

${ }^{10}$ For example, in order for a forecast from Model 2 to be included in the MAPE calculation, such forecast would need to be based on a rolling regression estimation that yielded a statistically significant coefficient for the FX implied volatility variable. For Model 3, the case of AUD/AUS, the in-sample estimation yields a regression coefficient for 


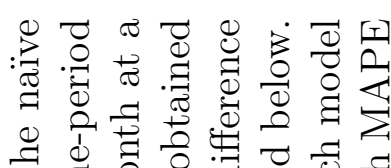

Ð

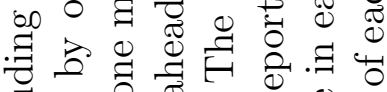

Ð

.

品

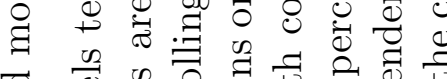

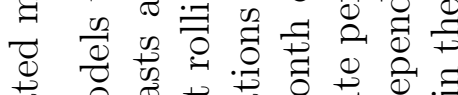

苛

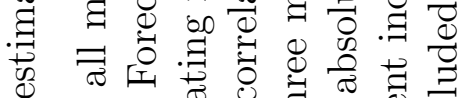

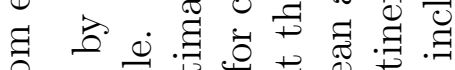

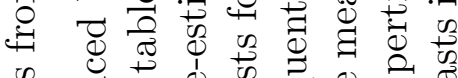

N

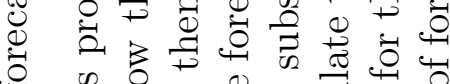

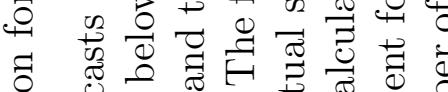

苛

党

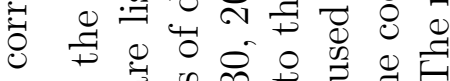

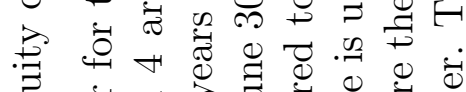

ఈ

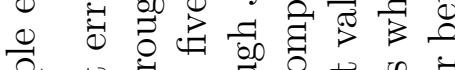

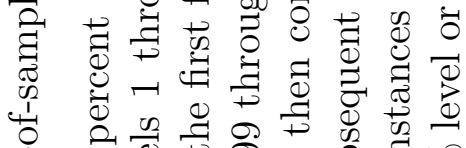

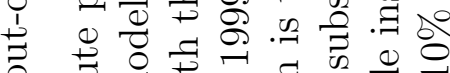

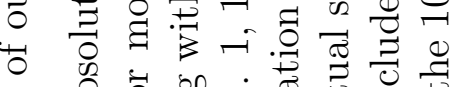

-

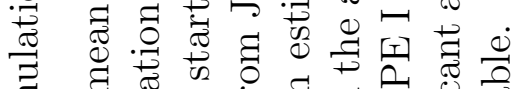

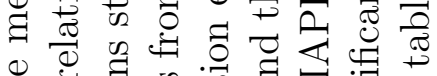

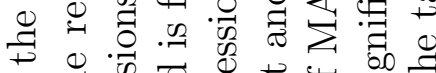

पै

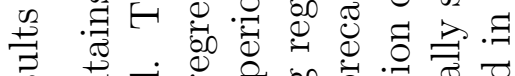

节它

$\simeq \quad 0$ O

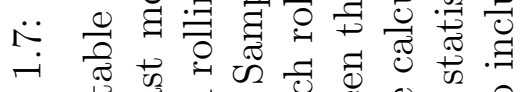

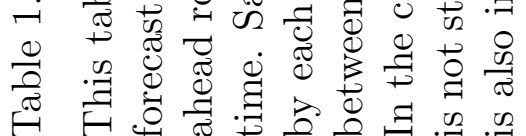

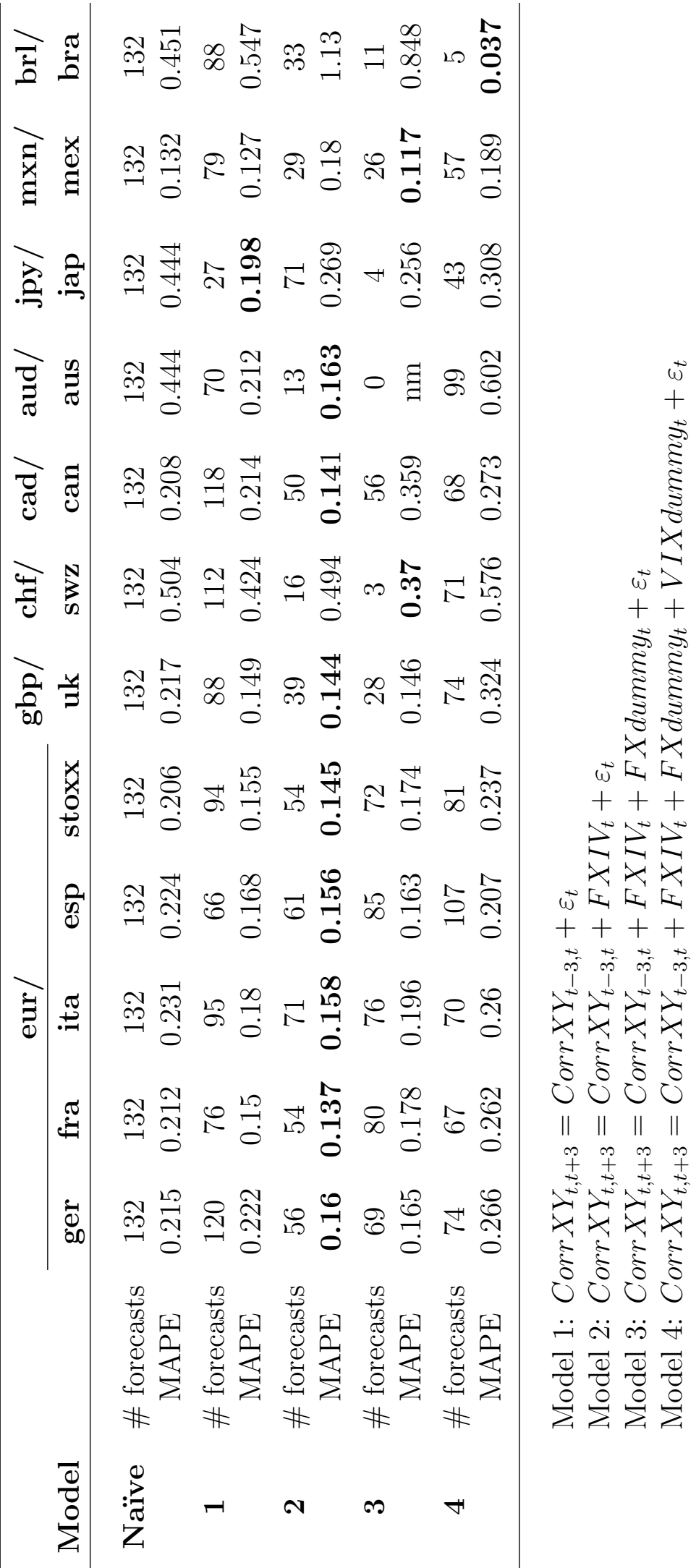


To summarize the results of the simulation experiments, the forecast MAPEs for nearly all the models are consistently lower than those for the naïve model. This is true across all currency/equity pairs. As expected, some models perform relatively better. For instance, models 2 and 3 produce the lowest MAPE in ten of the twelve currency/equity pairs. ${ }^{11}$ The fact that these two models are driven primarily by the FX implied volatility further strengthens my theoretical and empirical position that FX implied volatility contains important information in forecasting equity correlations.

\subsection{Summary and Conclusions}

Accurate forecasts of equity correlations are valuable in risk management and in construction of efficient portfolios. Among practitioners and academicians it is commonplace to use the most recent period equity correlations as the best forecasts for the subsequent period correlations. I consider this practice less desirable and instead provide a theoretical model to improve upon such naïve forecasts. I test and verify my theoretical position using extensive data across twelve global markets over 192 monthly periods. The findings are very supportive and encouraging.

The measurement and forecast of global equity market correlations have so far been mostly confined within the boundaries of the equity markets. Resort to external variables is rare since such variables are often considered to be unrelated to the

the FX IV dummy that is significant at the 10\% level (See Panel E in Table 1.5). However, none of the five-year rolling regressions yielded a statistically significant coefficient for this variable. Consequently, Table 1.7 contains no MAPE for Model 3, column AUD/AUS.

${ }^{11}$ Once again the Brazilian Real/Bovespa case was an exception. This is not surprising since this group has the least amount of data (starting in 2003 versus 1999 for all other cases) and the FX implied volatility for the Brazilian Real is the least accurate forecast of actual observed currency volatility. See Table 1.2. 
equity markets. I depart from this position and hypothesize that such variables, e.g., option implied FX volatilities, may indeed possess valuable information though they may appear 'seemingly unrelated'.

I establish a theoretical model that links foreign exchange rate volatility to global equity correlations. I test this model empirically and evaluate its relative ex-ante forecast accuracy extensively. I start with a stochastic model for exchange rates that is driven primarily by the interest rate differentials among the countries. Further assuming that market expectations for interest rates are based on the Taylor rule and applying international finance parity fundamentals, I show that when exchange rate volatility is elevated, the correlation between pertinent broad equity markets are also elevated.

My theoretically derived relations between the international equity market correlations and the exchange rate volatilities are contemporaneous. Therefore, an effective predictor of exchange rate volatility would also be effective in predicting equity market correlations. I find that option implied FX rate volatility is a good predictor of subsequently observed exchange rate volatility, especially for the onemonth and three-month horizons. I show empirically that this variable is related to the subsequent equity market correlations. In other words, options implied FX rate volatility is an effective ex-ante predictor of equity market correlations.

Since my predictor, i.e., the option implied FX rate volatility, depends on currency option quotes and trades, the empirical evidence on the relation between this variable and equity correlations appears stronger when the liquidity in the currency options markets is higher. Further, I find this relation to be stronger among the major currencies such as the British Pound, Japanese Yen, Euro, Canadian Dollar, Australian Dollar, and the Swiss Franc. The Mexican Peso and the Brazilian Real yield weaker and in some instances statistically insignificant relations. 
I also test the theoretical model in light of a few prior models. For instance, since the relation between equity correlations and the value of the VIX as a proxy for equity volatility is well established, I show that options implied FX volatility yields further insights into such relation. I analyze this position by evaluating models with and without the VIX as an independent variable. My findings indicate that for nearly all markets the options implied FX volatility remains a significant factor in all model variations. The full model in my analysis, which includes FX implied volatility as well as a variables that indicate elevated levels of VIX and FX volatility, yields the best forecasts.

Testing the practitioners' current positions against my empirically derived forecasts further demonstrates the robustness and the practical use of my theoretically derived and empirically tested models. To be thorough, I consider both 'dynamic' and 'static' processes in forecasting, wherein under the dynamic there would be no updating of any measures whatsoever. I perform such tests out-of-sample for the last six periods in my data sample. Based on the criteria of mean absolute percent errors, I verify that my theoretical and empirical positions do indeed provide substantial enhancements over the naïve positions that the practitioners often tend to take. This outcome is yielded under both processes.

Lending further support to my theoretical framework, I carry out a simulation that results in a total of up to 132 out-of-sample forecasts for all variations of the models, including the naïve model. This simulation effort, which is open to a longer time horizon and is thus more stringent, uses a rolling 60-month window and models wherein the estimated coefficients are statistically significant. This strategy can easily be implemented by practitioners in their search for optimized portfolios. It is simply an extra effort to take advantage of the relations that are uncovered in this study. The simulation results underscore the superiority of my 
theoretical/empirical models under all model variations. This again represents a solid empirical confirmation of my theoretical position. 
CHAPTER 2

\section{CURRENCY VOLATILITY AND BID-ASK SPREADS OF ADRS AND LOCAL SHARES}

\subsection{Introduction}

Foreign exchange volatility is one of the main differentiating factors that drives cross-sectional differences in liquidity across international markets when compared with liquidity drivers in domestic markets; yet, previous studies have largely ignored this important liquidity driver in international equities. Using bid-ask spread as a proxy for liquidity, I identify a significant positive relation between spreads and option-implied foreign exchange volatility (hereafter 'FX volatility'). I document that FX volatility accounts for a sizeable $16.6 \%$ of the variance in my comprehensive sample of ADRs.

Due to the largeness of my sample, a low-frequency estimator is used for estimating bid-ask spreads. The increasing availability of high-frequency data has not obviated the use of low-frequency spread estimators. Studies that cover time periods preceding the availability of intraday data and those that include comprehensive samples of international stocks for which intraday data are unavailable still make use of such estimators. Opting to stay in this domain of analysis, I employ the bid-ask spread estimator introduced by Corwin and Schultz (2012) to pioneer a comprehensive study of the impact of currency volatilities on the spreads of ADRs and their underlying local shares. Frequent swings in currency markets lend further

relevance to a comprehensive study of the impact of currency volatilities on market liquidity, as measured by spread, across global markets.

My analysis contributes to current literature by proposing FX implied volatility as a determinant of liquidity and examining whether the relation between spreads 
and FX implied volatility is stronger for ADRs than for local shares. My insights add to the understanding of the interconnectedness of global markets and could be used by global investors when choosing between ADRs and underlying local shares in their portfolios.

Aside from Corwin and Schultz (2012), several other low-frequency bid-ask spread estimators exist. Roll (1984) covariance spread estimator is a seminal example and is still in use today. Other examples include the estimators described in Lesmond et al. (1999), hereafter 'LOT estimator', and Holden (2009). I choose to employ Corwin and Schultz (2012) due to the simplicity in the calculation of the bid-ask spread estimator and the higher correlation of the estimator, as opposed to the aforementioned additional estimators, with the actual spread calculated using intraday TAQ data as documented in their paper. The ease of calculation makes the use of a comprehensive stock sample possible and the documented higher accuracy of the bid-ask spread estimator increases the confidence that my results reflect accurate spread variations in the sample.

In finance literature, liquidity measures come in various flavors. The quoted or effective bid-ask spread is a common barometer of liquidity in a market. It is also well established that price, volume, volatility, and firm size are major factors in the liquidity of stocks. Stoll (2000) provides evidence of the cross-sectional relation of quoted proportional half spread $(0.5 \times($ Bid-Ask $) /$ Price $)$ to these trading characteristic factors (price, volume, volatility and firm size) using high-frequency data for 3,890 NYSE-, AMSE-, and NASDAQ-listed stocks (excluding ADRs and REITs) over the three-month period from December 1997 to February 1998. The impact of currency volatility on the bid-ask spread of global stocks is largely unexplored. Most studies linking foreign exchange and global shares focus on the role of foreign exchange, in conjunction with their underlying local shares, in driving ADR 
returns. Examples of such studies include Alsayed and McGroarty (2012), Gagnon and Karolyi (2010), Aquino and Poshakwale (2006), Ely and Salehizadeh (2002), Kim et al. (2000), Poshakwale and Aquino (2008), and Suarez (2005).

Stoll (2000) attributes the link of quoted proportional half spread with the stocks trading characteristics to such factors as inventory and order processing attributes. Higher volume, frequency of trades, and larger firm size increase the odds of locating a counterparty thus reducing the risk of inventory buildup. The stock prices control for discreteness and reflect the expectation that lower-priced stocks tend to be riskier. With the minimum tick size at $\$ 0.01$ in the U.S., lower priced stocks will tend to have larger proportional spreads than their higher-priced counterparts all else being equal. Currency volatility is another source of firm risk for U.S. and international firms alike. Consistent with Jorion (1990), this is especially true for multinational corporations whose earnings and valuations are greatly affected by exchange rates. In contrast, Bartov and Bodnar (1994) find no significant correlation between abnormal returns of firms with international activities and fluctuations in the U.S. dollar.

My study aims to explain and reconcile the above controversial findings. I focus on the relation of bid-ask spreads to currency volatility for ADRs and their underlying firms. Since ADRs are US dollar-denominated receipts for underlying shares of international firms, changes in the exchange rate should have a direct effect on the price of ADRs as the possibility of arbitrage ensures that ADR prices and the dollar-denominated prices of their underlying shares move in tandem. Currency fluctuation is also a source of risk for underlying local shares from the perspective of a foreign investor as it increases uncertainty in the dollar price of the asset.

Lesmond (2005) provides a comprehensive cross-sectional and time-series analysis of the liquidity of emerging markets. He uses the LOT bid-ask spread estimator 
as the primary measure of liquidity. He also performs a factor analysis of five liquidity measures including the LOT estimator, the Roll (1984) covariance bid-ask spread estimator, and Amihud (2002)'s illiquidity measure. Overall, he finds great dispersion in market liquidity across the 31 emerging markets in his sample. His findings attest to my aim to search for the source of these dispersions. I attribute this source, or a major portion of it, to FX volatility.

Liquidity has several aspects: effective spread, price impact, turnover, market depth, and relative trading frequency. As Amihud (2002) states, none of these measures capture all aspects of liquidity. The focus of this study is therefore not to evaluate the various liquidity measures. Rather, its goal is to investigate the impact of foreign exchange volatility on one of the measures of liquidity, i.e., the bid-ask spread as estimated by Corwin and Schultz (2012). I examine the FX volatility impact in a simple one-factor model and in conjunction with known determinants of spreads such as price, volume, size, and volatility. I also employ fixed effects and dynamic panel analyses to contrast the impact of foreign exchange volatility on ADRs with their underlying local shares.

By definition, ADR prices should be a function of the underlying local share prices and the pertinent foreign exchange rates. Therefore, ADR volatility and bid-ask spreads should be positively related to foreign exchange volatility and FX bid-ask spreads assuming no offsetting fluctuations in the underlying local share prices. The relation between bid-ask spreads of the underlying local shares and FX volatility is not as clear-cut. Nonetheless, it intuitively makes sense that increased volatility in a given foreign exchange rate would be interpreted by the market as increased risk for assets denominated in that currency, thus impacting the liquidity in foreign local shares. In the case of firms whose products are closely linked to the US dollar, such as commodity producers, the link between their local share prices and 
foreign exchange volatility should be even stronger. I find that currency volatility has a stronger impact on the bid-ask spread of ADRs than on their underlying local shares.

\section{$2.2 \quad$ Prior literature}

The main sources of liquidity drivers considered in Stoll (2000) - namely, volume, price, size, and volatility - have previously been identified separately as determinants of trading friction/costs. Harris (1994) considers price as a proxy for discreteness. He notes that minimum price variations imposed by stock exchanges result in discrete bid-ask spreads. He also argues that in the presence of these imposed minimum spreads, the resulting spreads are wider than they would be otherwise. Using a discrete spread model, he shows that stocks priced below $\$ 10$ would have $38 \%$ lower spreads if the minimum spread were to be set at $1 / 16$ as opposed to $1 / 8$ effective at the time of his analysis. Since then, the US Securities and Exchange Commission (SEC) has mandated decimalized quoted stock prices (as of April 9, 2001), resulting in tighter spreads and a current minimum tick of $\$ 0.01$ in the US.

Benston and Hagerman (1974) investigate the determinants of bid-ask spreads in the over-the-counter (OTC) market. Among the significant determinants of spread identified in their study is price per share. This is consistent with the notion in Stoll (2000) that price is a proxy for risk since lower-priced stocks tend to be riskier.

Pagano (1989) examines the relation between trading volume and liquidity. Under the assumption that in thin markets traders placing large orders will experience adverse price changes, he suggests a positive feedback loop where trading volume and market liquidity feed on each other. Brennan and Subrahmanyam (1995) corroborate that volume is related to market depth. Stoll and Whaley (1983) show that firm size is negatively associated with trading costs as reflected in the bid- 
ask spreads. They contend that the higher transaction costs for small firms partly explain the small firm effect attributed to Banz (1981) and Reinganum (1981).

Prior to Stoll (2000), other studies examined the relation of trading costs to a combination of these aforementioned liquidity drivers. For instance, in their study of determinants of transaction costs for institutional investors with different investment styles, Keim and Madhavan (1997) find that volume, volatility, price, and firm size are associated with trading costs. They also find differences in trading costs driven

by the exchange on which the stock was listed. In turn, Cohen et al. (1976) argue that volatility and liquidity are inversely related since less liquid markets tend to be more volatile. They also identify market thinness as a major determinant of common stock returns volatility across international markets.

\subsection{Data and methodology}

For FX volatility, I use the forward-looking at-the-money one-month implied volatility calculated by Bloomberg using quotes for currency options. The Bloomberg data is daily but I use only the month-end observations thus yielding monthly observations for my sample universe. Bloomberg implied volatility measures can be used to obtain the correct Black Scholes price for a delta-neutral straddle struck at maturity. Bid-ask spreads are estimated according to Corwin and Schultz (2012) using Bloomberg's historical daily closing, high, and low prices for ADRs and their respective underlying local shares. For each security in my sample I estimate an average bid-ask spread for each month. I also use historical monthly averages for price, trading volume and market capitalization as additional independent variables in my regressions. Recent stock return volatility is the remaining independent variable in my analysis. The value for this variable is calculated monthly using daily stock returns over the most recent twelve months. For example, the recent return 
volatility for a given stock $i$ in my sample for the monthly observation corresponding to December 2014 is calculated as the variance of the daily returns for stock i from January 1, 2014 through December 31, 2014. My sample period is from January 1, 1999 to December 31, 2015. My sample includes 545 securities (including single ADRs, ADRs, and underlying shares) from firms across 34 markets with 25 distinct local currencies.

In calculating the estimated bid-ask spread, I implement the adjustments described in Corwin and Schultz (2012). To adjust for overnight price movements, two adjustments are made. When the low price at day $t+1$ is greater than the closing price at day $t$, both the high and low prices for day $t+1$ are decreased by the assumed overnight move from day $t$ close to day $t+1$ low. Conversely, when the high price at day $t+1$ is less than the closing price at day $t$, both the high and low prices for day $t+1$ are increased by that difference. For stocks that trade infrequently, sometimes the low and high prices for a given day $t$ are equal. In those instances, the previous day's high/low range is used as day's $t$ high and low prices as long as the initial equal high and low prices for day $t$ are within the previous day's high/low range. If these high/low prices are outside the previous day's high/low range, then day $t$ 's high and low prices are adjusted to reflect the same range as the previous day, but adjusted (increased or decreased) by the amount that the initial high/low price was outside the previous day's range. Finally, the bid-ask estimate may be negative. This happens because the estimator assumes that the variance of a given stock over a two-day period is twice as large as the variance over a single day, and this does not always happen during volatile periods or when overnight changes are large. In case of negative bid-ask estimates, the estimate is set to zero. The bid-ask 
spread estimate is calculated as:

$$
S=\frac{2[\exp (\alpha)-1]}{1+\exp (\alpha)}
$$

where $\alpha$ is defined as:

$$
\alpha=\frac{\sqrt{2 \beta}-\sqrt{\beta}}{3-2 \sqrt{2}}-\sqrt{\frac{\gamma}{3-2 \sqrt{2}}}
$$

and $\beta$ and $\gamma$ are calculated as:

$$
\beta=\sum_{j=0}^{1}\left[\ln \left(\frac{H_{t+j}}{L_{t+j}}\right)\right]^{2}
$$

and

$$
\gamma=\left[\ln \left(\frac{H_{t, t+1}}{L_{t, t+1}}\right)\right]^{2}
$$

The notations are as follows. $H_{t+j}$ represents the high price for a given stock on day $t+j, L_{t+j}$ represents the low price for a given stock on day $t+j, H_{t, t+1}$ represents the high price for a given stock over a two-day period from $t$ to $t+1$, and $L_{t, t+1}$ represents the low price for a given stock over a two-day period from $t$ to $t+1$. For a detailed derivation of the above formulas please see Corwin and Schultz (2012).

For each stock in my universe and for each month-end day t in my sample period I calculate a rolling thirty-day average of the estimated bid-ask spreads calculated as described above. This thirty-day period corresponds to the time to expiration for the currency options used in the calculation of the FX implied volatility. This yields a potential maximum $204(12 \times 17$ years $)$ monthly observations for each ADR in my sample that have been in effect for the entire sample period. The number of observations for each ADR and underlying local share varies according to the number of months in my sample period over which the security has been listed and for which I can estimate the spread according to my methodology. Each monthly observation in my sample includes the 30-day option-implied FX volatility observed 
at month-end, the estimated average bid-ask spread over that same 30-day period, and the monthly averages for historical price, volume, market capitalization, and recent return variance calculated as described in the beginning of this section. In line with Stoll (2000), price, volume, and size are log scaled in my regression analyses.

Initially, I divide my universe into two subgroups: ADRs and local shares. I perform separate simple pooled OLS regressions for each subgroup to estimate the relation between the average monthly bid-ask spread and option implied currency volatility. I then examine whether the slopes in the relation for these two subgroups are equal. Specifically, I estimate:

$$
\operatorname{Spread}_{i, t, t+30}=\lambda_{0}+\lambda_{1} F X I V_{i, t}+\varepsilon_{t}
$$

where $\operatorname{Spread}_{i, t, t+30}$ is the average spread for stock $i$ over the thirty-day calendar period from $t$ to $t+30$, and $F X I V_{i, t}$ is the 30-day option implied volatility for the relevant currency $i$ observed at day $t$. I also estimate an expanded version of relation 2.5 that includes price, volume, firm size (market capitalization) observed on day $t$, and recent daily return variance over the past year (see relation 2.6 below). The last variables are included to capture the long-term effect, if any, and evaluate whether currency volatility yields any additional information regarding bid-ask spreads than what can be inferred by price, volume, firm size, and recent return variance. The expanded formulation I evaluate is:

$$
\begin{aligned}
\operatorname{Spread}_{i, t, t+30} & =\lambda_{0}+\lambda_{1} \text { FXIV }_{i, t}+\lambda_{2} \text { Price }_{i, t, t+30}+\lambda_{3} \text { Vol }_{i, t, t+30} \\
& +\lambda_{4} \text { Size }_{i, t, t+30}+\lambda_{5} \sigma_{i, t-252, t}^{2}+\varepsilon_{t}
\end{aligned}
$$

where Price $_{i, t, t+30}$ is the log-scaled average daily closing price for stock $i$ over the thirty-day calendar period from $t$ to $t+30, V_{o l} l_{i, t+30}$ is the log-scaled average trading dollar or local currency volume (volume weighted average price multiplied 
by average share volume) for stock $i$ over the thirty-day calendar period from $t$ to $t+30$, Size $_{i, t, t+30}$ is the log-scaled average market capitalization for stock $i$ over the thirty-day calendar period from $t$ to $t+30$, and $\sigma_{i, t-252, t}^{2}$ is the average daily variance of returns for stock $i$ over the previous twelve months.

My sample universe is a panel data set with firms (ADRs and local shares) as cross-sections over monthly periods. For the local shares, price, volume, and firm size are measured in their respective local currencies. Therefore, a simple pooled OLS regression of the observations for all these firms would be problematic. I thus perform a panel analysis and estimate firm fixed effects. I also employ dynamic panel data estimation to evaluate a modified version of relation 2.6 that includes the first lag of the dependent variable as an instrumental variable in the GMM estimation. The expanded relation is:

$$
\begin{aligned}
\text { Spread }_{i, t, t+30} & =\lambda_{0} \text { Spread_1 }_{i, t-30, t}+\lambda_{1} F X I V_{i, t}+\lambda_{2} \text { Price }_{i, t, t+30}+\lambda_{3} \operatorname{Vol}_{i, t, t+30} \\
& +\lambda_{4} \text { Size }_{i, t, t+30}+\lambda_{5} \sigma_{i, t-252, t}^{2}+\varepsilon_{t}
\end{aligned}
$$

I initially estimate relation 2.7 for the entire ADR subgroup. Then, I subdivide the entire sample universe into ADRs and local shares subgroups, and estimate it separately for each currency. I follow the methodology proposed by Blundell and Bond (1998), which is an extension of the model in Arellano and Bond (1991). These methodologies employ GMM-style instruments making use of multiple lags. Blundell and Bond (1998) employ both lagged levels and lagged differences, while Arellano and Bond (1991) uses only lagged levels. The difference GMM approach transforms the data to remove the fixed effects. The number of instruments produced are quadratic in the length of the time series. Because the length of the time series in my panel data is well over 100, I limit the number of past lags used to 5. Dynamic panel data estimators are highly sensitive to model specification and instruments. 
So, I impose a couple of different lag restrictions in the dynamic panel data analysis to ensure that my model is reasonably robust to these variations.

Because price, trading volume, and firm size are by definition interconnected (e.g. firm size $=$ price $\times$ shares outstanding) I expect a high degree of correlation among these variables. In order to construct a more parsimonious model devoid of multicollinearity, I subject the predictor variables in equation 2.6 to a principal components analysis. This analysis yields insights into the proportions of the variance in the data that is explained by each retained component. I then utilize these uncorrelated (orthogonal by design) components to construct optimally-weighted composite component scores for each observation in the data. These scores are used to identify variables in a more parsimonious model to examine the relation between bid-ask spreads and liquidity drivers after eliminating the multicollinearity issues inherent in the estimation of equation 2.7. I limit my principal components analysis to the ADR subgroup in my sample because the variables in the local shares subgroup are measured in various distinct currencies.

\subsection{Empirical results}

Table 2.1 contains summary statistics for the bid-ask spread and FX implied volatility employed in my analyses. Single ADRs ${ }^{1}$ consist primarily of Chinese firms (82 out of 101 firms) whose underlying currency does not float freely against the US dollar. To account for this special situation, I provide the major results of my analyses with and without these firms. Excluding single ADRs, the underlying assets for the firms in my sample are mostly denominated in Euro, British Pound, Brazilian Real, and the Ruble. The magnitudes of FX implied volatility in my sample range

\footnotetext{
${ }^{1}$ Single ADRs are ADRs for foreign firms that do not have local exchange listed shares in their respective home markets.
} 
from as low as 0.64 for the Hong Kong dollar, due to its peg to the US dollar, to as

high as 16.6 for the South African Rand. The estimated monthly spread estimates range from below $0.1 \%$ to as high as $28.6 \%$. My pooled sample contains a total of 74,551 firm/month observations though some of these records are dropped in the regression analyses due to missing values for some variables.

\subsubsection{Correlation among independent variables}

The trading characteristics (price, trading volume, size, and recent return variance) suggested by Stoll (2000) as cross-sectional determinants of proportional half spreads exhibit strong correlations with each other. Higher prices are associated with larger size as well as higher trading volume. In turn, larger firm size is also associated with larger trading volume. The relation between FX implied volatility and these trading characteristics is not well defined. A low correlation would be an indication that FX implied volatility contains information about the bid-ask spread that is not captured in these trading characteristics. I calculate, and report in Table 2.2, Pearson correlation coefficients for the FX implied volatility, price, trading volume, size and recent return variance for four subsamples: all ADRs and local shares (Panel A), non-single ADRs and local shares (Panel B), all ADRs (Panel C) and all local shares (Panel D). I find that there is very low correlation, in some cases negative, between FX implied volatility and the other trading characteristics. As expected, correlation among these trading characteristics are high, ranging from 0.49 to 076 . This raises the issue of multicollinearity when regressing bid-ask spreads on these variables. While the overall reliability of the model would not necessarily be compromised, the interpretation of the impact of each predictor on the bid-ask spread would be challenging from the results of the full model. 


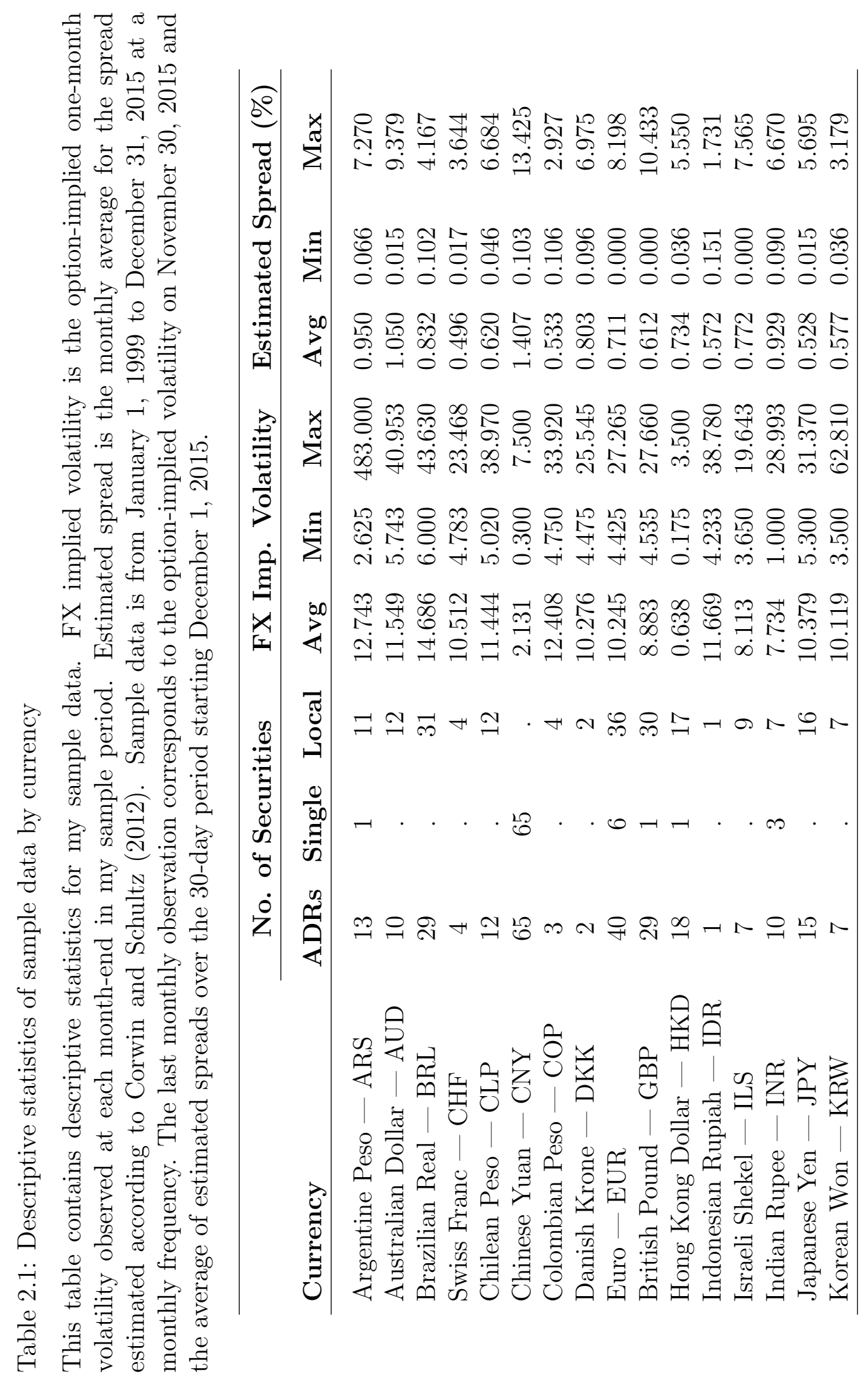




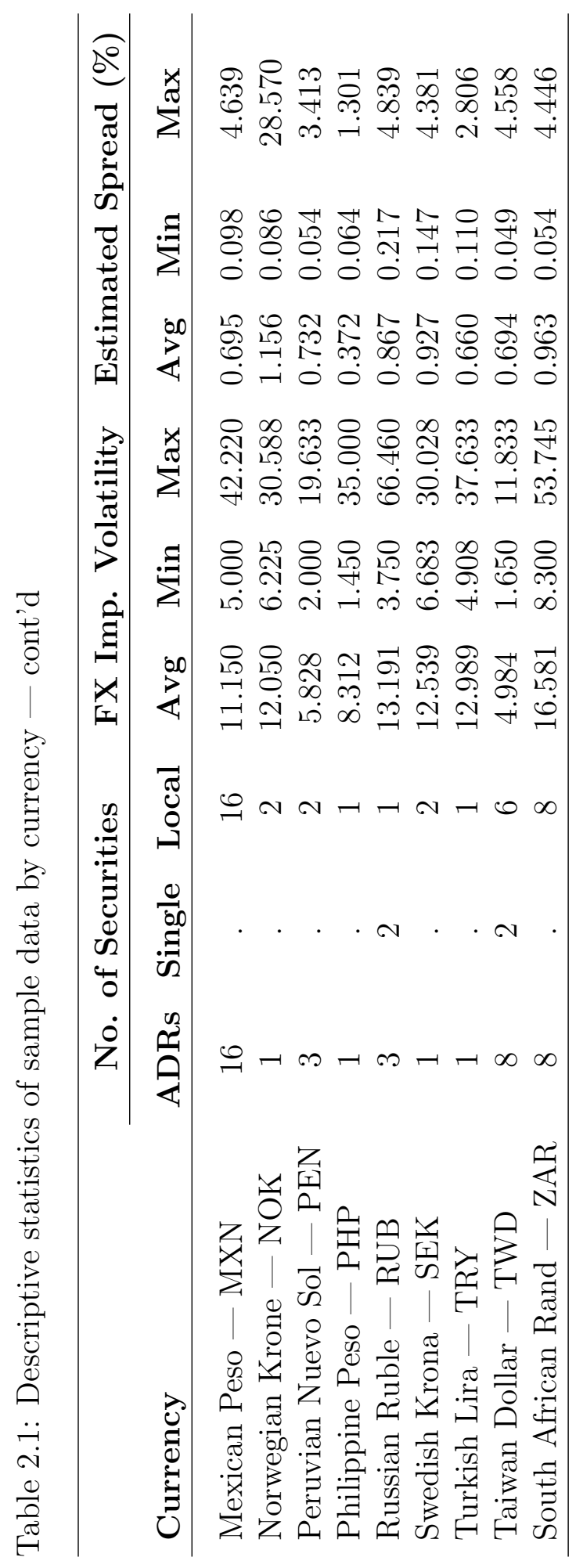




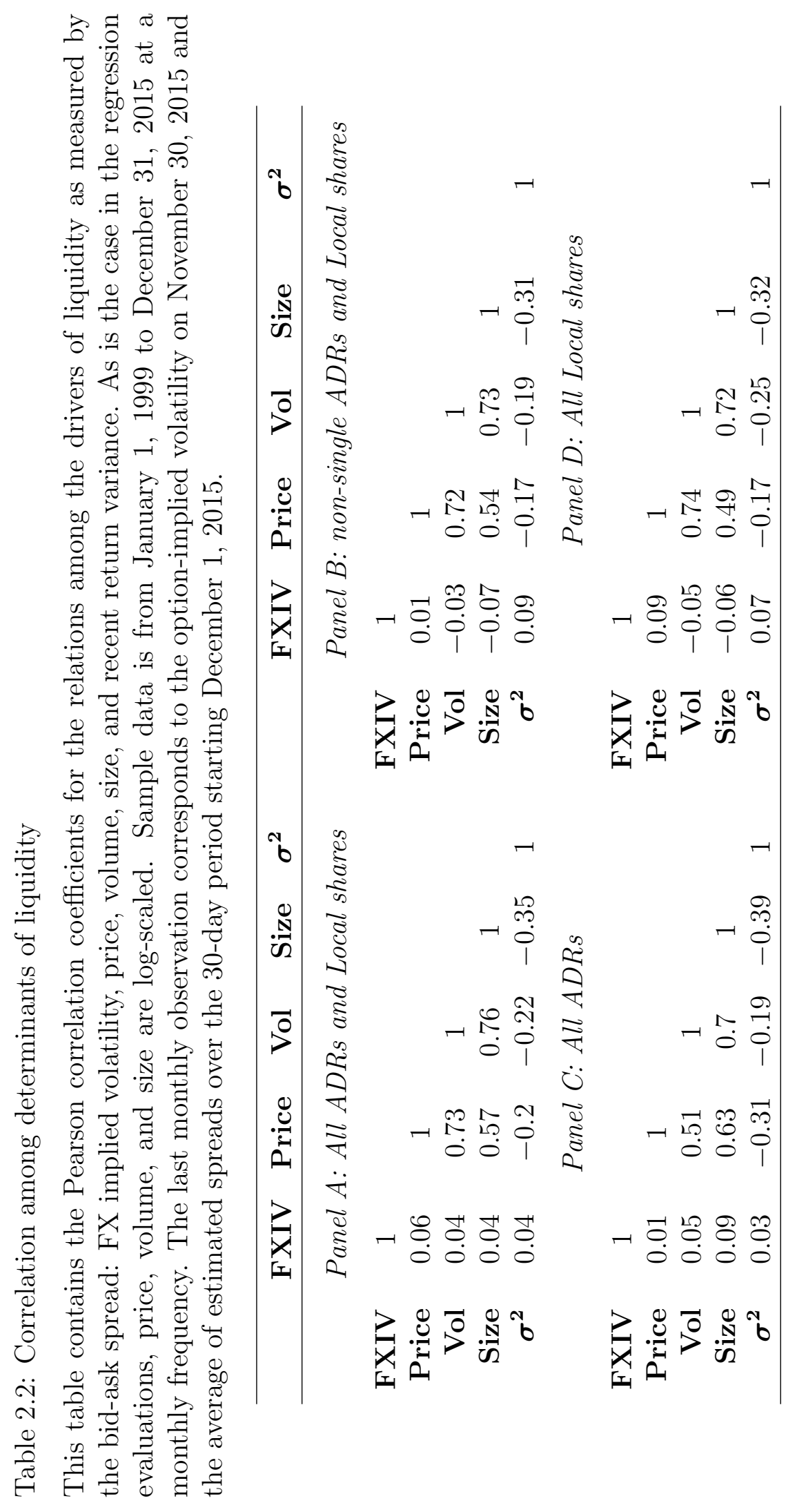




\subsubsection{ADRs versus Local shares}

I initially examine the effect of FX implied volatility on the estimated spreads. I also investigate whether the strength of the relation between bid-ask spread and FX implied volatility is different for the ADRs versus the local shares subgroups. I estimate pooled regression separately for the ADRs (excluding single ADRs) and for the local shares. I then test for the equality of regression coefficients in these two estimations. The results of this analysis are tabulated in Table 2.3. The relation for ADRs yields a higher $R^{2}$.

I also compute least square means ${ }^{2}$ of the estimated spreads for the ADRs and the local shares separately. I use least square means, as opposed to an arithmetic mean, in order to account for unbalanced/missing data when comparing the two subsamples. I find that average spreads for ADRs are significantly smaller than average spreads for local shares in my sample. Because my high-low spread estimator is measured in percentages, the spreads in my estimations can be compared across currencies. My findings suggest lower trading costs for the NYSE and NASDAQ where the ADRs trade than for the various exchanges where their corresponding underlying shares trade. Taxes, fees, commissions, and structural differences across markets will likely widen the gap in cost differences. Lesmond (2005) includes commissions in his comparison of liquidity across emerging markets.

\subsubsection{Fixed-effects analysis}

Before employing panel estimation on relation 2.6, I find a statistically significant relation between bid-ask spread and FX implied volatility, price, volume, size, and

\footnotetext{
${ }^{2}$ Least square means is a mean estimated from a linear model after controlling for other covariates in the model.
} 
Table 2.3: Relation of bid-ask spreads to FX volatility: ADRs vs. Local shares

This table displays the results of separate estimations for the pooled regression of my estimated monthly average spread on implied FX volatility for ADRs (excluding single ADRs) and local shares from my sample universe. Also included below are the test for equality of the slopes for the ADR and Local share estimation as well as the least square means of their respective estimated average spreads. Sample data is monthly from January 1, 1999 to December 31, 2015. The last monthly observation corresponds to the option implied volatility on November 30, 2015 and the average of estimated spreads over the 30-day period starting December 1,2015 . $^{*},{ }^{* *}$, and ${ }^{* * *}$ indicate statistical significance at the $10 \%, 5 \%$, and $1 \%$ level, respectively. T-stats are in parentheses.

$$
\text { Spread }_{i, t, t+30}=\lambda_{0}+\lambda_{1} F X I V_{i, t}+\varepsilon_{t}
$$

\begin{tabular}{cccccc}
\hline & & & Prob. & LSMean $\dagger$ \\
Obs. & Int. & FXIV & $\mathbf{R}^{2}$ & $>$ F-val & Spread \\
\hline
\end{tabular}

Panel A: Regression Results

$\begin{array}{lcccc}\text { ADRs } & 32,129 & 0.4766^{* * *} & 0.0143^{* * *} & 0.058 \\ & & (111.88) & (44.46) & \\ \text { Local Shares } & 36,017 & 0.6317^{* * *} & 0.0156^{* * *} & 0.02\end{array}$

(96.38)

Panel B: Test for equality of slopes

ADRs vs. Local

0.034

Panel C: Least Square Means

ADRs

0.6198

Local Shares

0.7884

Panel D: Test for equality of LS-Means

H0:

LSMean ADR $=$ Local $<.0001$

$\dagger$ Least square means is a mean estimated from a linear model after controlling for other covariates in the model.

recent return variance using simple pooled univariate regressions. To conserve space, I do not tabulate these results. Based on adjusted $R^{2}$, size and recent return variance explain most of the variation in the estimated spread when compared with the other independent variables. FX implied volatility yields the third highest adjusted R2 among the univariate estimations. The signs of the regression coefficients are 
consistent with the results in Stoll (2000). FX implied volatility is positively related to spread suggesting that higher FX volatility is associated with larger spreads. The intuition behind this relation is that high $\mathrm{FX}$ volatility increases the volatility in the US dollar denominated value of international firms, thereby prompting traders in these shares to opt for different strategies, such as a preference for market orders over limit orders.

The relation of bid-ask spreads to the other variables considered in my study are well documented in the finance literature. I confirm a negative relation between price and spreads, consistent with price being a proxy for risk and the notion, as in Stoll (2000), that lower-priced stocks tend to be riskier. It is also consistent with Harris (1994) who finds price as a proxy for discreteness, as well as Benston and Hagerman (1974) who show a negative relation between price and bid-ask spreads in the OTC market. I also observe a negative relation between market depth and bid-ask spreads, where dollar trading volume is a proxy for market depth. This view is supported by Pagano (1989) and Brennan and Subrahmanyam (1995). The relation between bid-ask spreads and firm size is also negative, consistent with Stoll and Whaley (1983). The intuition behind this relation is that larger firm sizes lead to larger trading volumes and this increased liquidity in turn drives down trading spreads. Finally, I confirm a positive relation between bid-ask spread and recent return variance, a measure of volatility. Volatile stocks usually induce traders to favor market orders over limit orders for improved immediacy in trading execution. This has the effect of overall wider spreads. Volatility is also associated with lower liquidity, a concept well documented in Cohen et al. (1976).

I do not necessarily, a priori, expect the sign of these relations to hold in a multivariate regression due to multicollinearity and endogeneity. For instance, Keim and Madhavan (1997) document that price, volume, firm size, and volatility are 
related to trading costs. In the multivariate fixed-effects estimation reported in Panel A of Table 2.4, the coefficients on volume are positive (for both ADR and local share subgroups). This is contrary to the intuition suggesting a negative relation as discussed earlier in this section. I attribute this to shortcomings in estimation methodology, and at best consider it a novelty when other controlling variables are present. Note that for the universe of ADRs and local shares excluding single ADRs I find a Pearson correlation coefficient of 0.72 between volume and price and a correlation coefficient of 0.73 between volume and size (see Panel B, Table 2.2). This suggests that much of the impact of volume on bid-ask spreads might already be reflected by the price and firm size variables. The coefficients on FX implied volatility in Panel A of Table 2.4 remain positive and highly statistically significant. This suggests that FX implied volatility contains information about the bid-ask spread that is not captured by the other factors introduced by Stoll (2000), confirming a major premise in the motivation for this study. This notion is reinforced by the low correlation between FX implied volatility and the other Stoll (2000) variables reported in Table 2.2.

\subsubsection{Relation of bid-ask spread to liquidity factors by currency}

Panel B contains the results from panel regression estimation of relation 2.6 for each currency in my sample, estimated separately for ADRs and local shares. The results exclude some of the currencies in my sample due to lack of sufficient data and/or the presence of only a single firm cross-section in the panel data for each of those currencies. Considering each currency sub-panel separately is likely to underestimate/overestimate the explanatory power of the liquidity factors, but it also serves to highlight the differences in the relation between spreads and liquidity determinants across currencies. The sample used in Stoll (2000) includes only 


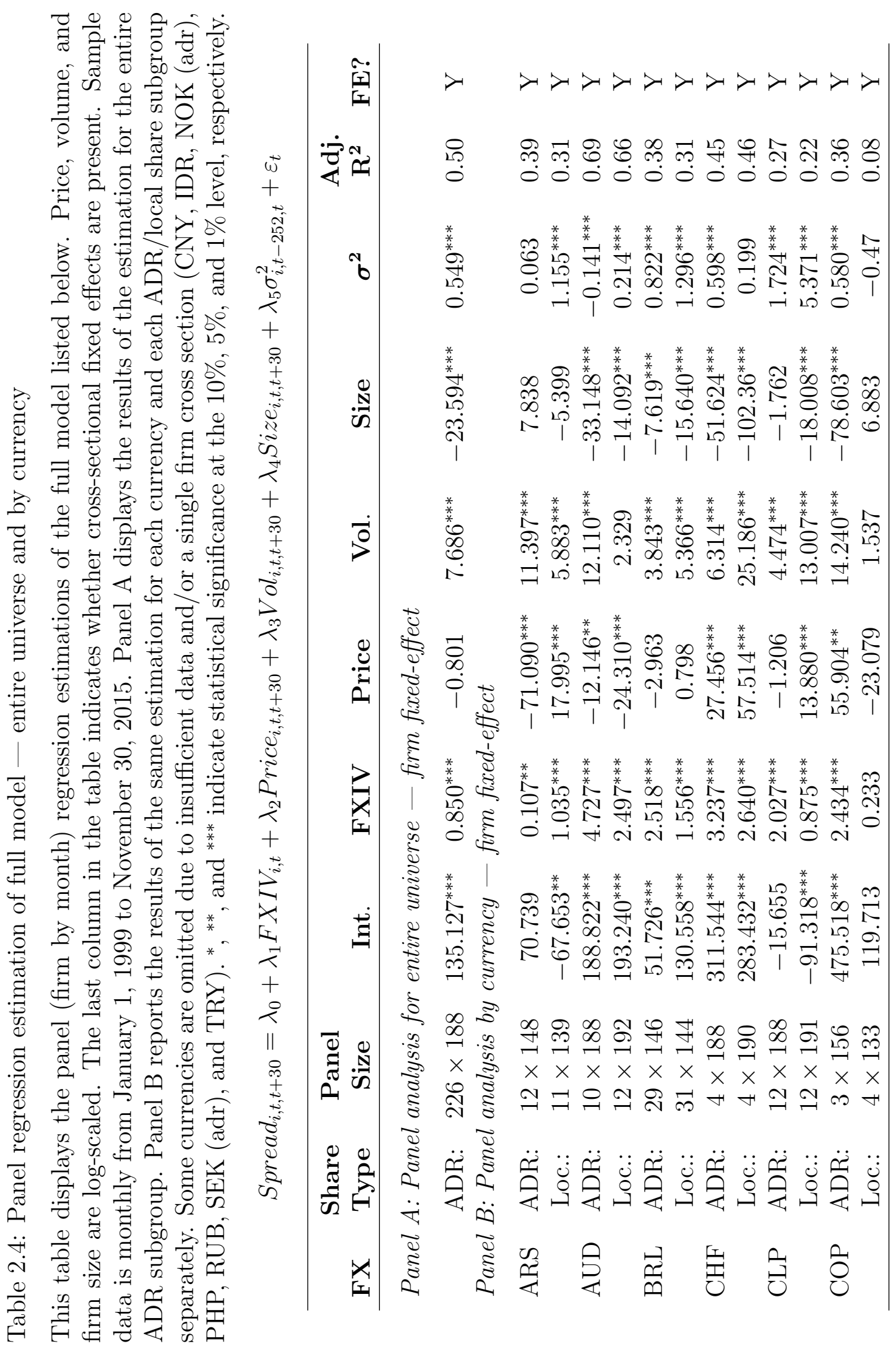




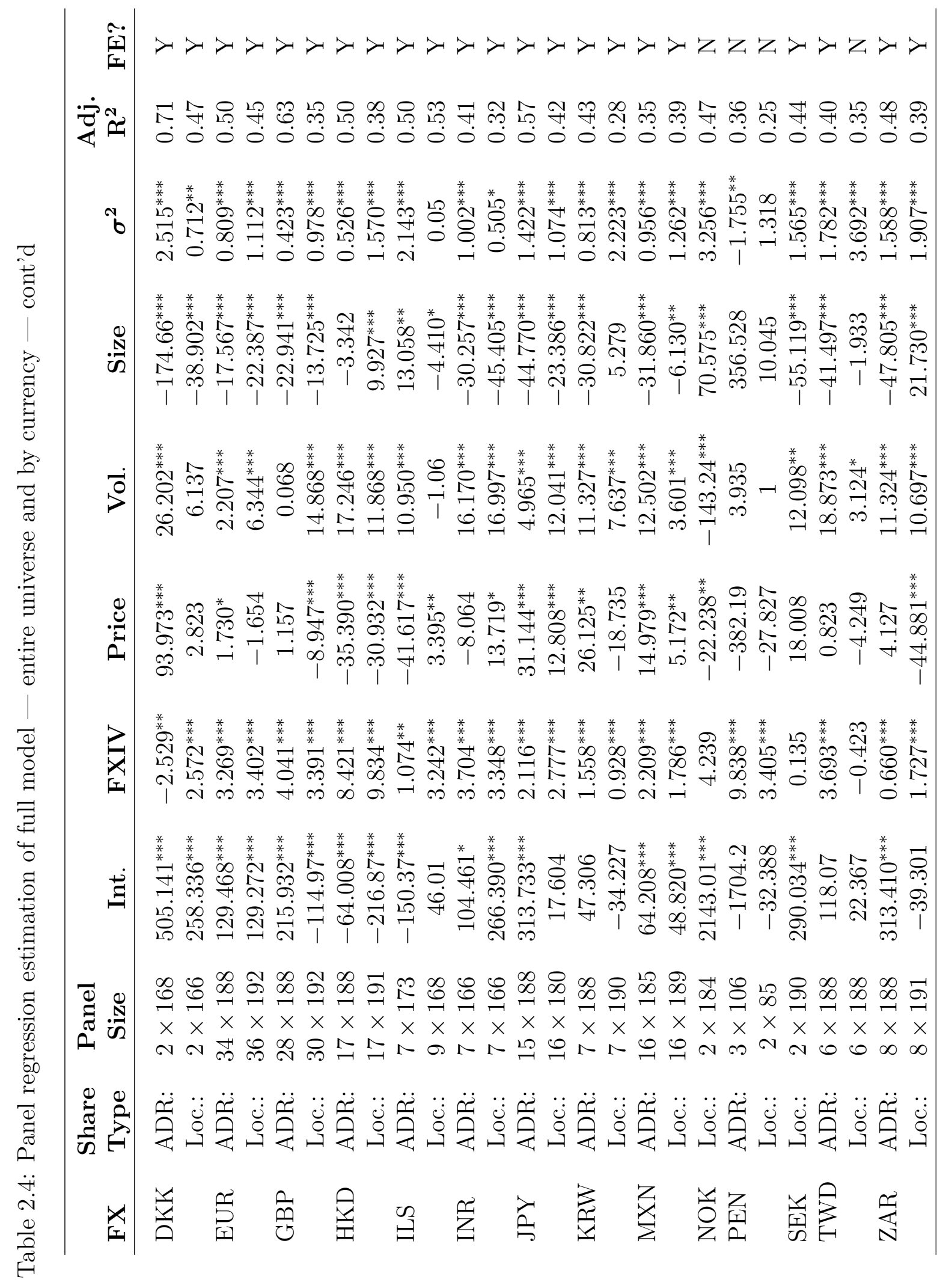


domestic US firms and is thus a more uniform sample than the one in my study. A more diverse sample is likely to exhibit cross-firm and cross-currency variations in liquidity, consistent with Chordia et al. (2000) and Hasbrouck and Seppi (2001) findings of weak commonality in liquidity. Another potential source of variation in liquidity in my sample, versus the domestic sample in Stoll (2000), is the variation in legal investor protection across countries. López de Silanes et al. (1998) document sources of liquidity variation between French/civil law countries and English/code law countries.

Firm fixed effects are detected in most of the estimations documented in Table 2.4. The exceptions are the estimations that use panel data for firms whose local currencies include the Norwegian Krone (NOK), the Peruvian Nuevo Sol (PEN), and the Taiwan Dollar (TWD). A common factor among these estimations is the small number of firm cross-sections, though firm fixed effects are still detected for other currencies with low numbers of firm cross-sections.

The signs on regression coefficients are not uniform across currencies. Some of the differences likely stem from unobserved effects related to each currency. A low number of cross-sections for some currencies likely also plays a part. The coefficient on FXIV, the main variable in my study, yields the most consistent result in Table 2.4. Forty-four of the 48 estimations in Panel B of Table 2.4 show a statistically significant and positive coefficient on FXIV as suggested by my theoretical position that high FX volatility should lead to wider spreads. Once again, multicollinearity is the likely cause of inconsistent regression coefficient signs in Panel B of Table 2.4. 


\subsubsection{Dynamic panel data estimation of relation between spreads and liquidity determinants}

Table 2.5 displays the results from the dynamic panel data estimations employing GMM. Panel A shows the results for ADRs and local shares separately but including firms across all currencies. All regression coefficients are significant but once again the sign on the coefficient for volume is contrary to the idea that higher trading volumes are associated with lower trading spreads. The low p-values for the Sargan test leads me to reject the null hypothesis that specification 2.7 is over-identified. Considering the estimations for each currency reported in Panel B, exceptions occur in only three instances.

Similar to the fixed-effects analysis for each currency discussed in Section 2.4.3, twelve currencies are dropped from the dynamic panel data estimation due to the insufficient number of firm cross sections for a given currency. As was the case in Table 4, the signs of the coefficients in Panel B in Table 2.5 are not consistent across the estimations for the various currencies. The coefficients on FX volatility for estimations with at least fifteen cross-section firms are consistently statistically significant and positive, indicating that high FX volatility is associated with higher spreads. The only exception is the case of the estimation for the Hong Kong dollar subsample when the coefficient on FX volatility is not significant for the ADR subgroup and is only significant at the $10 \%$ for the local shares subgroup. I at-

tribute this to the fact that the Hong Kong dollar is pegged to the US dollar thus substantially limiting the volatility in the HKD/USD exchange rate. 


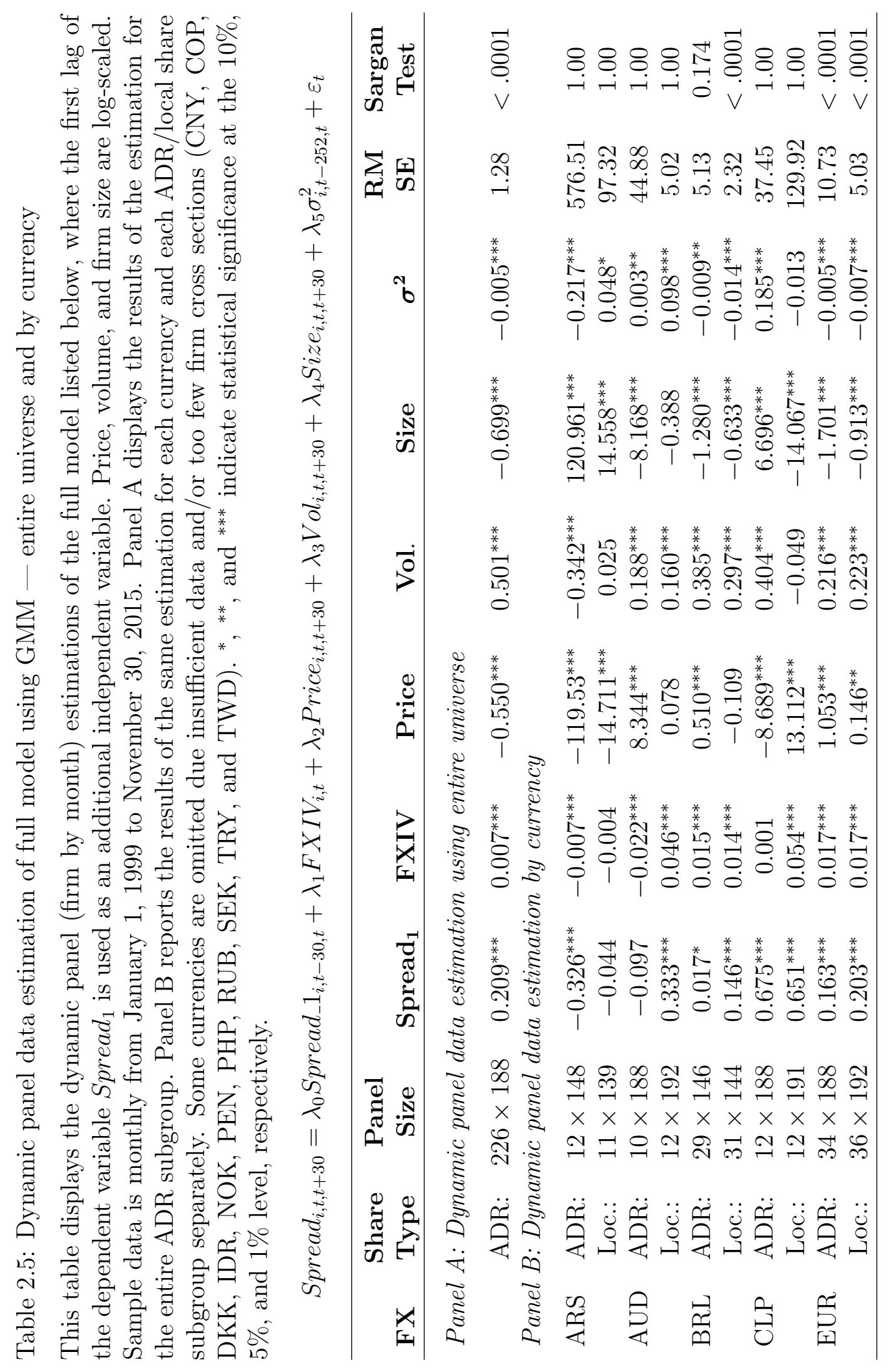




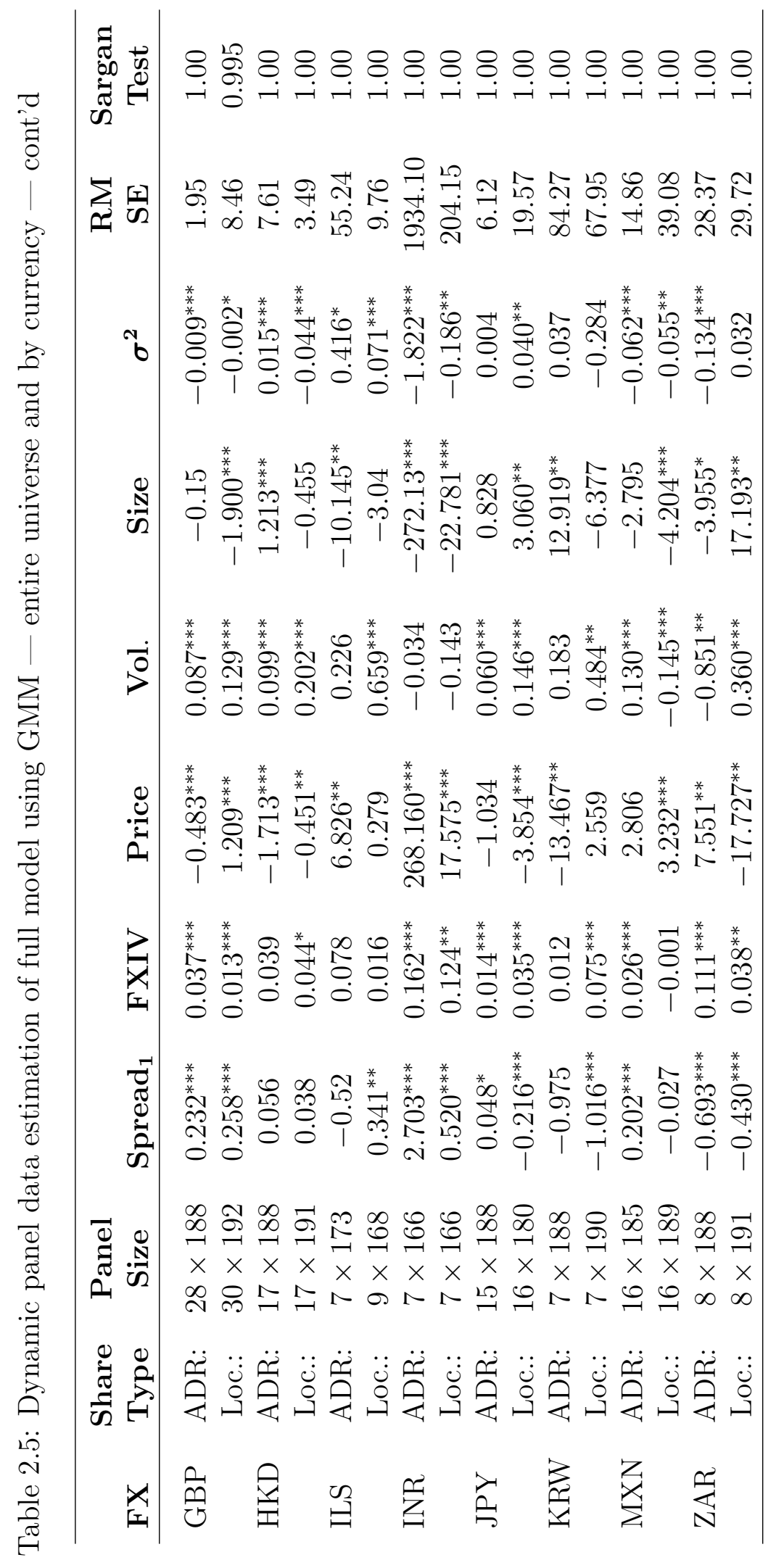




\subsubsection{Principal components analysis of determinants of liquidity}

As reported in Table 2.2, some of the determinants of liquidity in my analysis exhibit a high degree of correlation among themselves. Namely, using data for my entire sample universe, volume exhibits a Pearson correlation coefficient of 0.73 with price, and 0.76 with firm size. In turn, the correlation between firm size and price is 0.57 (see Table 2.2 Panel A). FX implied volatility and recent return variance show low correlations with each other and with the remaining liquidity drivers. I thus subject the determinants of liquidity in my multivariate formulation described in relation 2.6 to a principal components analysis. I limit this exercise to the ADR subsample to ensure that variables (specifically, price, volume, and firm size) are measured in the same currency. I extract three components, based on the results of a scree test, and perform an orthogonal rotation. Combined, these three components account for $82.3 \%$ of the variance in my data.

The estimates of liquidity variables and their corresponding factor loadings are presented in Table 2.6. Post rotation, a variable is considered to load on a given component when the factor loading is 0.40 or greater for that component and less than 0.40 for the others. Based on this criterion, three of the liquidity variables (i.e., price, volume, and firm size) are found to load on the first component. I label this component "current traits". Recent return variance is the only variable found to load on the second component, thus eponymously labeled "return variance". FX implied volatility is the only variable found to load on the third component, thus eponymously labeled "FX volatility". By design, the correlation among the retained components is zero.

Current traits, represented by component 1, accounts for $45 \%$ of the variance in the data. Recent return variance (component 2) accounts for 20.6\%, and FX implied 
volatility accounts for an additional 16.6\%. In total, the three retained components account for a combined $82.7 \%$ of the variance in the data. While component 3 , heavily loaded by FX implied volatility accounts for the smaller percentage of the variance in the data when compared to the other two retained components, it still accounts for a sizeable $16.6 \%$. This means that prior academic studies on determinants of liquidity in international markets did not include a significant driver of liquidity. This study closes that gap with a comprehensive analysis of the impact of well-established determinants of liquidity such as price, volume, firm size, and return variance in conjunction with my proposed variable - FX implied volatility.

Table 2.6: Principal components analysis of liquidity drivers — ADR subgroup

This table contains the results from the principal component analysis of the drivers of average monthly bid-ask spreads: price, volume, firm size, FX implied volatility, and recent return volatility. As in Stoll (2000), price, volume, and firm size are logscaled. Loadings on each component from each variable are included in the table. The proportional and cumulative variance explained by each component is included at the bottom of the table.

\begin{tabular}{cccc}
\hline & \multicolumn{3}{c}{ Component } \\
\cline { 2 - 4 } Variable & $\mathbf{1}$ & $\mathbf{2}$ & $\mathbf{3}$ \\
\hline FX imp. vol. & -0.04 & 0.05 & 0.99 \\
Price & 0.69 & -0.25 & -0.16 \\
Volume & 0.88 & -0.06 & 0.08 \\
Size & 0.88 & -0.21 & -0.04 \\
Return variance $\left(\sigma^{2}\right)$ & -0.16 & 0.97 & 0.04 \\
Pct. of Variance Explained & & & \\
\hline Proportion & & & \\
Cumulative & 0.4527 & 0.2084 & 0.1662 \\
& 0.4527 & 0.661 & 0.8273 \\
\hline
\end{tabular}

I then employ the derived principal components (PCs) as predictor variables in relation 2.6. By design, the multicollinearity that is present in the initial estimation of equation 2.6 is now fully eliminated. I estimate OLS regression for the ADR subsample. The results are reported in Table 2.7 . 
Table 2.7: Relation of spreads to principal components - ADR subgroup

This table contains the results from the OLS regression of the component scores from the principal component analysis on bid-ask spreads. These scores are optimallyweighted linear composites of the liquidity drivers that load on each component as reported in Table 6 . These drivers include price, volume, firm size, FX implied volatility, and recent return volatility. As in Stoll (2000), price, volume, and firm size are log-scaled. ${ }^{*},{ }^{* *}$, and ${ }^{* * *}$ indicate statistical significance at the $10 \%, 5 \%$, and $1 \%$ level, respectively. T-stats are in parentheses.

\begin{tabular}{cc} 
Spread $_{i, t+30}=\varphi_{0}+\varphi_{1}$ Comp $1+\varphi_{2}$ Comp $2+\varphi_{3}$ Comp $3+v_{t}$ \\
\hline Antercept & $0.6207^{* * *}$ \\
& $(267.9)$ \\
Princ. Comp 1 -Current Traits & $-0.1881^{* * *}$ \\
& $(-81.15)$ \\
Princ. Comp $2-$ Recent Variance & $0.2005^{* * *}$ \\
& $(86.49)$ \\
Princ. Comp3-FX Volatility & $0.1121^{* * *}$ \\
& $(48.35)$ \\
Obs. & 32,129 \\
Adj. $R^{2}$ & 0.338 \\
\hline
\end{tabular}

The estimated coefficients of each of the PCs - i.e., the predictor variables are consistent with the intuitions discussed in detail in Section 2.4.3. The first PC (current traits) has a negative coefficient reflecting the inverse relation between bidask spreads and the three trading characteristics that comprise the current traits component: price, volume, and firm size. Intuitively, all three traits are negatively related to spreads. Lower priced stocks tend to be riskier and are thus associated with larger trading spreads. Lower stock prices also tend to result in larger percent spreads due to fixed fees and commissions in some markets. Lower volume is associated with higher inventory risk, and consequently larger spreads, due to greater difficulty in locating counterparties for a trade. Smaller firms tend to attract less capital for trading, resulting in lower liquidity and larger spreads. The inverse rela- 
tion between market capitalization and bid-ask spreads is well documented in Stoll and Whaley (1983).

The coefficient for the second PC (recent variance) is positive, indicating a positive relation between volatility and bid-ask spreads. This results from the inverse relation between volatility and liquidity documented in Cohen et al. (1976).

The coefficient for the third PC (FX implied volatility) is also positive and highly statistically significant. This implies, as posited earlier in the motivation for this study, that higher volatility in FX markets increases the risk of foreign currency-denominated assets and that this risk is reflected in wider bid-ask spreads. Compared with the estimates reported in Tables 2.4 and 2.5, the results in Table 2.7 are more parsimonious and devoid of multicollinearity issues, leading to more reliable interpretations of the coefficients.

\subsection{Summary and conclusions}

I introduce a new factor to explain cross-sectional variations in liquidity, measured as proportional bid-ask spread, among international firms. I contribute to the extant literature by introducing this new factor and by expanding the analysis to the broad ADR universe and their underlying local shares. I find that FX implied volatility yields additional information about bid-ask spreads of international shares that is not captured by well-established liquidity factors documented in prior literature. I also employ the more recent spread estimator, which is a simple and more economical substitute for the spread measures that are derived from high-frequency data.

Since the liquidity factor I introduce is a forward-looking estimator of FX volatility, my results suggest that my factor can be used to predict subsequent trading

spread. This is in contrast with the contemporaneous relation for spread and trading 
characteristics reported in prior studies. This distinction expands and underscores the usefulness of my findings in a forward-looking setting.

I use a broad universe of international firms and ADRs to establish the relation between spread and liquidity determinants in a global setting. I find that when each variable is considered separately in univariate regressions, all relations hold according to previous findings and my a priori intuitions are supported - price, volume, and firm size are negatively related to spread, while recent return variance is positively related. FX volatility, central to the motivation for this study, is positively related to bid-ask spreads. To control for other variables, I expand the univariate pooled OLS regressions. Without such controls, the results will be distorted by the presence of the confounding effects. My analyses are conducted separately for ADRs and local shares and I show that these two universe are statistically significantly different from each other in their responses to the spreads. The average estimated spread for ADRs are smaller than those for local shares. This suggests that trading costs in ADRs on average are expected to be lower than in the local shares.

In multivariate analyses, the signs on the coefficients for the liquidity driver variables are inconsistent. I attribute this problem to multicollinearity driven by the high correlation among the trading characteristics variables: price, volume, and firm size. I report these correlations and show that FX implied volatility has very low correlations with these variables and thus represents an excellent addition to the multivariate analyses. I employ fixed-effects as well as dynamic panel estimations to test the theoretical specifications that I posit. I document the relation between spread and FX implied volatility for each currency subsample, highlighting the crosssectional variations that are driven by country and currencies.

Finally, I use principal components to address the multicollinearity in the data. I then show that for the ADR subsample, after adjusting for multicollinearity, the 
relation between liquidity drivers and spread behaves according to my a priori expectations. More importantly, I also show that FX implied volatility explains $16.6 \%$ of the variation in my data, implying that my proposed liquidity driver should have a material impact on spreads, heretofore largely unexplored in the financial literature. 
CHAPTER 3

\section{DO AGGREGATE ACCRUALS YIELD INCREMENTAL INSIGHTS INTO S\&P 500 VOLATILITY?}

\subsection{Introduction}

The S\&P 500 is one of the most important proxies for the U.S. market. As such, forecasting volatility trends for the index is vital in financial risk management. VIX, an implied volatility measure for the S\&P 500 developed by the CBOE, is widely used in risk management and has attracted interest from academic researchers. The CBOE has capitalized on the wide acceptance of the VIX measure as a benchmark for stock market volatility via the introduction of a bevy of derivative products such as VIX futures, VIX options, VIX binary options, and mini-VIX futures. In turn, academicians have proposed a multitude of models, mostly stochastic ones, for pricing VIX futures and options. This study is an effort to augment the current body of research on VIX and market volatility by investigating whether there is an accounting relation to subsequent U.S. market volatility. While such a link, if empirically established, could be used to develop a VIX futures pricing model, development of a full pricing model is beyond the scope of my efforts. Using accounting data, I examine the relation between total accruals, aggregated for all S\&P 500 members for which accruals can be calculated, and subsequent volatility for the S\&P 500 .

I then verify whether a relation holds in the presence of other market signals for one-year ahead market volatility. The outlook for earnings, interest rates, exchange rates, economic growth, and political developments all play a role in the equity markets' expectations for subsequent volatility. In the near term, the VIX, also known in Wall Street parlance, as the "fear gauge", is commonly believed to incorporate all of the factors reflecting the market's expectation for volatility in the 
S\&P 500 over the next thirty days. ${ }^{1}$ Versions of the VIX based on three-month and six-month S\&P 500 options are also disseminated by the CBOE, but are not as widely followed. While a version based on S\&P 500 options expiring in one-year could be computed according to the VIX methodology, further out-of-the-money strikes for longer horizon options are normally not very liquid, calling into question the accuracy of such a measure. Therefore, I employ liquid S\&P 500 options with strikes not more than $15 \%$ away from the value of the underlying index, and apply the Black Scholes formula to calculate an implied volatility for the index over a one-year horizon. I then utilize this calculated measure to examine whether aggregate S\&P 500 accruals yield any additional explanatory information regarding subsequent one-year S\&P 500 volatility.

\subsection{Prior literature}

The accrual anomaly, attributed to Sloan (1996), establishes that firm level accruals are negatively related to future stock returns. By decomposing earnings into accrual and cash flow components, Sloan (1996) demonstrates that the larger the accrual component of earnings, the less persistent the earnings tend to be. His finding that stock prices do not appear to reflect the information in the accrual component of earnings is convincing evidence that stock prices reflect naïve expectations about earnings. A large body of research in the accounting and finance literature has followed. Dechow and Dichev (2002) for instance, propose models for measuring accrual and earnings quality, while Chan et al. (2006) investigate how much of earnings quality is attributable to discretionary versus non-discretionary accruals.

\footnotetext{
${ }^{1}$ The VIX is based on a weighted average of out-of-the-money S\&P 500 options prices over two nearby maturities. See https://www.cboe.com/micro/vix/vixwhite.pdf for further details on the calculation of the VIX.
} 
More recently, Rajgopal and Venkatachalam (2011) show that deteriorating earnings quality is associated with higher idiosyncratic return volatility at the firm level. They measure accruals as per Sloan (1996), and use the residuals from regressing accruals on pertinent accounting metrics as a proxy for accruals quality. They also use the accruals quality measure developed by Dechow and Dichev (2002). The vast majority of accrual related studies, whether from an accounting or finance perspective, focus on accruals at the firm level. An exception, however, is Hirshleifer et al. (2009) who aggregate the accrual measure at the market level using the Center for Research in Security Prices (CRSP) value-weighted market index as a market proxy. They demonstrate that, contrary to Sloan (1996)'s findings, market-level aggregate accruals are positively associated with future returns.

In the realm of market volatility, the $\mathrm{S} \& \mathrm{P} 500$ is the most common market benchmark, and thus CBOE's VIX is the proxy for market volatility. Various models for pricing VIX futures have been proposed. Grünbichler and Longstaff (1996) assume a mean-reverting squared-root volatility process to construct a volatility futures and options pricing model. Zhang and Lim (2006) develop a stochastic pricing model for VIX futures, while Wu (2006) help establish lower and upper bounds for VIX futures prices. Zhu and Zhang (2007), based on the variance term structure, develop a no-arbitrage pricing model for VIX futures. Zhu and Lian (2012) derive an analytical formula for VIX futures pricing and present empirical evidence supporting the use of Heston (1993)'s stochastic volatility model in VIX futures pricing. Dupoyet et al. (2011) propose a constant elasticity variance (CEV) model, with and without jumps, to price volatility futures and empirically compare that model to the Cox-Ingersoll-Ross formulation. Finally, there have also been several models proposed for pricing VIX options, and Wang and Daigler (2011) provide an excellent objective assessment of these models. 
I link these two bodies of research by examining whether the accrual-volatility relation revealed by Rajgopal and Venkatachalam (2011) holds at the aggregate S\&P 500 level, and by evaluating whether accruals can be useful in VIX futures pricing.

The intuition behind the accrual anomaly (aka the earnings fixation hypothesis) is that markets fail to recognize that earnings boosted by accruals are not persistent, thus resulting in a negative surprise when the accruals reverse and earnings revert to normal levels. The reverse is true when earnings are artificially depressed by negative accruals. These surprises, especially for firms at the extremes of the accruals spectrum, are likely to be associated with higher volatility. I thus, à priori, expect increasing subsequent stock return volatility for firms as one moves away from the median firm ranked by total accruals. I also hypothesize that the absolute value of an aggregate, weighted measure of accruals for the S\&P 500 is positively related to subsequent volatility for the index, and is thus useful in pricing VIX futures.

\subsection{Data and methodology}

Total accruals are calculated at the firm level according to Sloan (1996) using Compustat data, while returns and volatility are calculated using CRSP (Center for Research in Securities Prices) data. I follow Kothari et al. (2005) in calculating performance-matched abnormal accruals. Compustat is also the source for historical members of the S\&P 500. Daily settlement prices for VIX futures, which started trading in March 2004, are from the CBOE. I calculate accruals at both the annual (1964-2012) and quarterly (1987-2012) frequencies. The start of my quarterly accrual sample coincides with the introduction of SFAS 95 that established standards for cash flow reporting. This is also the time when Compustat began including

the Standard Industrial Classification (SIC) code in its annual files, a vital piece of 
information used for grouping like firms in the calculation of performance-matched abnormal accruals.

\subsubsection{Sample construction and accrual calculation}

Sloan (1996)'s definition of accrual is based on the indirect balance sheet method. Under this original definition, accruals are computed as the change in non-cash current assets less change in current liabilities excluding the change in short-term debt and change in income taxes payable, minus depreciation and amortization expense. Formulaically, it is defined as:

$$
\text { Accruals }=(\Delta C A-\Delta C a s h)-(\Delta C L-\Delta S T D-\Delta T P)-D e p
$$

where $\triangle C A$ represents change in current assets (Compustat item act and actq), $\Delta$ Cash represents change in cash/cash equivalents (Compustat item che and cheq), $\triangle C L$ represents change in current liabilities (Compustat item lct and lctq), $\triangle S T D$ represents change in debt included in current liabilities (Compustat item dlc and

dlcq), $\Delta T P$ represents change in income taxes payable (Compustat item txp and txpq), and Dep represents depreciation and amortization expense (Compustat item $d p$ and $d p q)$. The Compustat item mnemonics in parentheses are Compustat data field names for the annual and quarterly Compustat files, respectively.

At annual frequencies, total accruals for each firm are calculated according to equation 3.1 using Compustat data items from the annual Compustat database. This results in an accrual measure for each firm for each fiscal year in the sample period. Firms' fiscal years may end in any month of the year, though December is the most common fiscal year-end for the North-America Compustat universe. In my sample, December fiscal year-ends comprise $63 \%$ of the observations. For firms with fiscal years ending in any of the first five calendar months of the year up to 
and including the month of May, the fiscal year for the firm is noted as the previous calendar year. For example, the 2012 fiscal year for Oracle Corp. (symbol ORCL), whose fiscal year ends in May, corresponds to the calendar period spanning from June 2012 through May 2013.

Return and volatility for each firm are measured over a twelve month period starting four months after the fiscal year-end of the firm. This delay is necessary to avoid look-ahead bias and is consistent with Alford et al. (1994) who find that four months after fiscal year-end the SEC form 10-K for most firms are publicly available $^{2}$. Sloan (1996) also incorporates this delay. So, in the case of fiscal year 2012 for Oracle Corp., accruals are measured during the fiscal period from June 1, 2012 through May 31, 2013, while subsequent returns and volatility are measured for the twelve-month period beginning on October 1, 2013 and ending on September 30, 2014. My sample for the annuals accrual analysis includes Compustat data for fiscal years from 1964 through 2012. The sample begins in 1964 because that is the earliest year for which there are data for a sufficient number of firms. I limit the upper bound of the sample to fiscal year 2012 because the empirical analysis requires return and volatility data through September 2014. Finally, I also exclude firms for which the accrual measure cannot be calculated due to missing data. As a rule, such data is not available for banks, life insurance, and property and casualty insurance companies. This results in a total of 182,052 firm-year observations for the annual data sample.

Abnormal accruals for each firm are calculated on a yearly basis according to the Kothari et al. (2005) performance-matched measure derived from the Jones (1991)

\footnotetext{
${ }^{2}$ Since 2005 the SEC has imposed further restrictions on the filing deadline for firms listed in the U.S., requiring firms with $\$ 700 \mathrm{mn}$ or more in market capitalization to file within 60 days and firms with more than $\$ 75 \mathrm{mn}$ to file within 75 days. Only smaller firms have a total of 90 days to file. See http://www.sec.gov/answers/form10q.htm.
} 
model. In the Jones model, discretionary accruals are estimated cross-sectionally each year as the residual of the following regression model:

$$
T A_{i, t}=\beta_{0}+\beta_{1}\left(1 / A S S E T S_{i, t-1}\right)+\beta_{2} \Delta S A L E S_{i, t}+\beta_{3} P P E_{i, t}+\varepsilon_{i, t}
$$

where $T A_{i, t}$ represents total accruals for firm $i$ at time $t, A S S E T S_{i, t-1}$ are lagged total assets for firm $i, \triangle S A L E S_{i, t}$ represents change in sales scaled by lagged total assets $A S S E T S_{i, t-1}, P P E_{i, t}$ represents property, plant, and equipment also scaled by lagged total assets, and $\varepsilon_{i, t}$ is an error term. Kothari et al. (2005) include the financial performance metric return-on-assets $(R O A)$ as an additional independent variable to the Jones (1991) model expressed in relation 3.2. The goal is to control for the effect of financial performance on measured discretionary accruals. Employing Kothari et al. (2005) model, I estimate:

$$
T A_{i, t}=\delta_{0}+\delta_{1}\left(1 / A S S E T S_{i, t-1}\right)+\delta_{2} \Delta S A L E S_{i, t}+\delta_{3} P P E_{i, t}+\delta_{4} R O A_{i, t-1}+v_{i, t}
$$

where $R O A_{i, t-1}$ is the return-on-assets for firm $i$ at period $t-1$ calculated as net income divided by average total assets over the period. All other independent variables are as described for equation 3.2. Estimation of equation 3.3 is performed annually for each two-digit SIC code group. I employ a robust regression using the Maximum-likelihood method introduced by Huber (1973) in order to accommodate outliers in the data (these are common when calculating accruals across a large universe of firms). The residuals from equation 3.3 constitute my measure of performance-adjusted abnormal accruals for each firm.

The calculation of accruals at a quarterly frequency follows essentially the same methodology save for some adjustments. First, in this case the data comes from the quarterly Compustat files. The year-over-year change for each balance sheet item in equation 3.1 is calculated using quarterly data, while the depreciation term is summed over the prior four quarters. For each fiscal year I aggregate my quarterly 
sample into four quarters denoted as: March, June, September, and December. For firms with fiscal quarters ending in other calendar months, I group them with the quarter denoted by the month that is the next closest month in the year. For instance, the quarterly subsample for March 2012 includes firms with quarters ending in January, February and March 2012. Since U.S. listed firms are required to file 10Q forms quarterly with the SEC, each of my quarterly sub-samples includes all firms, regardless of the firm's fiscal year-end month. Initially, I use the entire universe of quarterly data in order to calculate the abnormal accruals for each firm. I then compute a value-weighted aggregate measure of accruals for the S\&P 500 for each of the denoted quarters in my sample. This process yields a total of 106 quarterly aggregate accruals observations from March 1987 through June 2012.

\subsubsection{Analysis of accruals vs returns and volatility}

Similar to Sloan (1996), I use the annual sample data to build deciles based on accruals levels calculated for each firm for each year. I then calculate average accruals, subsequent average returns, and subsequent average volatility (defined as

the annualized standard deviation of daily returns) for each decile. Next I calculate the averages for each decile across years. Denoting the lowest decile as the decile with the worst (highest) average accruals level, I expect average returns to increase somewhat monotonically with the decile ranking in accordance with the results obtained by Sloan (1996). I also calculate the average firm market capitalization for each decile. Firm size, as measured by market capitalization, is a well- established predictor of future returns. Therefore, in studies examining relations between economic and/or accounting factors and future stock returns, it is common practice to adjust returns for size and/or to employ CAPM to calculate abnormal returns. Sloan (1996) adjusts returns by size. I do not make such adjustments as my focus is 
on examining the relation between accruals and subsequent volatility, not returns. Nonetheless, I compute average firm market capitalization for each decile in order to demonstrate that there is not a size bias in the higher deciles. In fact, I expect both extreme deciles to exhibit lower average market capitalization as smaller firms are more susceptible to extreme accruals. Regarding the accrual-volatility relation, I expect the highest and lowest deciles to exhibit the highest average volatility levels, while the middle deciles exhibit the lowest average volatility levels. This bifurcated pattern is expected because according to the earnings fixation hypothesis, investors are expected to be surprised by future earnings for firms whose current earnings are either materially increased or materially reduced by accruals.

At first, I examine the relation between accruals and subsequent volatility for each firm in my annual accruals sample. As stated above, volatility is measured with a four-month lag to avoid look-ahead bias. I choose a robust regression with M-estimation and Huber weighting for my estimation to adjust for outliers in the data. I perform my analysis separately using positive and negative accruals, as well as using the absolute value of accruals. Each of these scenarios are repeated using first a total accruals measure and then an abnormal accruals measure. This results in a combined total of six different scenarios that I examine in my analysis of annual data.

Next, I repeat the analysis using rolling four quarters of data to calculate my accruals measures. I repeat the analysis for the six scenarios examined with annual data, however, this time I further segment my analysis into pre- and post-2000 as well as pre- and post-2002 periods. Prior to March 15, 2000 the SEC allowed firms to have their quarterly filings reviewed as part of the annual audit rather than prior to filing. That changed when the SEC issued Regulation S-K which required timely reviews (Securities and Exchange Commission, 1999a,b). Since the passage of the 
Sarbanes-Oxley Act $^{3}$ in 2002 (heretofore SOX 2002), the principal officers (normally the chief executive officer and the chief financial officer) are required to approve and certify the accuracy and integrity of the financial results of their firms on a quarterly basis. À priori, I expect the impact of accruals on subsequent volatility to be modestly weaker post 2000 and even weaker post 2002 .

Finally, I aggregate S\&P 500 firms weighted by their market capitalization to construct an aggregate accrual level for the S\&P 500 on a quarterly basis. I then compute subsequent twelve-month returns and volatility for the S\&P 500 starting four months after each quarterly measurement as described in section 3.1. I once again employ robust regressions to investigate whether aggregate accruals are significantly related to subsequent volatility in the S\&P 500 index. The analysis of the association of aggregate $\mathrm{S} \& \mathrm{P} 500$ accruals and subsequent $\mathrm{S} \& \mathrm{P} 500$ returns is similar to that in Hirshleifer et al. (2009), but involves the use of quarterly data to account for the fact that less than $65 \%$ of S\&P 500 firms in my sample have fiscal years ending in December. The results involving aggregate accruals and subsequent volatility constitute a major contribution of this research.

\footnotetext{
${ }^{3}$ The Act was enacted July 30, 2002. In the Senate, it was called the "Public Company Accounting Reform and Investor Protection Act", while in the House it was known as the "Corporate and Auditing Accountability and Responsibility Act." It is also known by its more informal moniker SOX. The Act contains eleven titles (or sections) and it was passed as a reaction to the accounting scandals at Enron and Worldcom. Tittle III of the Act requires the quarterly certification of results by firms' principal officers. For further details on this legislation see: http://www.gpo.gov/fdsys/pkg/PLAW-107publ204/html/PLAW107publ204.htm
} 


\subsubsection{Explanatory information about S\&P 500 volatility from aggregate accruals}

I next examine whether aggregate S\&P 500 accruals yield additional explanatory information regarding subsequent one-year ahead S\&P 500 volatility when compared with other market based volatility indicators. If my investigation were focused on short-term (thirty day) volatility expectations for the S\&P 500, CBOEs VIX would be the obvious choice for a well-established, market-driven, option-implied indicator of short-term volatility. However, because my analysis requires a twelve-month horizon indicator of S\&P 500 volatility, the choice for such an indicator is not so clear.

I consider two indicators for my tests. The first indicator I consider is the CBOEs Mid-Term volatility index (VXMT). As per the CBOE website this index is "a measure of the expected volatility of the S\&P 500 Index over a 6-month time horizon. It is calculated using the well-known VIX methodology applied to SPX options that expire 6-to-9 months in the future." Data for the VXMT index is, however, only available starting in January 2008. As a result, my sample contains two few quarterly data points for analysis. The second indicator I consider more closely matches my intended twelve-month time horizon. Using OPRA (Options Price Reporting Authority) data and the Black-Scholes formula, I calculate oneyear option implied volatility from daily SPX options prices. Specifically, I use data from VIX futures expiration days when trading in SPX options is often very active. My sample data for SPX options is from May 2005 to December $2013^{4}$. Because March, June, September and December are the only months in my dataset that

\footnotetext{
${ }^{4}$ Prior to 2005, trading in S\&P 500 (SPX) options was less liquid. It was in 2003 that the CBOE started using SPX options for the VIX calculation. Before then the VIX was based on S\&P 100 options.
} 
always have options expiring in exactly twelve months, I relax the twelve-month requirement and, for each day in my dataset, calculate the option implied volatility for options expiring in eleven, twelve, or thirteen months. This is to ensure a minimum number of observations for my analysis.

The Black-Scholes formula also requires the dividend yield and the risk-free rate over the life of the option for the calculation of implied volatility. I use the annual ex-post value of S\&P 500 dividends as the ex-ante expectation of dividends since dividends paid by most S\&P 500 member firms rarely deviate far from their widely divulged dividend declarations. The present value of such dividends is then subtracted from the current value of the S\&P 500 index in order to adjust for the dividend yield. The risk free rate I employ is the twelve-month constant maturity Treasury Bill rate available from the Federal Reserve Bank of St. Louis Economic Data (FRED) website. I use strikes for out-of-the-money puts and calls that are within $15 \%$ of the current value of the underlying S\&P 500 index because these are the most liquid contracts. Data is obtained from the OPRA quotes files with nonzero bids within the first five minutes of the market open on VIX futures expiration days (my sample data contains 102 expiration days). The quote midpoint is used as the option price input in the Black-Scholes formula. I then employ the numerical method in Forsythe and Moler (1967) to solve for the option implied volatility of each strike within the aforementioned strike range. The option implied volatility for each day in my dataset is computed as the average of the calculated implied volatilities for these option strikes on that day.

I expect my one-year horizon option implied volatility measure to be an effective predictor of subsequent twelve-month volatility in the S\&P 500. My focus is to examine whether aggregate S\&P 500 accruals yield further insights about subsequent S\&P 500 volatility. I regress twelve-month subsequent S\&P 500 volatility 
on aggregate accruals and option implied volatility. I test for statistical significance of the aggregate accruals coefficient to determine whether aggregate accruals has additional explanatory information about subsequent S\&P 500 volatility.

\subsection{Empirical results}

Table 3.1 presents average twelve-month returns and volatility across deciles. Grouping the Compustat universe into deciles based on total accruals per fiscal year reveals that companies at the highest and lowest deciles exhibit higher subsequent volatility than the rest of the sample. Firm size also appears to play a role as the highest and lowest deciles have lower average market capitalization. This suggests that the observed higher volatility may be partly due to smaller firm size. The results in Table 1 also show that higher deciles (lower accruals) are associated with higher subsequent twelve-month returns, consistent with Sloan (1996)'s findings.

\subsubsection{Firm level accruals and subsequent twelve-month volatility}

In my analysis of the association between firm level accruals and subsequent twelve-month volatility, I perform robust regressions with M-estimation and Huber weights. Because extreme accruals, both negative and positive, are associated with subsequent volatility, the primary independent variable in my regressions is the absolute value of accruals. Nonetheless, two other estimations of the main model are separately performed for firms with positive accruals and negative accruals. The results of my tests are summarized in Table 2. Panel A contains the results of the regressions using the abnormal accruals measure of Kothari et al. (2005) as the primary independent variable, while Panel B contains analogous results employing

the Sloan (1996) total accruals measure. Each estimation of the model contains only 
Table 3.1: Average 12-mo returns and volatility across yearly accrual deciles

This table groups the annual sample data (FY1964-FY2012) by accrual level deciles and displays the subsequent twelve-month return, annualized average daily volatility, and average market capitalization for each decile. Deciles are generated yearly so firms can fall under different deciles on a given year depending on the firms accrual level for that year. Return and volatility for each firm are measured over a twelvemonth period starting four months after the fiscal year-end for the firm, and then averaged within each decile for each fiscal year. Market capitalization for each firm is measured at the beginning of the period when returns are measured. Firms with market capitalization below $\$ 100 \mathrm{mn}$ are excluded.

\begin{tabular}{cccccc}
\hline & & Average & $\begin{array}{c}\text { Average } \\
\text { Recile }\end{array}$ & $\begin{array}{c}\text { Average } \\
\text { Volatility }\end{array}$ & $\begin{array}{c}\text { Average } \\
\text { Mkt. Cap } \mathbf{( \$ m n )}\end{array}$ \\
\hline 1 & 8,322 & 0.1378 & 0.0419 & 0.5724 & 975.00 \\
2 & 8,346 & 0.0325 & 0.0897 & 0.4915 & $1,743.80$ \\
3 & 8,347 & 0.0032 & 0.1086 & 0.4568 & $2,254.20$ \\
4 & 8,347 & -0.0146 & 0.1253 & 0.4298 & $3,224.10$ \\
5 & 8,338 & -0.0284 & 0.1208 & 0.4183 & $3,321.90$ \\
6 & 8,359 & -0.0408 & 0.1235 & 0.4102 & $3,907.00$ \\
7 & 8,349 & -0.0541 & 0.1363 & 0.4248 & $3,634.80$ \\
8 & 8,344 & -0.0703 & 0.1237 & 0.4446 & $3,349.00$ \\
9 & 8,350 & -0.0946 & 0.1287 & 0.4779 & $2,624.60$ \\
10 & 8,327 & -0.1768 & 0.1306 & 0.5600 & $1,561.00$ \\
\hline
\end{tabular}

one accruals measure as the independent variable, resulting in a total of six distinct estimations of the following general model:

$$
V O L_{i, t+1}=\lambda_{0}+\lambda_{1} A C C_{\_} a b s_{i, t}+\lambda_{2} A C C_{-} p_{0 s} s_{i, t}+\lambda_{3} A C C \_n e g_{i, t}+\varepsilon_{i, t}
$$

where $A C C_{-} a b s_{i, t}$ is the absolute value of total firm level accruals for firm $i$ at period $t, A C C_{-}$pos $_{i, t}$ is the total firm level accruals for firm $i$ at time $t$ whose total accruals are greater than or equal to zero, $A C C_{-} n e g_{i, t}$ is the total firm level accruals for firm $i$ at time $t$ whose total accruals are negative, and $V O L_{i, t+1}$ represents the daily average return volatility of firm $i$ measured over a twelve-month period starting four months after fiscal year end over which accruals were calculated. 
In every variation of the regressions in the general model 3.4, the results reveal a statistically significant association between firm level accruals and subsequent firm returns volatility. This association is stronger when abnormal accruals are the independent variable as evidenced by the higher $R^{2}$ s in Panel A of Table 3.2. It is also clear that negative accruals have a stronger impact on subsequent volatility than positive accruals since the Model 3 variations in both Panel A and B yield the highest $R^{2}$ within their respective panels. As is often the case in regressions with a single accounting metric as the sole independent variable, overall $R^{2} \mathrm{~s}$ in Table 3.2 are low.

The results of my estimations of the general model 3.4 using quarterly data are summarized in Table 3.3. In this version of the analysis, accruals are calculated using rolling four quarters of accounting data. The calculation is performed at a quarterly frequency such that each firm-quarter accrual calculation uses a four rolling quarter period that has three overlapping quarters with the previous firm-quarter observation. This leads to a larger number of observations than were available for my analysis using annual data.

Prior to March 15, 2000 the SEC allowed firms to have their quarterly filings reviewed as part of the annual audit rather than prior to filing. That changed when the SEC issued Regulation S-K which required timely reviews (Securities and Exchange Commission, 1999a,b). Manry et al. (2003) show that prior to this mandate, fourth quarter "settling up" was reduced, and the association of earnings with returns was higher for firms that elected to have their quarterly reports reviewed prior to filing. Manry et al. (2003) also show that firms electing to have their quarterly filings reviewed as part of the year end audit (retrospective reviews), tended to report more "optimistically" in interim quarters. Since total firm level accruals embed all discretionary and non-discretionary accruals, analysis of total accruals measured at 
Table 3.2: Robust regressions of subsequent 12-mo volatility on current period accrual measures - annual data

This table contains the results of robust regressions of twelve-month subsequent volatility on firm accruals for three variations of the general model. In Panel A, the accrual measure used in the regression is the abnormal accrual in relation 3.3 proposed by Kothari et al. (2005). The regressions are evaluated three separate ways. Model 1 uses the absolute value of abnormal accruals, Model 2 includes only firms with positive abnormal accruals, and Model 3 includes only firms with negative abnormal accruals. The values in parentheses below the regression coefficients are p-values. Panel B is analogous to Panel A, except that in Panel B the accrual measure in the dependent variable is the Sloan (1996) measure expressed in relation 3.1. Data for accrual calculation are from Compustat annual files for all firms with total assets of $\$ 50$ million or higher. Sample period is from fiscal year 1987 through 2012. General regression model evaluated is as follows:

$$
V O L_{i, t+1}=\lambda_{0}+\lambda_{1} A C C \_a b s_{i, t}+\lambda_{2} A C C_{-} p_{0} s_{i, t}+\lambda_{3} A C C \_n e g_{i, t}+\varepsilon_{i, t}
$$

\begin{tabular}{|c|c|c|c|c|c|c|}
\hline & Obs. & $\begin{array}{c}\text { Intercept } \\
\lambda_{0}\end{array}$ & $\begin{array}{c}\text { Accruals } \\
\text { (abs. value) } \\
\lambda_{1}\end{array}$ & $\begin{array}{c}\text { Positive } \\
\text { Accruals } \\
\lambda_{2}\end{array}$ & $\begin{array}{c}\text { Negative } \\
\text { Accruals } \\
\lambda_{3}\end{array}$ & $\mathbf{R}^{2}$ \\
\hline \multicolumn{7}{|c|}{ Panel A: Subsequent 12-mo $v$} \\
\hline Model 1: & 78,689 & $\begin{array}{c}.027 \\
(<.0001)\end{array}$ & $\begin{array}{c}.076 \\
(<.0001)\end{array}$ & & & .040 \\
\hline Model 2: & 40,008 & $\begin{array}{c}.027 \\
(<.0001)\end{array}$ & & $\begin{array}{c}.0689 \\
(<.0001)\end{array}$ & & .031 \\
\hline Model 3: & 38,681 & $\begin{array}{c}.0271 \\
(<.0001)\end{array}$ & & & $\begin{array}{c}-.0821 \\
(<.0001)\end{array}$ & .048 \\
\hline \multicolumn{7}{|c|}{ Panel B: Subsequent 12-mo volatility on Sloan (1996) total accrual measure } \\
\hline Model 1: & 79,868 & $\begin{array}{c}.0266 \\
(<.0001)\end{array}$ & $\begin{array}{c}.0583 \\
(<.0001)\end{array}$ & & & .035 \\
\hline Model 2: & 19,332 & $\begin{array}{c}.0307 \\
(<.0001)\end{array}$ & & $\begin{array}{c}.041 \\
(<.0001)\end{array}$ & & .027 \\
\hline Model 3: & 60,536 & $\begin{array}{c}.025 \\
(<.0001)\end{array}$ & & & $\begin{array}{c}-.0686 \\
(<.0001)\end{array}$ & .041 \\
\hline
\end{tabular}

quarterly frequencies using pre-2000 data should yield more insights into potential market surprises when such accruals are unwound versus a similar analysis using data post 2000 . 
Table 3.3: Robust regressions of subsequent 12-mo volatility on current period accrual measures - quarterly data

This table contains the results of robust regressions of twelve-month subsequent volatility on firm accruals for three variations of the general model. This table is analogous to Table 2, but in this table accruals are calculated using four rolling quarters of data. In Panel $\mathrm{A}$, the accrual measure used in the regression is the abnormal accrual in relation 3.3 proposed by Kothari et al. (2005). The regressions are evaluated four separate ways. Model 1 uses the absolute value of abnormal accruals. Model 1 is partitioned into pre/post 2000 and pre/post 2002 to yield four sub-models. Model 2 includes only firms with positive abnormal accruals, and Model 3 includes only firms with negative abnormal accruals. The values in parentheses below the regression coefficients are p-values. Panel B is analogous to Panel A, except that in Panel B the accrual measure in the dependent variable is the Sloan (1996) measure expressed in relation 3.1. Data for accrual calculation are from Compustat quarterly files for all firms with total assets of $\$ 50$ million or higher. Sample period is from fiscal year 1987 through 2012. General regression model evaluated is:

$$
V O L_{i, t+1}=\lambda_{0}+\lambda_{1} A C C_{\_} a b s_{i, t}+\lambda_{2} A C C_{-} p s_{i, t}+\lambda_{3} A C C_{\_} n e g_{i, t}+\varepsilon_{i, t}
$$

\begin{tabular}{|c|c|c|c|c|c|c|}
\hline & Obs. & $\begin{array}{c}\text { Intercept } \\
\lambda_{0} \\
\end{array}$ & $\begin{array}{c}\text { Accruals } \\
\text { (abs. value) } \\
\lambda_{1}\end{array}$ & $\begin{array}{c}\text { Positive } \\
\text { Accruals } \\
\lambda_{2}\end{array}$ & $\begin{array}{c}\text { Negative } \\
\text { Accruals } \\
\lambda_{3}\end{array}$ & $\mathbf{R}^{2}$ \\
\hline \multicolumn{7}{|c|}{ Panel A: Subsequent 12-mo volatility on Kothari et al. (2005) abnormal accruals } \\
\hline Model 1: & 186,684 & $\begin{array}{c}.0249 \\
(<.0001)\end{array}$ & $\begin{array}{c}.0738 \\
(<.0001)\end{array}$ & & & .036 \\
\hline $\begin{array}{l}\text { Model 1B: } \\
\text { (Pre Mar 2000) }\end{array}$ & 93,806 & $\begin{array}{c}.0242 \\
(<.0001)\end{array}$ & $\begin{array}{c}.0764 \\
(<.0001)\end{array}$ & & & .043 \\
\hline $\begin{array}{l}\text { Model 1C: } \\
\text { (Post Mar 2000) }\end{array}$ & 92,878 & $\begin{array}{c}.0254 \\
(<.0001)\end{array}$ & $\begin{array}{c}.072 \\
(<.0001)\end{array}$ & & & .031 \\
\hline $\begin{array}{l}\text { Model 1D: } \\
\text { (Pre Jul 2002) }\end{array}$ & 112,758 & $\begin{array}{c}.0255 \\
(<.0001)\end{array}$ & $\begin{array}{c}.08 \\
(<.0001)\end{array}$ & & & .042 \\
\hline $\begin{array}{l}\text { Model 1E: } \\
\text { (Post Jul 2002) }\end{array}$ & 73,926 & $\begin{array}{c}.0243 \\
(<.0001)\end{array}$ & $\begin{array}{c}.058 \\
(<.0001)\end{array}$ & & & .024 \\
\hline Model 2: & 94,221 & $\begin{array}{c}.0251 \\
(<.0001)\end{array}$ & & $\begin{array}{c}0.0652 \\
(<.0001)\end{array}$ & & .027 \\
\hline Model 3: & 92,463 & $\begin{array}{c}.0247 \\
(<.0001)\end{array}$ & & & $\begin{array}{c}-0.0811 \\
(<.0001)\end{array}$ & .046 \\
\hline
\end{tabular}


Table 3.3: Robust regressions of subsequent 12-mo volatility on current period accrual measures — quarterly data — cont'd

\begin{tabular}{|c|c|c|c|c|c|c|}
\hline & Obs. & $\begin{array}{c}\text { Intercept } \\
\lambda_{0} \\
\end{array}$ & $\begin{array}{c}\text { Accruals } \\
\text { (abs. value) } \\
\lambda_{1}\end{array}$ & $\begin{array}{c}\text { Positive } \\
\text { Accruals } \\
\quad \lambda_{2} \\
\end{array}$ & $\begin{array}{c}\text { Negative } \\
\text { Accruals } \\
\lambda_{3} \\
\end{array}$ & $\mathbf{R}^{2}$ \\
\hline \multicolumn{7}{|c|}{ Panel B: Subsequent 12-mo volatility on Sloan (1996) total accrual measure } \\
\hline Model 1: & 252,875 & $\begin{array}{c}.0251 \\
(<.0001)\end{array}$ & $\begin{array}{c}.0565 \\
(<.0001)\end{array}$ & & & .032 \\
\hline $\begin{array}{l}\text { Model 1B: } \\
\text { (Pre Mar 2000) }\end{array}$ & 111,149 & $\begin{array}{c}.0243 \\
(<.0001)\end{array}$ & $\begin{array}{c}.058 \\
(<.0001)\end{array}$ & & & .035 \\
\hline $\begin{array}{l}\text { Model 1C: } \\
\text { (Post Mar 2000) }\end{array}$ & 141,726 & $\begin{array}{c}.0257 \\
(<.0001)\end{array}$ & $\begin{array}{c}.056 \\
(<.0001)\end{array}$ & & & .030 \\
\hline $\begin{array}{l}\text { Model 1D: } \\
\text { (Pre Jul 2002) }\end{array}$ & 137,727 & $\begin{array}{c}.0256 \\
(<.0001)\end{array}$ & $\begin{array}{c}.0649 \\
(<.0001)\end{array}$ & & & .039 \\
\hline $\begin{array}{l}\text { Model 1E: } \\
\text { (Post Jul 2002) }\end{array}$ & 115,148 & $\begin{array}{c}.0248 \\
(<.0001)\end{array}$ & $\begin{array}{c}.0426 \\
(<.0001)\end{array}$ & & & .020 \\
\hline Model 2: & 61,130 & $\begin{array}{c}.0283 \\
(<.0001)\end{array}$ & & $\begin{array}{c}0.0374 \\
(<.0001)\end{array}$ & & .018 \\
\hline Model 3: & 191,745 & $\begin{array}{c}.0237 \\
(<.0001)\end{array}$ & & & $\begin{array}{c}-0.0665 \\
(<.0001)\end{array}$ & .040 \\
\hline
\end{tabular}

Note: Number of observations in Model 1 from Panel B is higher than in Panel A because the calculation of abnormal accrual used in Panel A requires a minimum number of records from the same two-digit SIC code. Abnormal accrual in Panel A is calculated as the residual of the regression in relation 3.3 for each firm in a two-digit SIC code group.

Similarly, the Sarbanes-Oxley (SOX) Act (passed in 2002) requires officers of the firm to certify the accuracy of the financial statements. Cohen et al. (2008) document a decline in earnings management through accruals following SOX. This would lead me to expect that partitioning my sample pre versus post SOX would reveal an even greater difference than what I expect to find by partitioning on the timely review requirement. In order to investigate these conjectures, Model 1 is estimated using quarterly data for post March of 2000 and post June of 2002 observations. These additional estimations are denoted as Models B, C, D and E in Table 3.3. As expected, the regression coefficients and $R^{2} \mathrm{~s}$ for Model 1B versus Model 1 in Table 
3.3 reveal that post 2002, firm level accruals have less of an impact on subsequent firm return volatility. Notice that this is the case in both Panel A and B of Table 3.3, implying that this conclusion holds whether Kothari et al. (2005) abnormal accruals or Sloan (1996) total accruals are employed. Once again, as was the case in my analysis using annual data, the overall results in Table 3.3 Panel A, employing Kothari et al. (2005) abnormal accruals, show a stronger relation between accruals and subsequent volatility than the results in Panel B employing Sloan (1996) total accruals.

\subsubsection{S\&P 500 aggregate accruals and subsequent twelve-month S\&P 500 returns}

Similar to the work by Hirshleifer et al. (2009), I compute an aggregate marketcap weighted accrual measure for the S\&P 500 as a proxy for aggregate market accruals. All S\&P 500 member firms for which accruals can be calculated are included in this aggregate measure. This means banks, insurance companies and other financial services firms are excluded from this aggregate measure. The calculations are made quarterly by aggregating firms at quarters denoted as March, June, September, and December. About $63 \%$ of the firms in my sample have fiscal years ending in December. The remaining firms have fiscal years ending in all of the other months of the year, though after December, the three most popular months are March, June and September. In the end, every firm with an accruals measure is included in every quarterly S\&P 500 aggregate accrual calculation. In contrast, Hirshleifer et al. (2009) employ annual data for the accruals calculation and aggregate them based on the CRSP value-weighted market index.

At the firm level, Sloan (1996) demonstrates that accruals are negatively associated with subsequent stock returns. In sharp contrast, Hirshleifer et al. (2009) find 
that "aggregate accruals is a strong positive time series predictor of aggregate stock returns." Hirshleifer et al. (2009) provide an excellent discussion of the various reasons why the accrual anomaly may not hold at the aggregate level. In this research, I empirically examine the time series relation between S\&P 500 aggregate accruals and subsequent returns as a stepping stone to my ultimate goal of examining the relation between aggregate accruals and subsequent volatility.

Table 3.4 contains the results of robust regressions of subsequent twelve-month S\&P 500 returns on various accruals measures. The general model evaluated, including all the considered accruals measures, is:

$$
\begin{aligned}
S P_{-} R E T_{t+1} & =\lambda_{0}+\lambda_{1} T O T_{\_} A C C_{t}+\lambda_{2} T O T_{\_} A C C_{\_} a b s_{t}+\lambda_{3} A B_{-} A C C_{t} \\
& +\lambda_{4} A B_{\_} A C C_{\_} a b s_{t}+\varepsilon_{i, t}
\end{aligned}
$$

where TOT_ACC $C_{t}$ is the S\&P 500 aggregate total accrual measure constructed by market-cap weighting total accruals for member firms at period $t, T O T_{\_} A C C_{\_} a b s_{t}$ is an analogous measure constructed with the absolute value of total accruals for member firms at period $t, A B_{-} A C C_{t}$ is the $\mathrm{S} \& \mathrm{P} 500$ aggregate abnormal accrual measure constructed by market-cap weighting abnormal accruals for member firms at period $t, A B_{-} A C C_{\_} a b s_{t}$ is an analogous measure constructed with the absolute value of abnormal accruals for member firms at period $t$, and $S P_{-} R E T_{t+1}$ represents the twelve-month subsequent return for the S\&P 500 starting four months after the end of the four rolling fiscal quarters over which accruals were calculated. In all regression variations (Models 1 thru 4) in Table 3.4, there were 106 quarterly observations corresponding to the sample period from March 1987 through June 2012. Contrary to the findings by Hirshleifer et al. (2009) I find a negative, though not statistically significant, relation between S\&P 500 returns and aggregate S\&P 500 accruals. See Models 1 and 3 in Table 3.4. Employing the absolute value of 
accruals to aggregate $\mathrm{S} \& \mathrm{P} 500$ accruals yields a positive relation to subsequent S\&P 500 returns, but again this is not statistically significant.

\subsubsection{S\&P 500 aggregate accruals and subsequent twelve-month S\&P 500 volatility}

I now turn to the main focus of my aggregate accrual analysis — the relation between S\&P 500 subsequent twelve-month volatility and aggregate S\&P 500 accruals. According to the earnings fixation hypothesis, naïve investors tend to fixate on firms' reported earnings figures, while neglecting the magnitude of the relative contributions from the cash flow and accruals components that make up the earnings. This fixation leads investors to overvalue firms with a high component of accruals in their earnings, causing such firms to earn low abnormal subsequent returns as the accruals reverse (a negative surprise to naïve investors). The reverse is true for firms with a low accruals component in their earnings. This observed pattern is illustrated in Table 1 where firms' subsequent annual returns are negatively related to the firms' current relative total accruals level grouped by deciles. The relation between accruals and volatility is more symmetrical, with volatility increasing monotonically from the middle to the outer deciles in Table 3.1. Accordingly, I employ the absolute value of my two accruals measures (total accruals and abnormal accruals) when analyzing the relation between subsequent S\&P 500 volatility and aggregate S\&P 500 accruals.

Several important characteristics of financial market volatility have been well documented. Some of these documented characteristics are: a leptokurtic distribution of risky asset returns, temporal dependence of volatility, volatility clustering, and volatility mean reversion. Diebold et al. (1998) argue that the forecast of volatility is highly dependent on the current level of volatility, its persistence and speed 


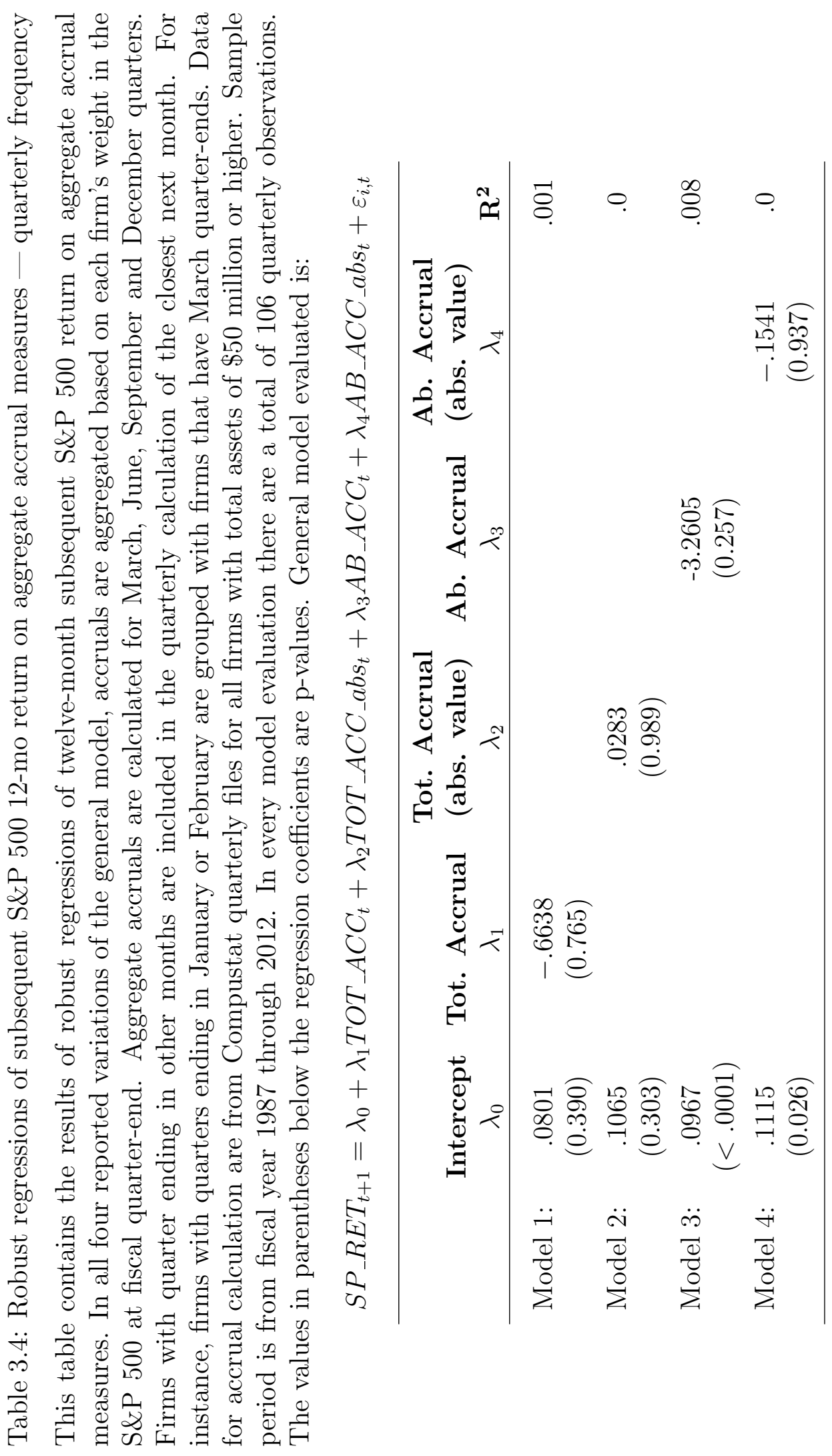


of mean reversion, and the forecast horizon. For horizons longer than six months, Alford and Boatsman (1995) and Figlewski (1997) suggest employing a simple historical model with low frequency data over a horizon at least as long as the forecast horizon. Taking into consideration these documented features of volatility in financial time series, I consider the most recently observed three-month and twelve-month S\&P 500 volatility as additional independent variables in my analysis. In that fashion, I can evaluate whether my constructed S\&P 500 aggregate accruals measure reveals any additional explanatory information about subsequent S\&P 500 volatility than what could be construed from the most recently observed volatility alone.

I employ robust regressions with M-estimates and Huber weighting to estimate the variations of the following general model:

$$
\begin{aligned}
S P_{-} V O L_{t+1} & =\lambda_{0}+\lambda_{1} T O T_{\_} A C C_{\_} a b s_{t}+\lambda_{2} A B_{-} A C C_{-} a b s_{t}+\lambda_{3} V O L_{-} 3 M O_{t} \\
& +\lambda_{4} V O L_{-} 12 M O_{t}+\varepsilon_{i, t}
\end{aligned}
$$

where TOT_ACC_abs $s_{t}$ is the S\&P 500 aggregate total accruals measure constructed by market-cap weighting the absolute value of total accruals for member firms at period $t, A B \_A C C \_a b s_{t}$ is the $\mathrm{S} \& \mathrm{P} 500$ aggregate total accruals measure constructed by market-cap weighting the absolute value of abnormal accruals for member firms at period $t, V O L_{-} 3 M O_{t}$ is the volatility of the $\mathrm{S} \& \mathrm{P} 500$ for the three-month period ending at time $t, V O L \_12 M O_{t}$ is the volatility of the $\mathrm{S} \& \mathrm{P} 500$ for the twelve-month period ending at time $t$, and $S P_{-} V O L_{t+1}$ is the subsequent twelve-month volatility in the S\&P 500 starting at time $t$.

The accruals measures are computed over four rolling fiscal quarters and time $t$ refers to the time following the four-month lag when the accounting data for calculating the accruals measure is assumed to be publicly available. More specifically, taking the March 2000 quarter as an example, the aggregate S\&P 500 accrual mea- 
sure includes the firm level accrual for all member firms using four rolling quarters of accounting data ending in January, February, or March 2000, depending on the fiscal quarter-end for each firm. Consistent with Alford et al. (1994), it is assumed that after a four-month lag the accounting data for all firms would be available to calculate the aggregate accrual for the S\&P 500. In the example of the March 2000 quarter, this four-month lag would extend through the end of July 2000. Consequently, the subsequent twelve-month volatility in the S\&P 500 is then measured from August 2000 to August 2001. Staying with the same example, the three-month historical volatility in the $\mathrm{S} \& \mathrm{P} 500$, denoted as $V O L_{3} M O_{t}$ in equation 3.6, would be measured over the three-month period starting in the beginning of May 2000 through the end of July 2000. Analogously, the twelve-month historical volatility in relation 3.6 would be measured from July 1999 through July 2000.

Table 3.5 contains the results of the nine different estimations of equation 3.6. The first variation (Model 1), shows a significant relation between subsequent S\&P 500 volatility and aggregate S\&P 500 aggregate total accruals at the 5\% level. Employing the absolute value of aggregate abnormal accruals, Model 2 confirms the statistical significance of this relation at the $5 \%$ level but with a much higher $R^{2}$. This result is consistent with the assumption that abnormal accruals are more likely to generate subsequent earnings surprises than total accruals. Because of the material impact of requiring timely reviews and of SOX on publicly traded firms' accounting practices, I again partition my sample by pre/post March 2000 and pre/post June 2002. My results reveal that pre 2000 the association of aggregate abnormal accruals and subsequent S\&P 500 volatility was highly significant, accounting for a large portion of the variation in subsequent S\&P 500 volatility (Model 2B in Table 3.5). The same holds true when I partition on SOX (Model 2D). Likewise, the association of aggregate abnormal accruals and subsequent S\&P 500 volatility is significant in 
the post timely review test (Model 2C), but at a lower level $(p \leq 0.051)$. When I run my tests on the post SOX observations, however, the association of aggregate abnormal accruals and subsequent S\&P 500 volatility is no longer significant in my test.

The results for Models 3, 4 and 5 demonstrate that simple historical volatility, whether it is over the most recent three or twelve months, is positively associated with volatility in the S\&P 500 over the following twelve months. This is consistent with the notion of volatility persistence in financial markets time series. Combined with aggregate abnormal accruals, the predictive power of historical three-month volatility grows stronger. Note the higher $R^{2}$ in Model 3 versus Model 4 in Table 3.5. The relation is the strongest when only pre 2000 observations are considered (Model 3B yields the highest $R^{2}$ in Table 3.5). Once again, post SOX aggregate abnormal accruals show no relation to subsequent S\&P 500 volatility as indicated by the statistically insignificant $\lambda_{2}$ coefficient in Model 3E. In contrast to my results for Model 2C, aggregate abnormal accruals are no longer significant post Regulation S-K when historical volatility is included in the model. These results are consistent with the findings of Manry et al. (2003) who document a decline in interim quarter "optimism" when firms have their quarterly reports reviewed prior to filing. The results are also consistent with Cohen et al. (2008) who document a decline in accrual- based earnings management following the passage of the Sarbanes-Oxley Act.

The loss of statistical significance in abnormal accrual coefficients post SOX 2002 could be caused by the lower number of observations in the sub-sample (40 observations vs 62 pre SOX observations). Alternatively, it might be explained by reduced earnings management through discretionary accruals brought on by the passage of the Sarbanes-Oxley Act. Yet another possible explanation is the impact of Quan- 


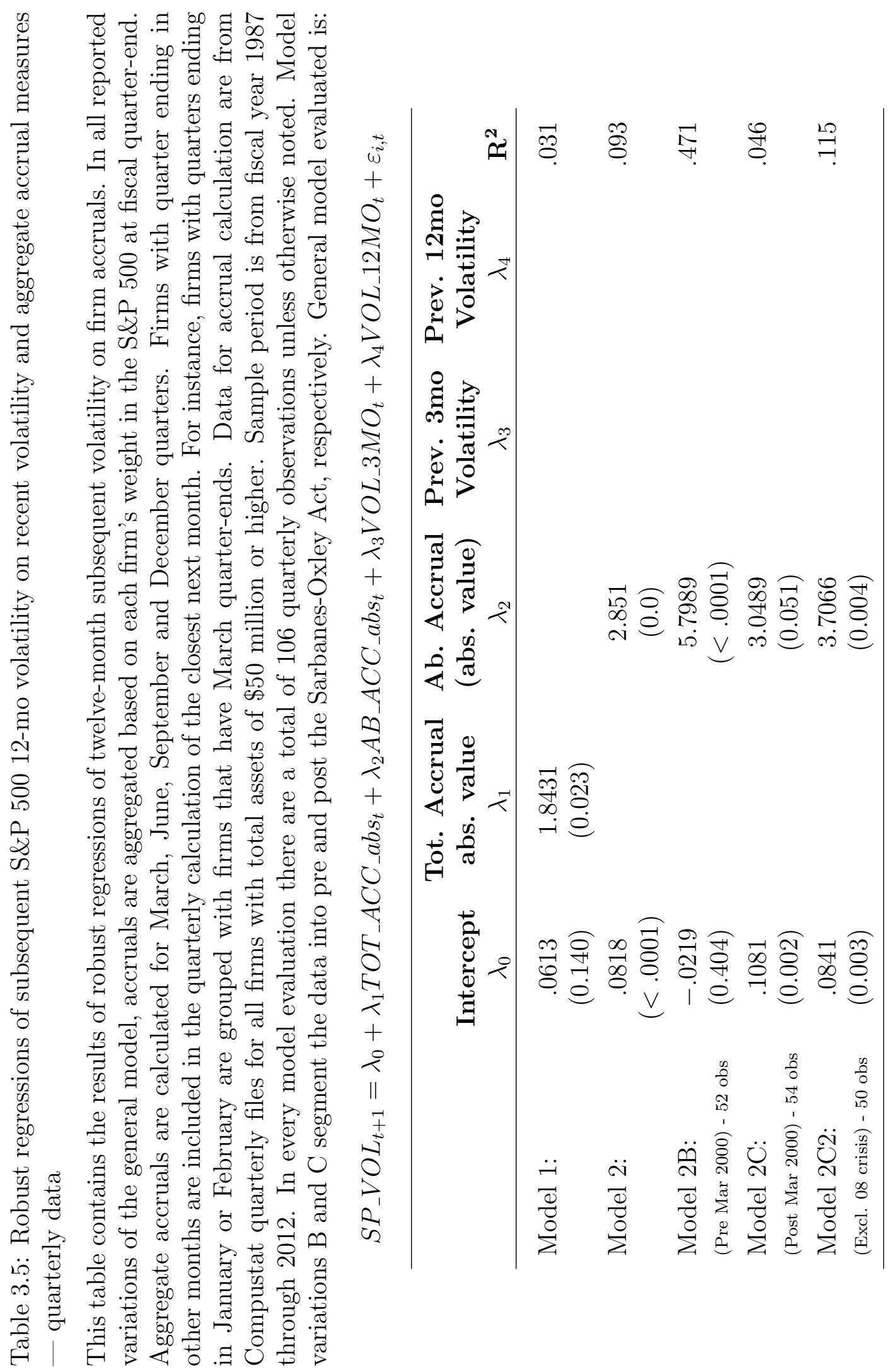




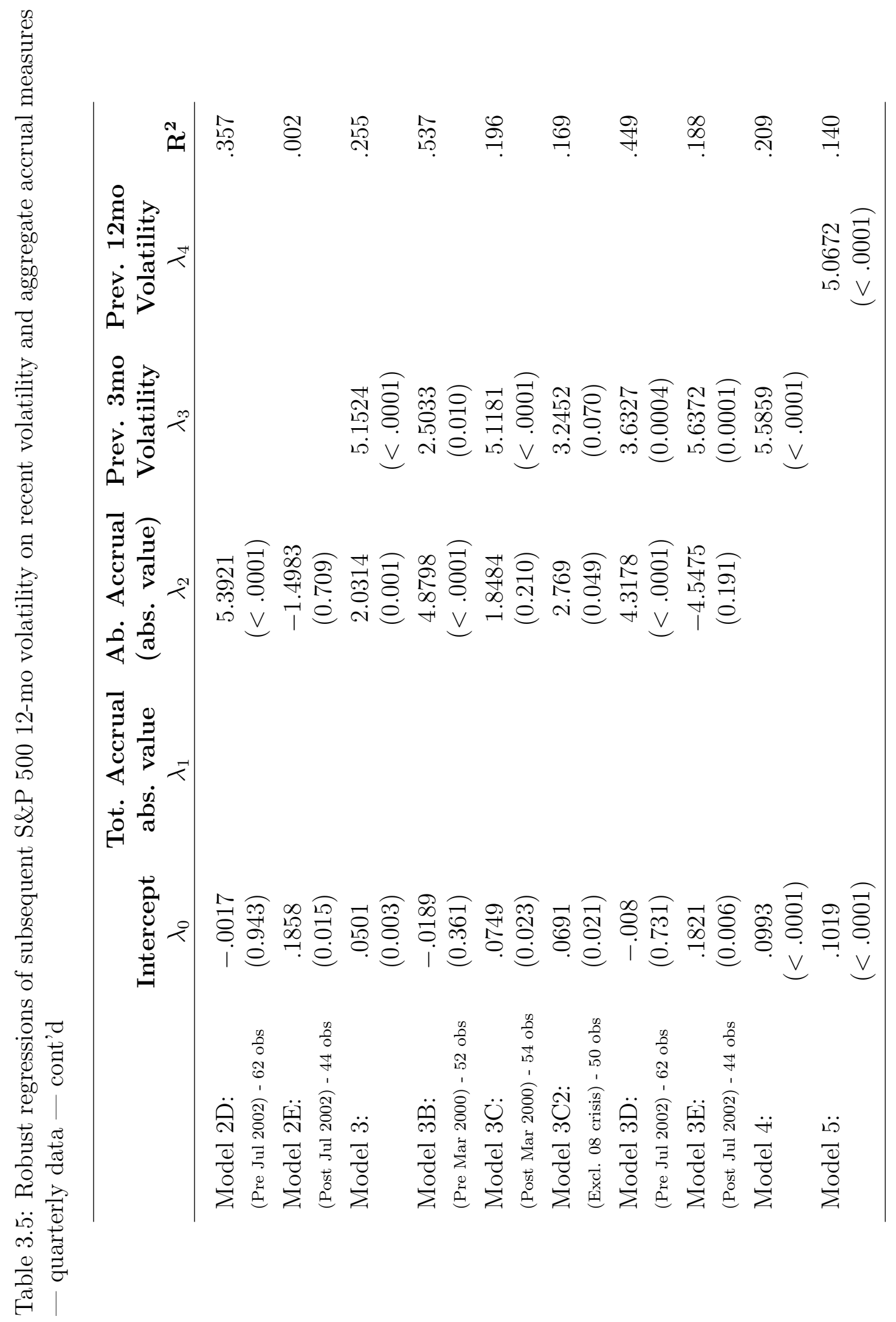


titative Easing on overall market volatility. It is possible that quantitative easing by the world's major central banks has kept equity market volatility artificially low over the 2010-2015 period. Under this assumption, the association between S\&P 500 volatility and aggregate accruals may be distorted over this period.

\subsubsection{Do option implied volatilities entirely capture insights from the S\&P 500 volatility and aggregate accruals relation?}

In section 3.4.3 I show that although twelve-month volatility in the S\&P 500 is strongly related to the most recent preceding three or twelve-month observed volatility in the index, aggregate S\&P 500 accruals yield incremental information regarding subsequent S\&P 500 volatility. For robustness, I examine whether this would still be true if option implied volatility, instead of the most recent three-month volatility, is considered.

Diebold et al. (1998) suggest that the most recently observed volatility of a random financial returns time series is a good naïve forecast for next period volatility. My finding that twelve-month S\&P 500 volatility is related to the most recently observed three-month volatility lends support to their suggestion. Nonetheless, an option implied volatility measure that incorporates both historical information as well as future market expectations should be even more strongly related to subsequently observed volatility in the S\&P 500. Employing highly liquid SPX options, I find that this is indeed the case. I replace the most recent historically observed twelve-month volatility in equation 3.6 with the twelve-month option implied volatility calculated using options data at time $t$. I thus estimate:

$$
\begin{aligned}
S P_{-} V O L_{t+1} & =\lambda_{0}+\lambda_{1} T O T_{\_} A C C_{\_} a b s_{t}+\lambda_{2} A B_{-} A C C_{-} a b s_{t}+\lambda_{3} V O L_{-} 3 M O_{t} \\
& +\lambda_{4} I V O L_{-} 12 M O_{t}+\varepsilon_{i, t}
\end{aligned}
$$


Table 3.6 contains the results of estimating the six separate variations of equation 3.7. Due to data availability, the estimation periods in my study start in March 2005. SPX options have been used by the CBOE to calculate the VIX cash and settlement values since 2003. Before then, S\&P 100 options were used. Notice that my entire estimation period for this robustness check falls within the post SOX era (where the association between S\&P 500 volatility and aggregate S\&P 500 accruals is not significant). Unsurprisingly, these results are confirmed in estimation of Model 1 and Model 2 variations reported in Table 3.6.

Results from estimating Models 3 and 4 in Table 3.6 show that for the post 2005 period S\&P 500 volatility exhibits no significant relation to aggregate abnormal accruals when either the most recent three-month volatility or the option implied volatility measure are employed as additional independent variables. Model variations 5 and 6 in Table 3.6 can be used to compare the predictive power of the most recent three-month volatility versus the twelve-month option implied volatility regarding the subsequently observed twelve-month volatility in the S\&P 500 . Both Models 5 and 6 yield statistically significant coefficient estimates while Model 6 yields a higher $R^{2}$. This is consistent with my expectation that S\&P 500 option implied volatility calculated from highly liquid SPX options would be a better predictor of subsequent twelve-moth S\&P 500 volatility than a naïve forecast based solely on the most recent three-month volatility. I am not, however, able to draw conclusions regarding the impact of option implied volatility on the relation between S\&P 500 volatility and aggregate accruals post 2005 .

I attribute the lack of association between S\&P 500 volatility and aggregate accruals post 2005 partly on the accounting changes brought upon by SOX 2002, but also suspect that quantitative easing has played a role in artificially suppressing volatility on the S\&P 500 since 2010. It would be interesting for future research 


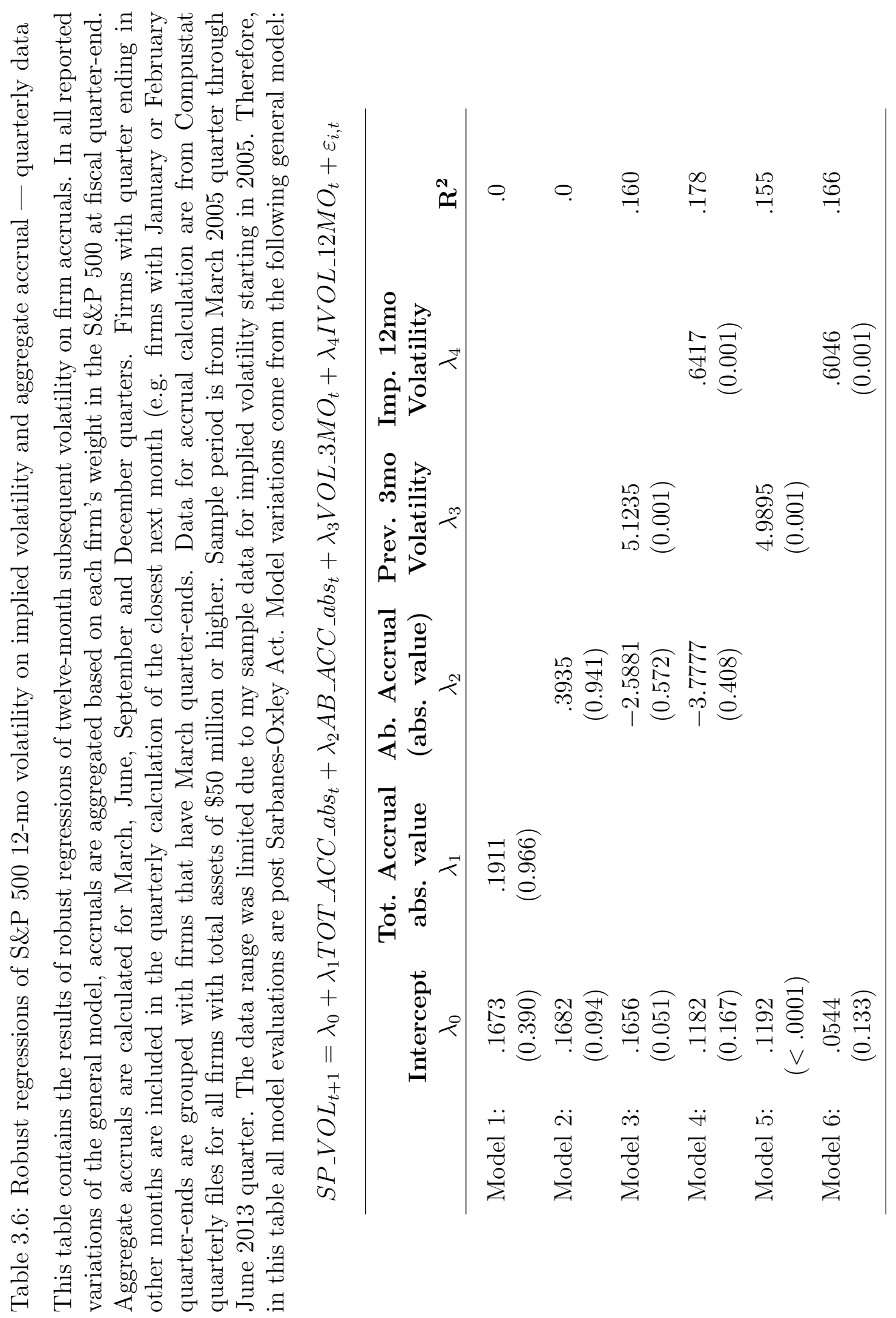


to investigate whether my documented S\&P 500 volatility and aggregate accruals association will re-emerge post the end of quantitative easing and further passage of time post SOX.

\subsection{Summary and conclusions}

The volatility of the S\&P 500 is widely accepted as representative of broad equity market volatility in the U.S. and is often also considered a benchmark for global equity volatility. In turn, equity volatility plays a vital role in risk management and portfolio optimization, and has important economic repercussions. Consequently, understanding the drivers of volatility in the S\&P 500 is of great importance to academicians and market participants. Most of the academic literature has focused on forecasting volatility over short time horizons. Time series models and option implied standard deviation models are the two common methodologies employed in volatility forecasting (Poon and Granger (2003) provide a comprehensive review of volatility forecasting models). In this paper I have introduced an accounting based signal for subsequent twelve-month volatility in the S\&P 500. It contributes to current literature both in the sense of the uniqueness of employing aggregate abnormal S\&P 500 accruals as an indicator of future S\&P 500 volatility and by the fact that this volatility indicator is for the less common longer horizon of twelve months.

The accrual anomaly, attributed to Sloan (1996), has spurred several accounting and finance studies related to earnings manipulation and stock returns. Hirshleifer et al. (2009) pioneer the aggregation of firm accruals for the broad market at a yearly frequency and report that contrary to Sloan (1996)'s findings, at the aggregate level accruals are positively associated with subsequent twelve-month broad equity market returns. I construct an aggregate abnormal accrual measure for the S\&P 
500 at a quarterly frequency and find no significant relation between subsequent S\&P 500 returns and this aggregate accrual measure. More importantly, I find a statistically significant relation between S\&P 500 twelve-month volatility and the aggregate absolute value of abnormal accruals for the S\&P 500 calculated at the beginning of the twelve-month volatility measurement period. Thus, I conclude that aggregate S\&P 500 accruals contain useful information regarding the index's subsequent twelve-month volatility.

After the passage of the Sarbanes-Oxley Act of 2002, Cohen et al. (2008) show that accrual-based earnings management has declined and has been replaced with real earnings management. I partition my sample period into pre and post SOX (2002) and find that the relation between S\&P 500 volatility and aggregate S\&P 500 accruals is insignificant post SOX. I also examine whether the information contained in aggregate accruals about subsequent $\mathrm{S} \& \mathrm{P} 500$ volatility is incremental to what could be inferred from either a simple time series model or an option implied standard deviation model. I employ robust regressions with both aggregate accruals and recently observed S\&P 500 volatility (both three-month and twelve-month volatility) as independent variables. By themselves, I find both three-month and twelve-month volatility are effective indicators of subsequent twelve-month S\&P 500 volatility, consistent with the widely known clustering and persistence of volatility in financial returns time series. When aggregate accruals are included as an additional independent variable I show that accruals yield significant additional information about subsequent S\&P 500 volatility.

I then consider twelve-month S\&P 500 volatility implied from SPX option prices as a predictor of S\&P 500 volatility. Unsurprisingly, I show a strong relation between option implied volatility and subsequently twelve-month volatility observed for the S\&P 500, though its explanatory power is not much greater than that of a naïve 
forecast using the most recent three-month volatility. Because data for SPX option prices in my sample is limited to post 2005 (thus post SOX), I cannot draw any conclusions regarding the comparison of aggregate accruals predictive power versus option implied volatility pre-SOX. 


\section{REFERENCES}

Alford, A. W. and Boatsman, J. R. (1995). Predicting long-term stock return volatility: Implications for accounting and valuation of equity derivatives. Accounting Review, pages 599-618.

Alford, A. W., Jones, J. J., and Zmijewski, M. E. (1994). Extensions and violations of the statutory SEC Form 10-K filing requirements. Journal of Accounting and Economics, 17(1):229-254.

Alsayed, H. and McGroarty, F. (2012). Arbitrage and the law of one price in the market for american depository receipts. Journal of International Financial Markets, Institutions and Money, 22(5):1258-1276.

Amihud, Y. (2002). Illiquidity and stock returns: cross-section and time-series effects. Journal of financial markets, 5(1):31-56.

Ammer, J. and Mei, J. (1996). Measuring international economic linkages with stock market data. The Journal of Finance, 51(5):1743-1763.

Aquino, K. P. and Poshakwale, S. (2006). Price determinants of american depositary receipts (adr): a cross-sectional analysis of panel data. Applied Financial Economics, 16(16):1225-1237.

Arellano, M. and Bond, S. (1991). Some tests of specification for panel data: Monte carlo evidence and an application to employment equations. The review of economic studies, 58(2):277-297.

Aslanidis, N. and Casas, I. (2013). Nonparametric correlation models for portfolio allocation. Journal of Banking \&6 Finance, 37(7):2268-2283.

Banz, R. W. (1981). The relationship between return and market value of common stocks. Journal of financial economics, 9(1):3-18.

Bartov, E. and Bodnar, G. M. (1994). Firm valuation, earnings expectations, and the exchange-rate exposure effect. The journal of Finance, 49(5):1755-1785.

Benston, G. J. and Hagerman, R. L. (1974). Determinants of bid-asked spreads in the over-the-counter market. Journal of Financial Economics, 1(4):353-364.

Blundell, R. and Bond, S. (1998). Initial conditions and moment restrictions in dynamic panel data models. Journal of econometrics, 87(1):115-143.

Bodart, V. and Reding, P. (1999). Exchange rate regime, volatility and international correlations on bond and stock markets. Journal of International Money and Finance, 18(1):133-151. 
Brennan, M. J. and Subrahmanyam, A. (1995). Investment analysis and price formation in securities markets. Journal of financial economics, 38(3):361-381.

Cai, Y., Chou, R. Y., and Li, D. (2009). Explaining international stock correlations with CPI fluctuations and market volatility. Journal of Banking \& Finance, 33(11):2026-2035.

Chan, K., Chan, L. K. C., Jegadeesh, N., and Lakonishok, J. (2006). Earnings quality and stock returns. The Journal of Business, 79:1041-1082.

Chordia, T., Roll, R., and Subrahmanyam, A. (2000). Commonality in liquidity. Journal of Financial Economics, 56(1):3-28.

Clarida, R., Galı, J., and Gertler, M. (1998). Monetary policy rules in practice: some international evidence. european economic review, 42(6):1033-1067.

Cohen, D. A., Dey, A., and Lys, T. Z. (2008). Real and accrual-based earnings management in the pre-and post-sarbanes-oxley periods. The accounting review, 83(3):757-787.

Cohen, K. J., Ness, W. L., Okuda, H., Schwartz, R. A., and Whitcomb, D. K. (1976). The determinants of common stock returns volatility: An international comparison. The Journal of Finance, 31(2):733-740.

Connolly, R. A., Stivers, C., and Sun, L. (2007). Commonality in the time-variation of stock-stock and stock-bond return comovements. Journal of Financial Markets, 10(2):192-218.

Corwin, S. A. and Schultz, P. (2012). A simple way to estimate bid-ask spreads from daily high and low prices. The Journal of Finance, 67(2):719-760.

Dechow, P. M. and Dichev, I. D. (2002). The quality of accruals and earnings: The role of accrual estimation errors. The accounting review, 77(s-1):35-59.

Della Corte, P., Sarno, L., and Tsiakas, I. (2012). Volatility and correlation timing in active currency management. Handbook of Exchange Rates. Hoboken, NJ: Wiley.

Diebold, F. X., Hickman, A., Inoue, A., and Schuermann, T. (1998). Scale models. RISK Magazine, 11:104-107.

Dumas, B., Harvey, C. R., and Ruiz, P. (2003). Are correlations of stock returns justified by subsequent changes in national outputs? Journal of International Money and Finance, 22(6):777-811.

Dupoyet, B., Daigler, R. T., and Chen, Z. (2011). A simplified pricing model for volatility futures. Journal of Futures Markets, 31(4):307-339. 
Ely, D. and Salehizadeh, M. (2002). American depositary receipts: an analysis of international stock price movements. International Review of Financial Analysis, $10(4): 343-363$.

Engle, R. F. and Granger, C. W. (1987). Co-integration and error correction: representation, estimation, and testing. Econometrica: journal of the Econometric Society, pages 251-276.

Erb, C. B., Harvey, C. R., and Viskanta, T. E. (1994). Forecasting international equity correlations. Financial analysts journal, 50(6):32-45.

Evans, M. D. (2011). Exchange-rate dynamics. Princeton University Press.

Evans, M. D. and Lyons, R. K. (2009). Forecasting exchange rates and fundamentals with order flow. Georgetown University and UC Berkeley Working Paper.

Figlewski, S. (1997). Forecasting volatility. Financial markets, institutions \& instruments, 6(1):1-88.

Forbes, K. J. and Chinn, M. D. (2004). A decomposition of global linkages in financial markets over time. Review of Economics and Statistics, 86(3):705-722.

Forbes, K. J. and Rigobon, R. (2002). No contagion, only interdependence: measuring stock market comovements. The journal of Finance, 57(5):2223-2261.

Forsythe, G. E. and Moler, C. B. (1967). Computer solution of linear algebraic systems, volume 7. Prentice-Hall Englewood Cliffs, NJ.

Gagnon, L. and Karolyi, G. A. (2010). Multi-market trading and arbitrage. Journal of Financial Economics, 97(1):53-80.

Garman, M. B. and Klass, M. J. (1980). On the estimation of security price volatilities from historical data. Journal of business, pages $67-78$.

Graham, M., Kiviaho, J., and Nikkinen, J. (2012). Integration of 22 emerging stock markets: A three-dimensional analysis. Global Finance Journal, 23(1):34-47.

Grünbichler, A. and Longstaff, F. A. (1996). Valuing futures and options on volatility. Journal of Banking $\&$ Finance, 20(6):985-1001.

Harris, L. E. (1994). Minimum price variations, discrete bid-ask spreads, and quotation sizes. Review of Financial Studies, 7(1):149-178.

Hasbrouck, J. and Seppi, D. J. (2001). Common factors in prices, order flows, and liquidity. Journal of financial Economics, 59(3):383-411.

Heston, S. L. (1993). A closed-form solution for options with stochastic volatility 
with applications to bond and currency options. Review of financial studies, 6(2):327-343.

Hirshleifer, D., Hou, K., and Teoh, S. H. (2009). Accruals, cash flows, and aggregate stock returns. Journal of Financial Economics, 91(3):389-406.

Holden, C. W. (2009). New low-frequency spread measures. Journal of Financial Markets, 12(4):778-813.

Huber, P. J. (1973). Robust regression: asymptotics, conjectures and Monte Carlo. The Annals of Statistics, pages 799-821.

Jones, J. J. (1991). Earnings management during import relief investigations. Journal of accounting research, pages 193-228.

Jorion, P. (1990). The exchange-rate exposure of US multinationals. Journal of business, pages 331-345.

Keim, D. B. and Madhavan, A. (1997). Transactions costs and investment style: An inter-exchange analysis of institutional equity trades. Journal of Financial Economics, 46(3):265-292.

Kim, M., Szakmary, A. C., and Mathur, I. (2000). Price transmission dynamics between ADRs and their underlying foreign securities. Journal of Banking \&6 Finance, 24(8):1359-1382.

King, M., Sentana, E., and Wadhwani, S. (1994). Volatility and links between national. Econometrica, 62:901-933.

Kizys, R. and Pierdzioch, C. (2006). Business-cycle fluctuations and international equity correlations. Global Finance Journal, 17(2):252-270.

Kothari, S. P., Leone, A. J., and Wasley, C. E. (2005). Performance matched discretionary accrual measures. Journal of accounting and economics, 39(1):163197.

Lesmond, D. A. (2005). Liquidity of emerging markets. Journal of Financial Economics, $77(2): 411-452$.

Lesmond, D. A., Ogden, J. P., and Trzcinka, C. A. (1999). A new estimate of transaction costs. Review of Financial Studies, 12(5):1113-1141.

Longin, F. and Solnik, B. (1995). Is the correlation in international equity returns constant: 1960-1990? Journal of international money and finance, 14(1):3-26. 
Longin, F. and Solnik, B. (2001). Extreme correlation of international equity markets. The journal of finance, 56(2):649-676.

López de Silanes, F., La Porta, R., Shleifer, A., and Vishny, R. (1998). Law and finance. Journal of political economy, 106:1113-1155.

Manry, D., Tiras, S. L., and Wheatley, C. M. (2003). The influence of interim auditor reviews on the association of returns with earnings. The Accounting Review, 78(1):251-274.

Moskowitz, T. J. (2003). An analysis of covariance risk and pricing anomalies. Review of Financial Studies, 16(2):417-457.

Pagano, M. (1989). Trading volume and asset liquidity. The Quarterly Journal of Economics, pages 255-274.

Parhizgari, A. and Aburachis, A. (2003). Productivity and stock returns: 1951-2002. International Journal of Banking and Finance, 1(2):4.

Poon, S.-H. and Granger, C. W. (2003). Forecasting volatility in financial markets: A review. Journal of economic literature, 41(2):478-539.

Poshakwale, S. S. and Aquino, K. P. (2008). The dynamics of volatility transmission and information flow between ADRs and their underlying stocks. Global Finance Journal, 19(2):187-201.

Rajgopal, S. and Venkatachalam, M. (2011). Financial reporting quality and idiosyncratic return volatility. Journal of Accounting and Economics, 51(1):1-20.

Reinganum, M. R. (1981). Misspecification of capital asset pricing: Empirical anomalies based on earnings' yields and market values. Journal of financial Economics, 9(1):19-46.

Ribeiro, R. and Veronesi, P. (2002). The excess comovement of international stock markets in bad times: A rational expectations equilibrium model. Manuscript, Graduate School of Business, University of Chicago.

Roll, R. (1984). A simple implicit measure of the effective bid-ask spread in an efficient market. The Journal of Finance, 39(4):1127-1139.

Roll, R. (1988). The international crash of october 1987. Financial analysts journal, 44(5):19-35.

Securities and Exchange Commission (1999a). Final Rule: Audit Committee Disclosure, 17 CFR, Parts 210, 228, 229, and 240. SEC Release No. 34-42266. Washington, D.C.: Government Printing Office. 
Securities and Exchange Commission (1999b). Regulation S-K, item 302(a). 64 FR 73389, 73402. Washington, D.C.: Government Printing Office.

Sloan, R. (1996). Do stock prices fully reflect information in accruals and cash flows about future earnings? Accounting review, 71(3):289-315.

Stoll, H. R. (2000). friction. The Journal of Finance, 55(4):1479-1514.

Stoll, H. R. and Whaley, R. E. (1983). Transaction costs and the small firm effect. Journal of Financial Economics, 12(1):57-79.

Suarez, E. D. (2005). Enforcing the law of one price: nonlinear mean reversion in the ADR market. Managerial Finance, 31(8):1-17.

Taylor, J. B. (1993). Discretion versus policy rules in practice. In Carnegie-Rochester conference series on public policy, volume 39, pages 195-214. Elsevier.

Veronesi, P. (1999). Stock market overreactions to bad news in good times: a rational expectations equilibrium model. Review of Financial Studies, 12(5):975-1007.

Wang, Z. and Daigler, R. T. (2011). The performance of VIX option pricing models: empirical evidence beyond simulation. Journal of Futures Markets, 31(3):251-281.

Wu, L. (2006). A tale of two indices. The Journal of Derivatives, 13:13-29.

Zhang, Z. and Lim, K.-G. (2006). A non-lattice pricing model of american options under stochastic volatility. Journal of Futures Markets, 26(5):417-448.

Zhu, S.-P. and Lian, G.-H. (2012). An analytical formula for VIX futures and its applications. Journal of Futures Markets, 32(2):166-190.

Zhu, Y. and Zhang, J. E. (2007). Variance term structure and VIX futures pricing. International Journal of Theoretical and Applied Finance, 10(01):111-127. 


\section{APPENDIX A}

Attributed to economist John B. Taylor (1993), the Taylor rule dictates how central banks should set the nominal interest rate in response to changes in inflation and GDP. Mathematically, the rule is expressed as:

$$
r_{t}=\pi_{t}+r_{t}^{*}+\lambda_{\pi}\left(\pi_{t}-\pi_{t}^{*}\right)+\lambda_{y}\left(y_{t}-y_{t}^{*}\right)
$$

where $r_{t}$ represents the nominal short-term interest rate at time $t, \pi_{t}$ is the inflation at time $t, \pi_{t}^{*}$ is the target inflation rate, $r_{t}^{*}$ is the equilibrium real interest rate, $y_{t}$ is the log of real GDP and $y_{t}^{*}$ is the log of GDP potential.

Additionally, the rule requires that both coefficients $\lambda_{\pi}$ and $\lambda_{y}$ be positive. This means that according to the Taylor rule, interest rates should be set higher when inflation is above target or GDP is above its potential. As a rule of thumb, Taylor (1993) suggests that $\lambda_{\pi}=\lambda_{y}=0.5$. Under this assumption, when inflation rises by $1 \%$ equation A.1 would imply that the nominal interest rate should be raised by 1.5\%. Conversely, should GDP decline by $1 \%$, the appropriate response would be to cut nominal rates by $0.5 \%$. In more general terms, equation A.1 implies that the proper response for a $1 \%$ increase in inflation should be to raise nominal interest rates by more than $1 \%$ since $\lambda_{\pi}>0$ and the combined coefficient on $\pi_{t}$ is $\left(1+\lambda_{\pi}\right)$. Therefore, assuming financial markets use the Taylor rule to derive nominal interest rate expectations for the U.S. we have:

$$
\mathbb{E}_{t}\left[r_{U S, t+1}\right]=\left(1+\lambda_{\pi}\right) \mathbb{E}_{t}\left[\pi_{U S, t+1+i}\right]+\lambda_{y} \mathbb{E}_{t}\left[y_{U S, t+1}\right]+r_{U S}^{*}
$$

where $y_{U S, t}$ represents the difference between the log of current and potential GDP. The expression for interest rate expectation for Germany in the Euro zone can be expressed analogously. For consistency with empirical evidence, foreign central banks are assumed to also increase nominal rates when their currency depreciates 
relative to the US dollar. Clarida et al. (1998) demonstrate that to be the case for German and Japanese central banks. With this additional term, the expression for expected nominal rates in Germany analogous to equation A.2 is:

$$
\mathbb{E}_{t}\left[r_{E U R, t+1}\right]=\left(1+\lambda_{\pi}\right) \mathbb{E}_{t}\left[\pi_{E U R, t+1+i}\right]+\lambda_{y} \mathbb{E}_{t}\left[y_{E U R, t+1}\right]+r_{E U R}^{*}-\lambda_{\xi} \xi_{t+1}
$$

where $\xi_{t} \equiv S_{t}+p_{E U R, t}-p_{U S, t}$ is the real exchange rate. Assuming that the equilibrium real exchange rate in the U.S. and Germany are the same and subtracting equation A.2 from A.3 yields:

$$
\begin{aligned}
\mathbb{E}_{t}\left[r_{E U R, t+1}-r_{U S, t+1}\right] & =\left(1+\lambda_{\pi}\right) \mathbb{E}_{t}\left[\pi_{E U R, t+1+i}-\pi_{U S, t+1+i}\right] \\
& +\lambda_{y} \mathbb{E}_{t}\left[y_{E U R, t+1}-y_{U S, t+1}\right]-\lambda_{\xi} \mathbb{E}_{t} \xi_{t+1}
\end{aligned}
$$




\section{APPENDIX B}

Equation 1.3 reads:

$$
\mathbb{E}_{t} S_{t+1}=\mathbb{E}_{t} S_{t+2}+\mathbb{E}_{t}\left[r_{E U R, t+1}-r_{U S, t+1}\right]
$$

Substituting the expression for the expected nominal rate difference between Germany and the U.S. in equation A.4 into the second term of equation B.1 yields:

$$
\begin{aligned}
\mathbb{E}_{t} S_{t+1} & =\mathbb{E}_{t} S_{t+2}+\left(1+\lambda_{\pi}\right) \mathbb{E}_{t}\left[\pi_{E U R, t+1+i}-\pi_{U S, t+1+i}\right] \\
& +\lambda_{y} \mathbb{E}_{t}\left[y_{E U R, t+1}-y_{U S, t+1}\right]-\lambda_{\xi} \xi_{t+1}
\end{aligned}
$$

Plugging in the expression for real exchange rate $\xi_{t} \equiv S_{t}+p_{E U R, t}-p_{U S, t}$ into B.2 we have:

$$
\begin{aligned}
\mathbb{E}_{t} S_{t+1} & =\mathbb{E}_{t} S_{t+2}+\left(1+\lambda_{\pi}\right) \mathbb{E}_{t}\left[\pi_{E U R, t+1+i}-\pi_{U S, t+1+i}\right] \\
& +\lambda_{y} \mathbb{E}_{t}\left[y_{E U R, t+1}-y_{U S, t+1}\right]-\lambda_{\xi} \mathbb{E}_{t}\left[S_{t+1}+p_{E U R, t}-p_{U S, t}\right]
\end{aligned}
$$

Bringing the term with $\lambda_{\xi} \mathbb{E}_{t} S_{t+1}$ to the left hand side of equation B.3 we then have:

$$
\begin{aligned}
\left(1+\lambda_{\xi}\right) \mathbb{E}_{t} S_{t+1} & =\mathbb{E}_{t} S_{t+2}+\left(1+\lambda_{\pi}\right) \mathbb{E}_{t}\left[\pi_{E U R, t+1+i}-\pi_{U S, t+1+i}\right] \\
& +\lambda_{y} \mathbb{E}_{t}\left[y_{E U R, t+1}-y_{U S, t+1}\right]-\lambda_{\xi} \mathbb{E}_{t}\left[p_{E U R, t}-p_{U S, t}\right]
\end{aligned}
$$

Now let's define $\gamma=1 /\left(1+\lambda_{\xi}\right)<1$, since $\lambda_{\xi}>0$. Expressing $\lambda_{\xi}$ in terms of $\gamma$ and substituting into equation B.4 yields:

$$
\begin{aligned}
(1 / \gamma) \mathbb{E}_{t} S_{t+1} & =\mathbb{E}_{t} S_{t+2}+\left(1+\lambda_{\pi}\right) \mathbb{E}_{t}\left[\pi_{E U R, t+1+i}-\pi_{U S, t+1+i}\right] \\
& +\lambda_{y} \mathbb{E}_{t}\left[y_{E U R, t+1}-y_{U S, t+1}\right]+\left(\frac{1-\gamma}{\gamma}\right) \lambda_{\xi} \mathbb{E}_{t}\left[p_{E U R, t}-p_{U S, t}\right]
\end{aligned}
$$

By defining:

$$
\begin{aligned}
f_{t} & =\left(1+\lambda_{\pi}\right)\left[\pi_{E U R, t+1}-\pi_{U S, t+1}\right]+\lambda_{y}\left[y_{E U R, t+1}-y_{U S, t+1}\right] \\
& +\left(\frac{1-\gamma}{\gamma}\right) \lambda_{\xi} \mathbb{E}_{t}\left[p_{U S, t}-p_{E U R, t}\right]
\end{aligned}
$$


Equation B.5 can be simplified as:

$$
\mathbb{E}_{t} S_{t+1}=\gamma \mathbb{E}_{t} S_{t+2}+\gamma \mathbb{E}_{t} f_{t+1}
$$

Iterating equation B.7 forward one period, it follows that:

$$
\mathbb{E}_{t} S_{t+2}=\gamma \mathbb{E}_{t} S_{t+3}+\gamma \mathbb{E}_{t} f_{t+2}
$$

Substituting the result for $\mathbb{E}_{t} S_{t+2}$ from B.8 into equation B.7 yields:

$$
\mathbb{E}_{t} S_{t+1}=\gamma^{2} \mathbb{E}_{t} S_{t+3}+\gamma^{2} \mathbb{E}_{t} f_{t+2}+\gamma \mathbb{E}_{t} f_{t+1}
$$

Iterating forward equation B.8 and substituting the result for $\mathbb{E}_{t} S_{t+3}$ into equation B.9 yields:

$$
\mathbb{E}_{t} S_{t+1}=\gamma^{3} \mathbb{E}_{t} S_{t+4}+\gamma^{3} \mathbb{E}_{t} f_{t+3}+\gamma^{2} \mathbb{E}_{t} f_{t+2}+\gamma \mathbb{E}_{t} f_{t+1}
$$

Notice that if equation B.7 is iterated indefinitely the first term will become zero as $\mathbb{E}_{t} \lim _{i \rightarrow \infty} \gamma^{i} S_{t+i}=0$ since $\gamma=1 /\left(1+\lambda_{\xi}\right)<1$. The terms with $\gamma^{i} \mathbb{E}_{t} f_{t+i}$ become an infinite sum. Thus,

$$
\mathbb{E}_{t} S_{t+1}=\mathbb{E}_{t} \sum_{i=1}^{\infty} \gamma^{i} f_{t+1}
$$

which is the expression in equation 1.5. 


\section{APPENDIX C}

Equation 1.11 reads:

$$
r_{E U R, t+1}-r_{U S, t+1}=K_{1, t}\left[y_{E U R, t}-y_{U S, t}\right]+K_{2, t}
$$

Recall from the definition of the Taylor Rule in appendix A equation A.1, $y_{t}$ is the $\log$ of real GDP. Thus, by defining $Y_{t}$ to be real GDP, equation C.1 can be rewritten as:

$$
r_{E U R, t}-r_{U S, t}=K_{1, t}\left[\ln Y_{E U R, t}-\ln Y_{U S, t}\right]+K_{2, t}
$$

Rearranging equation C.2 and applying the logarithm property $\ln \frac{a}{b}=\ln a-\ln b$, yields:

$$
\ln \frac{Y_{E U R, t}}{Y_{U S, t}}=\frac{r_{E U R, t}-r_{U S, t}-K_{2, t}}{K_{1, t}}
$$

It then follows that:

$$
\frac{Y_{E U R, t}}{Y_{U S, t}}=\exp \left(\frac{r_{E U R, t}-r_{U S, t}-K_{2, t}}{K_{1, t}}\right)
$$

Defining $K_{0, t}=\exp \left(\frac{K_{2, t}}{K_{1, t}}\right)$, equation C.4 can be rewritten as:

$$
K_{0, t} \frac{Y_{E U R, t}}{Y_{U S, t}}=\frac{e^{r} E U R, t / K_{1, t}}{e^{r} U S, t / K_{1, t}}
$$

which is equivalent to equation 1.12

$$
K_{0, t} \frac{Y_{E U R, t}}{\exp \left(r_{E U R, t} / K_{1, t}\right)}=\frac{Y_{U S, t}}{\exp \left(r_{U S, t} / K_{1, t}\right)}
$$




\section{APPENDIX D}

Because of the time series nature of our data, the key assumption in ordinary least square regressions of independence in residuals would be violated. I account for the autocorrelation of the errors via an autoregressive model for the random error. Specifically, the autoregressive error model employed is:

$$
\begin{gathered}
y_{t}=x_{t}^{\prime} \beta+v_{t} \\
v_{t}=\varphi_{1} v_{t-1}-\varphi_{2} v_{t-2}-\cdots-\varphi_{m} v_{t-m}+\epsilon_{t} \\
\epsilon_{t} \sim \operatorname{IN}\left(0, \sigma^{2}\right)
\end{gathered}
$$

In this model $\epsilon_{t}$ is assumed to be normally and independently distributed with a mean 0 and variance $\sigma^{2}$ as expressed in relation D.3. Regression coefficients $\beta$ and error model parameters $\varphi_{t}$ are estimated simultaneously to correct for the autocorrelation in the times series data. 
VITA

ANTONIO M. FIGUEIREDO

1997

$1997-2012$

M.B.A., Finance

New York University

New York, New York

Investment Analyst \& Portfolio Manager

Prudential Securities, Caspian Securities,

Schroder Investment Management, and Safra Bank

New York, New York

\section{WORKING PAPERS AND PRESENTATIONS}

"Contemporaneous ADRs Pricing : Efficiency, Arbitrage And Anomalies", with Ali M. Parhizgari,

Global Finance Conference, 2013, Monterey, CA

"Stock Market Signals and Consequences of Securities Class Actions Lawsuits: A Microstructure Perspective", with Shahid Hamid

Global Finance Conference, 2014, Dubai, UAE, presented by co-author

Multinational Finance Society, 2014, Prague, Czech Republic

"A Multifaceted Analysis of Intraday Trading Patterns on Options Expiration Days", with P.K. Jain and Suchismita Mishra. 